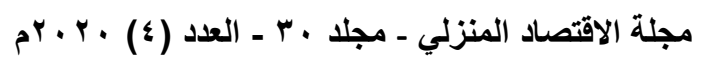

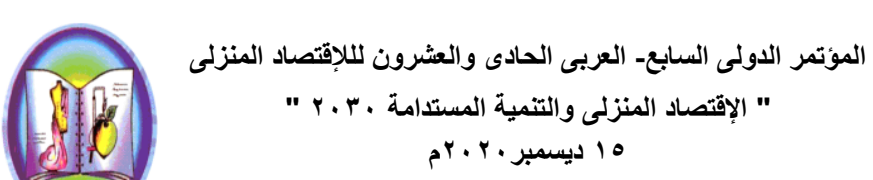

http://homeEcon.menofia.edu.eg

\section{Journal of Home} Economics

ISSN 1110-2578

\title{
مهارة التفاوض وعلاقتها بالتنبؤ بنجاح الحياة الأسرية لدي عينة من الفتيات المقبلات علي الزواج الأجناح
}

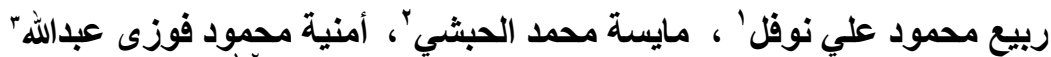

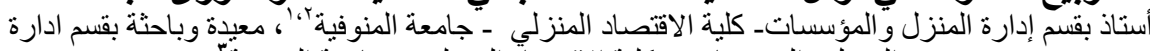

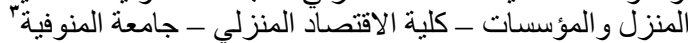

هدفت الدراسة الحالية إلي التعرف علي طبيعة العلاقة بين مهارة التفاوض بأبعادها الأربعة (الوعي بمهارة

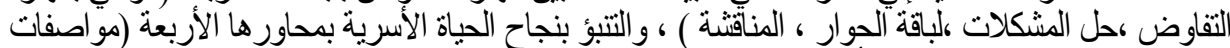

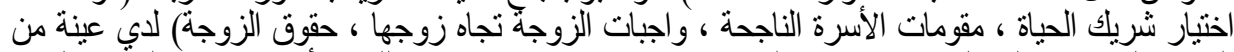

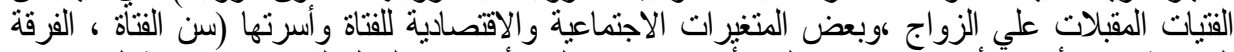

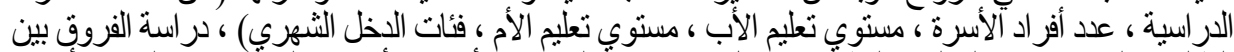

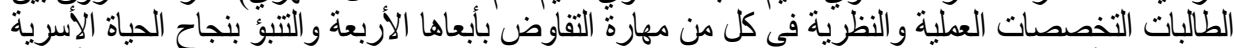

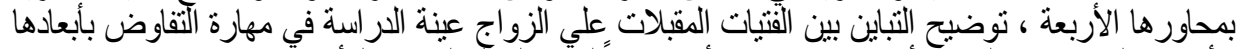

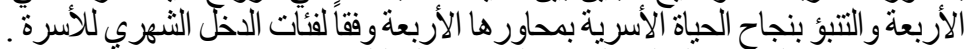

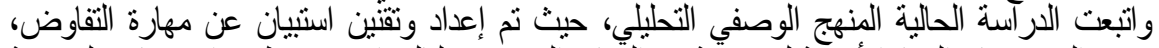

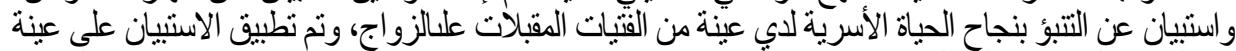

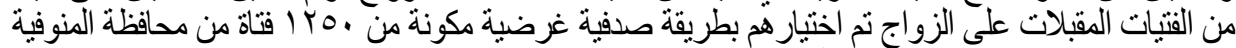

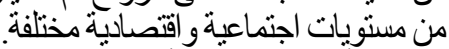

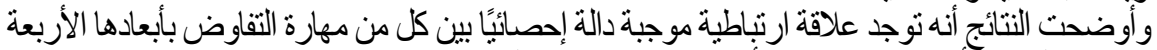

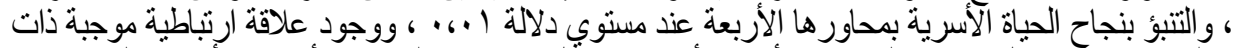

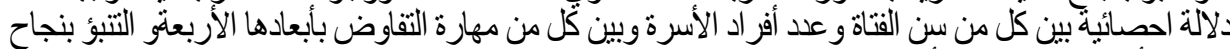

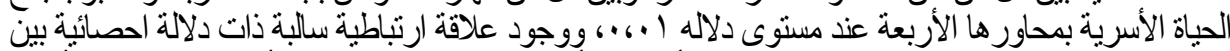

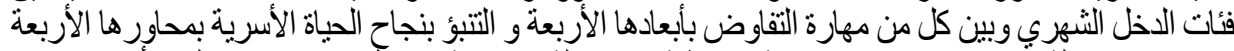

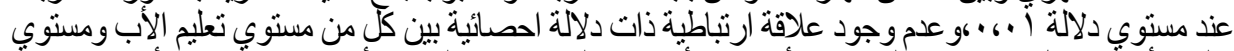

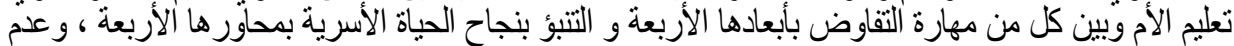

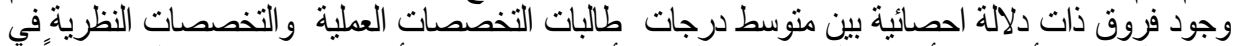

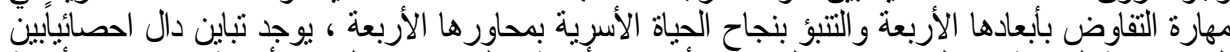

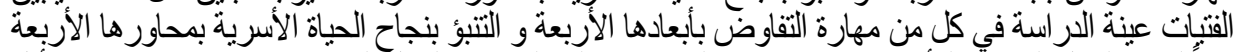

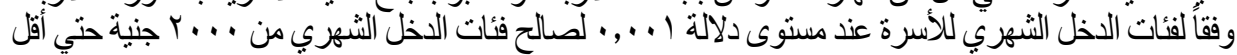

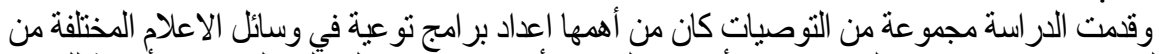

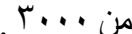

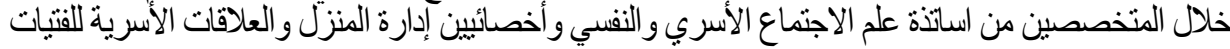




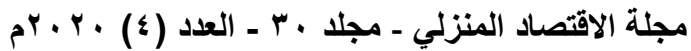

المقبلات على الزواج لتو عيتهم بكيفية بناء أسرة ناجحة، واللجوء للحوار البناءفي جميع شئوْن حياتها للتخفيف من

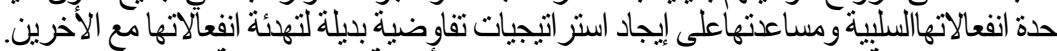

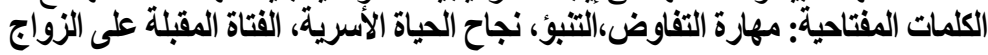

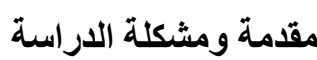

تعتبر مرحلة الثباب من أهم مراحل الحياة، فقيها يكتسب الثباب مهاب الثهار اته الانسانية

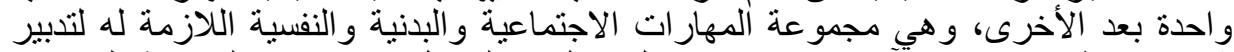

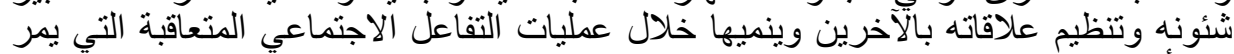

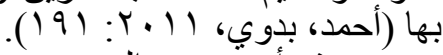

وقد أصبح من الضروري إعداد الفرد ليصبح له القدرة على مواكبة هذا التغير ليكون

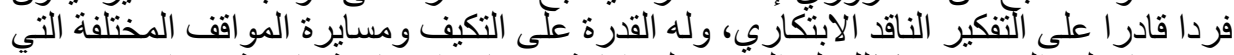

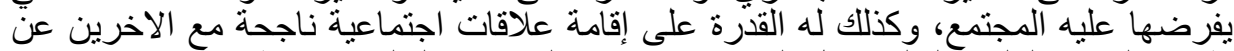

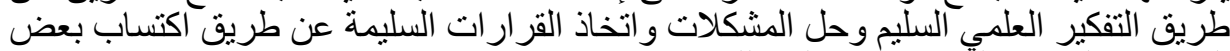

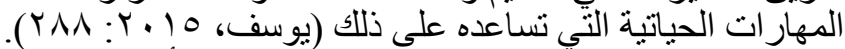

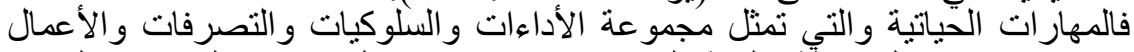

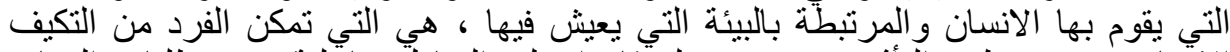

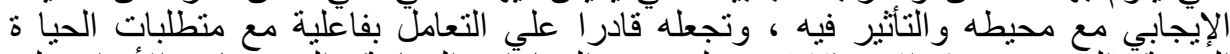

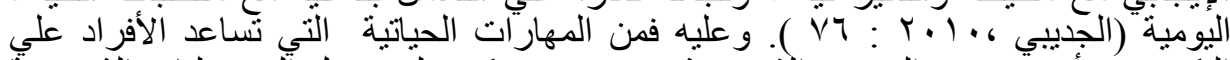

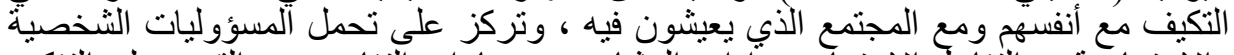

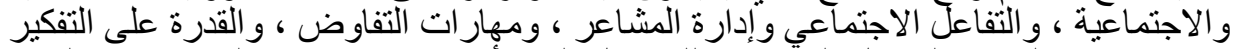

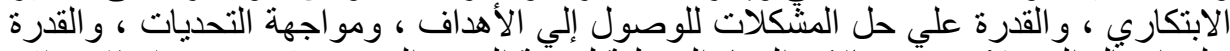

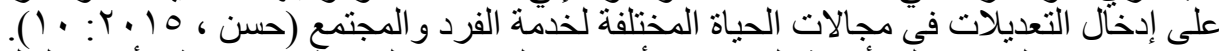

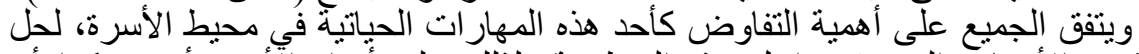

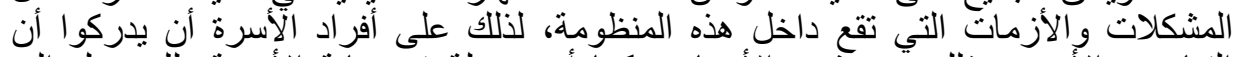

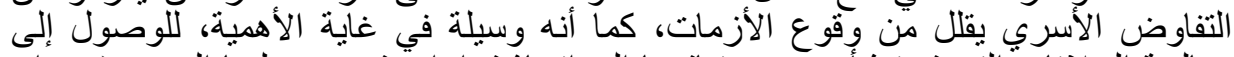

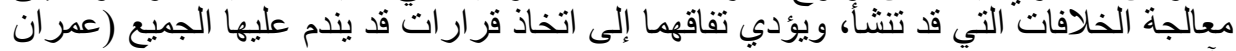

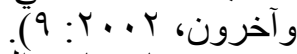

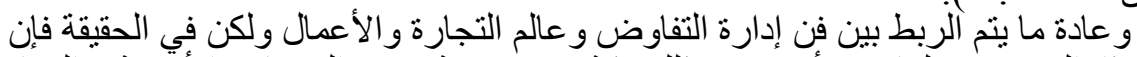

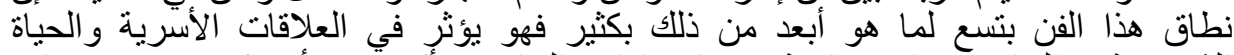

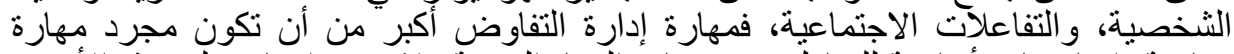

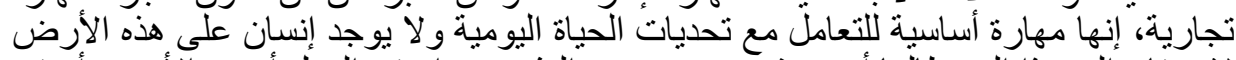

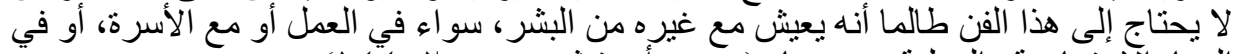

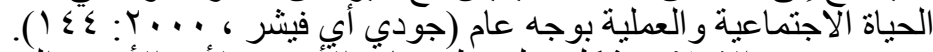

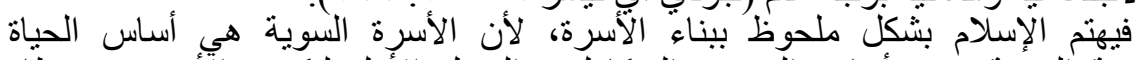

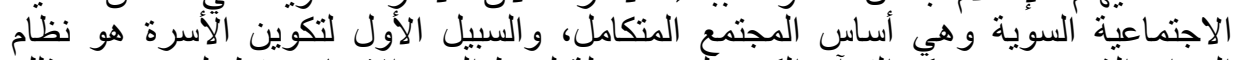

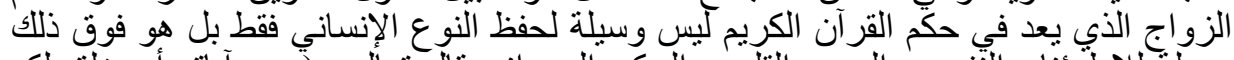

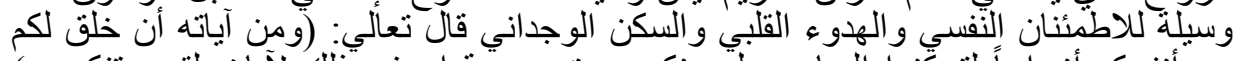

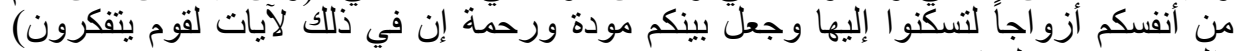

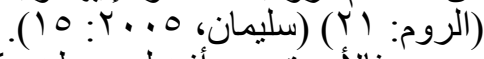

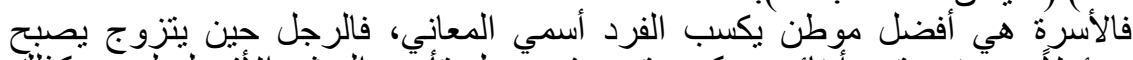

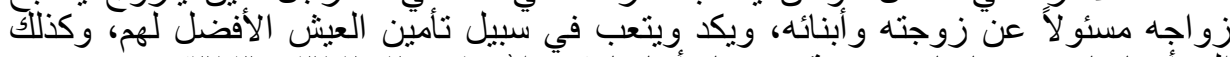

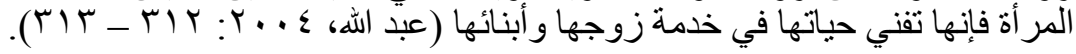




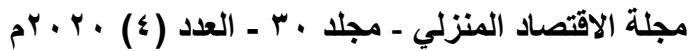

فالتفاوض في المجالات الاجتماعية هو تفاوض غنى ومتعدد وله حيويته وأهميته التي

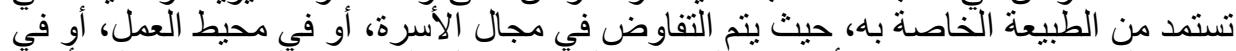

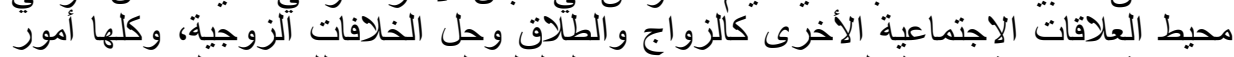

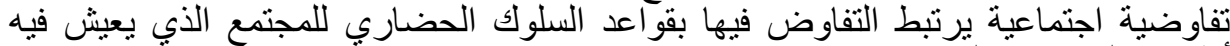

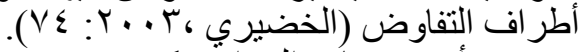

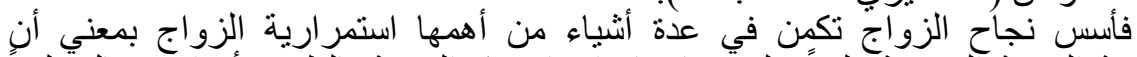

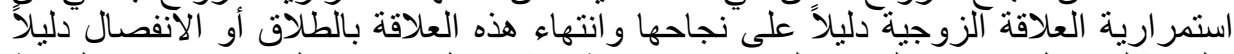

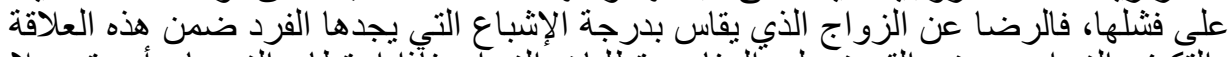

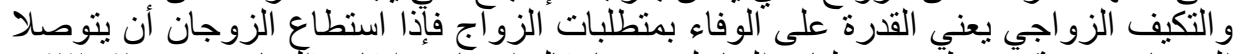

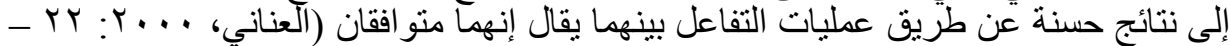

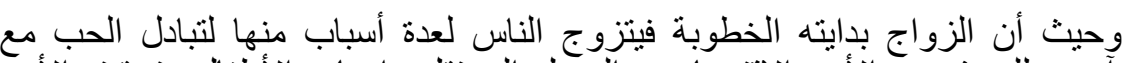
. (VY

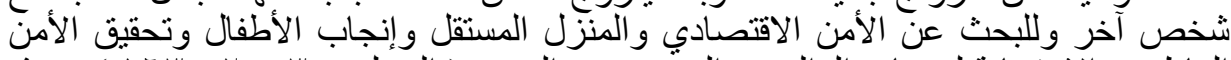

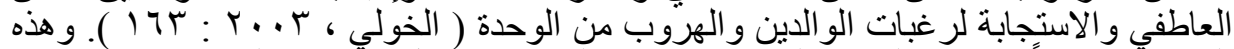

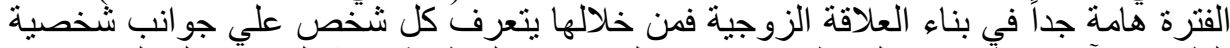

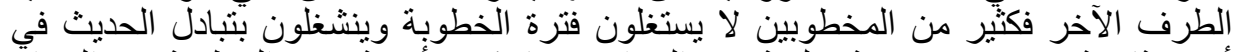

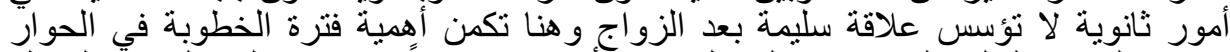

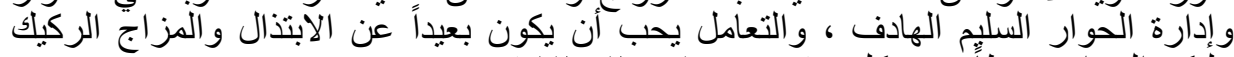

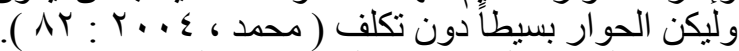
فالزواج المشبع هو الذي يتسم بالنضج يكون نتيجة التفهم القائم بين الزوجين والقئ القدرة

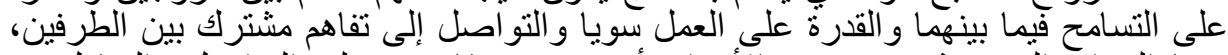

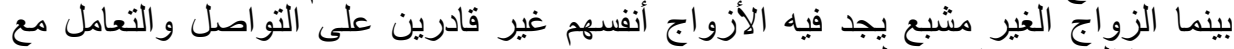

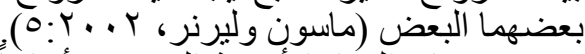

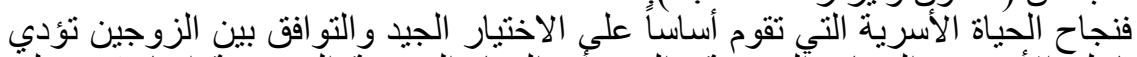

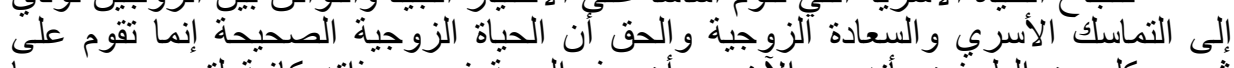

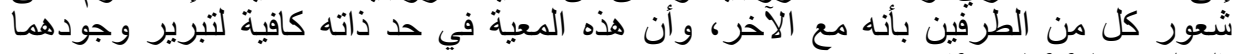

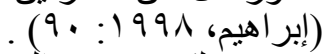

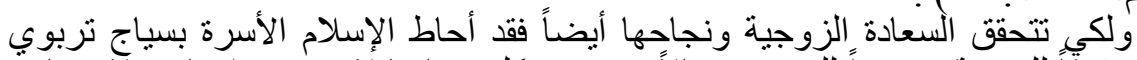

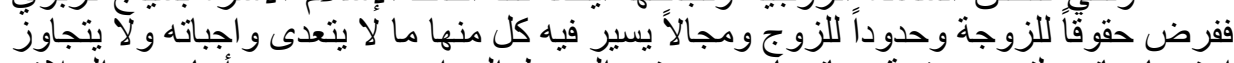

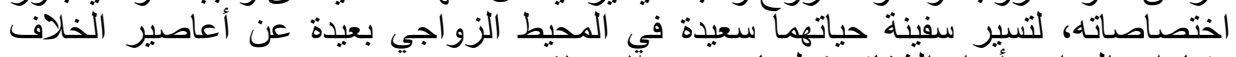

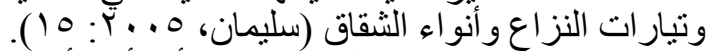

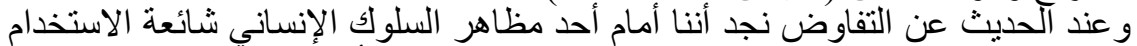

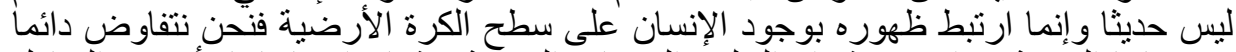

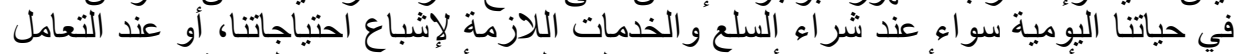

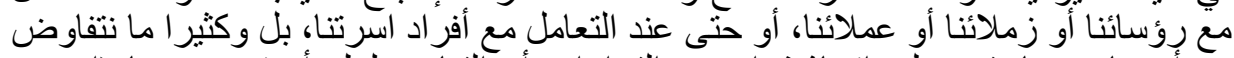

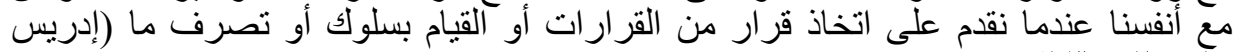

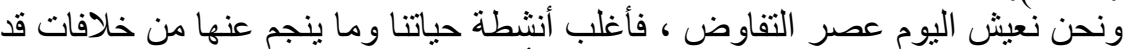

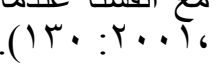

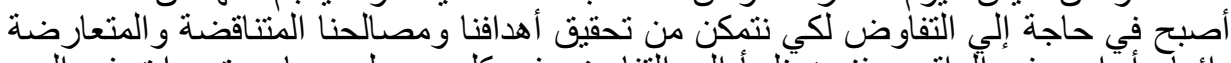

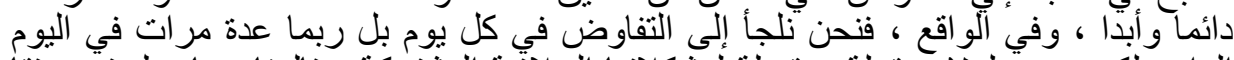

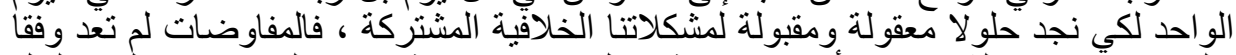

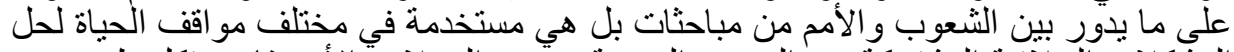

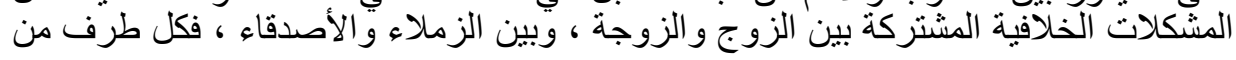




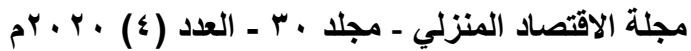

هذه الأطر اف يسعي للحصول علي أفضل النتائج بأقل قدر ممكن من الصراع الذي يهدد الجهد

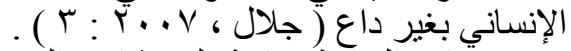

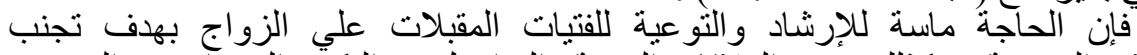

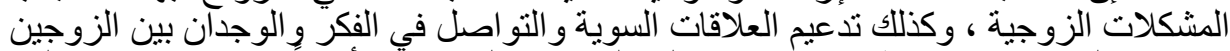

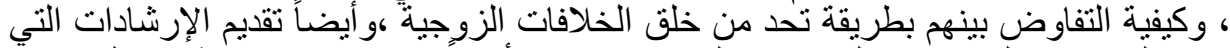

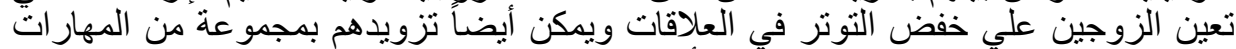

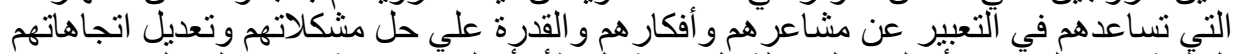

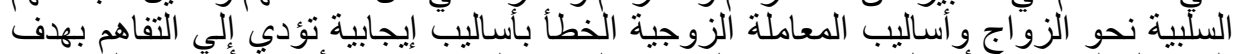

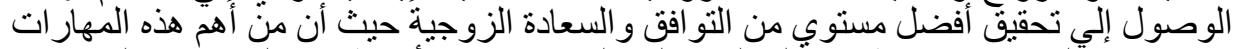

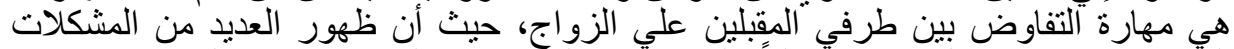

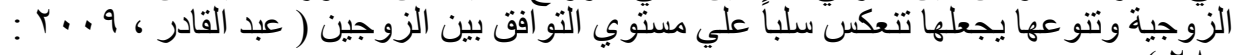

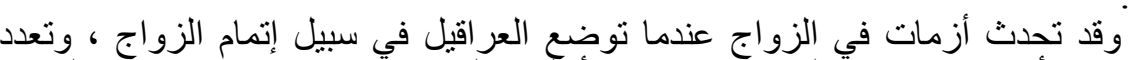
(r)o

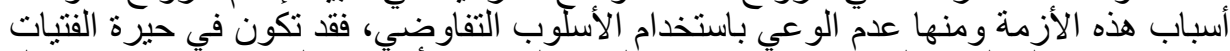

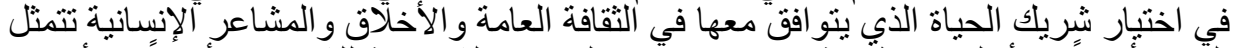

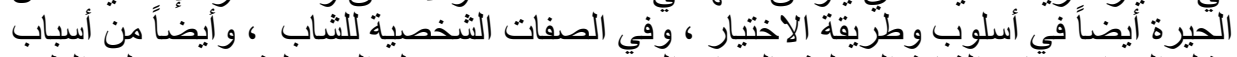

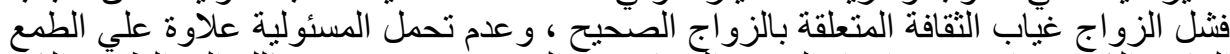

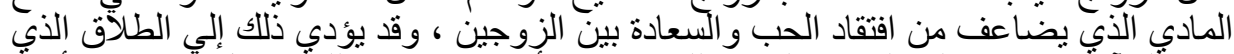

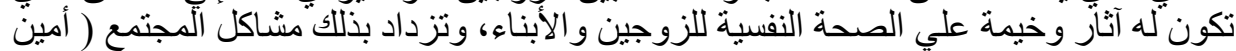

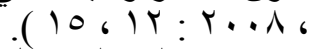

فعمليه التواصل الزواجي بين العوامل الهامة التي تساعد في نجاح الحياة الزوجية

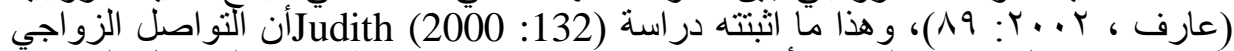

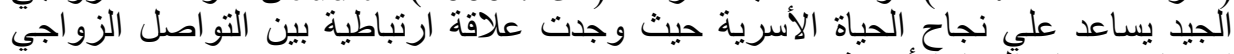
الإيجابي ونجاح آلحياة الأسرية.

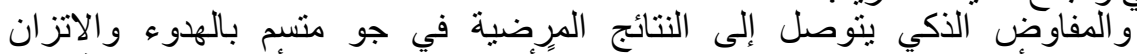

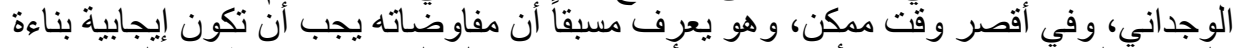

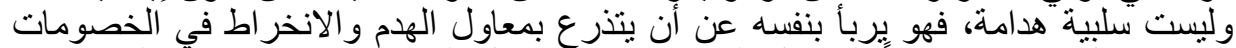

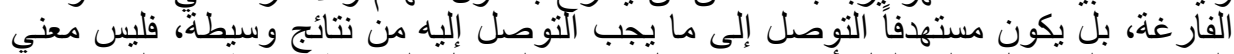

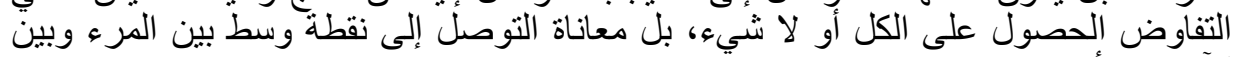

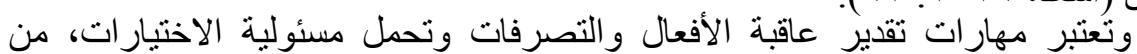

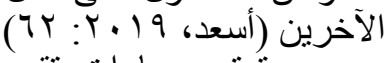

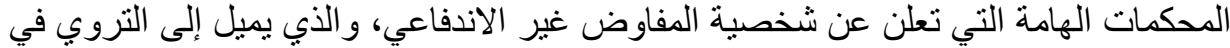

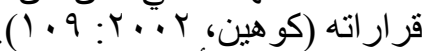

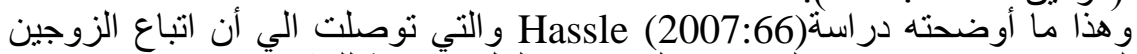

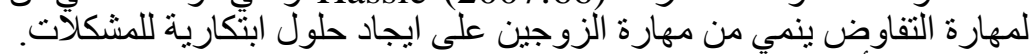

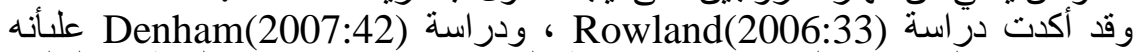
كلما زادت مهارة الفرد في التفاوض زادة زاد ضبط الفرد لانفعالاته و إدارته لعاطفته السلبية واوضحت وجود علاقة ارتباطية دالة بين مهار ات التفاوض التفاوض والتقام المنطور و الكفاءة في إدارة

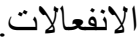

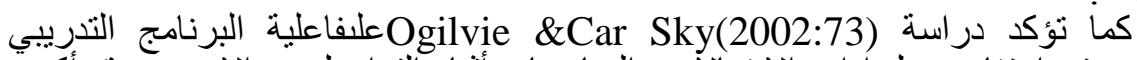

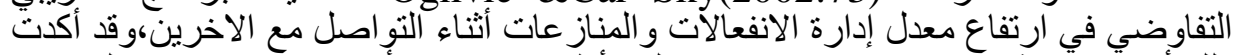

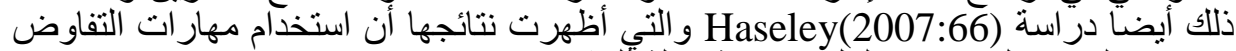
يزيد من القدرة على إيجاد حلول ابتكارية بديلة للمشكلات. 


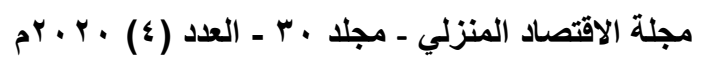

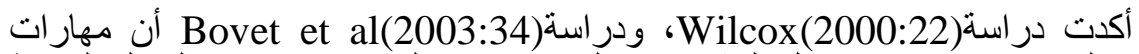

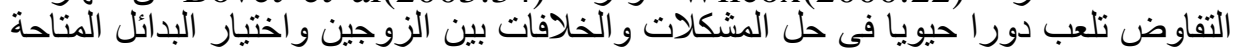
لحل المشكلات، وكل ذلك يدل على فاعلية استخدام مهار ات التفاوض الزّرضين في الامور المشتركة بين

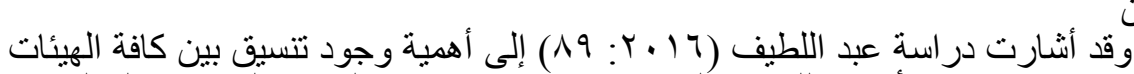
الزوجين

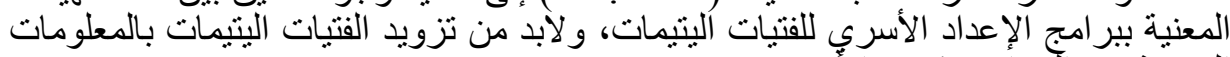
اللازمة عن الزّواج وتأكوين الأسرة.

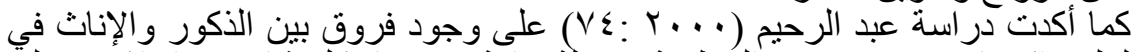

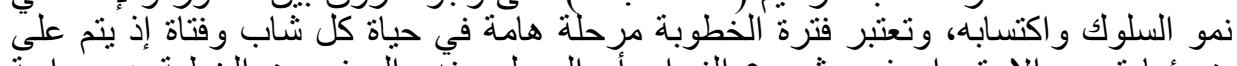

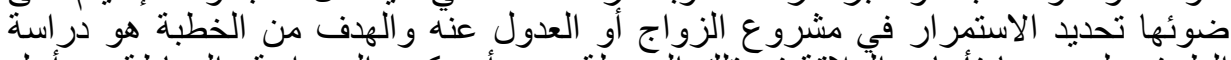

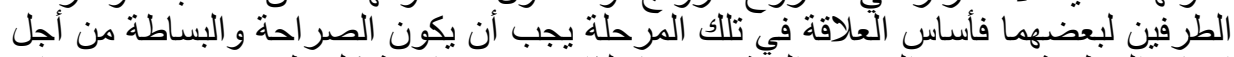

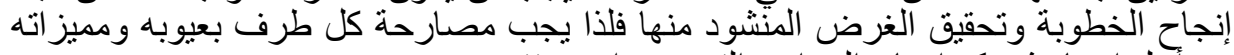

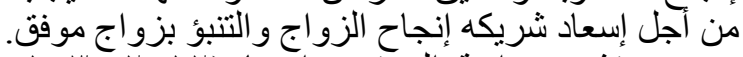

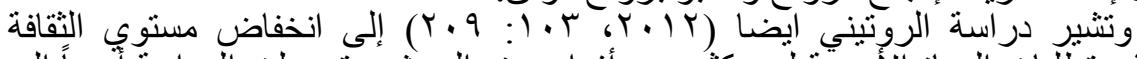

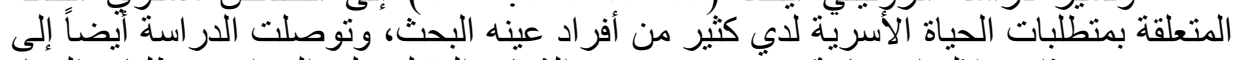

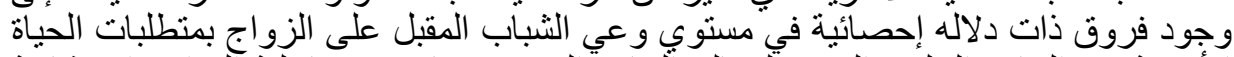

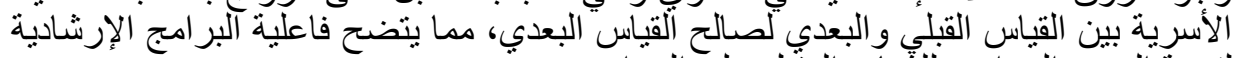

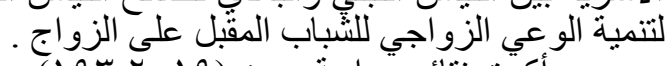

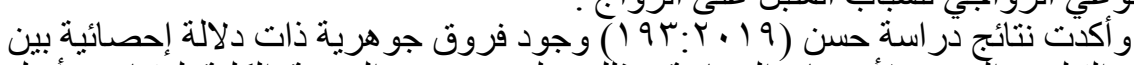

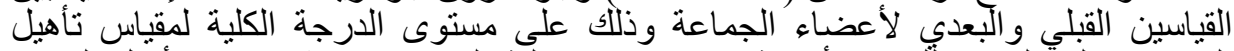

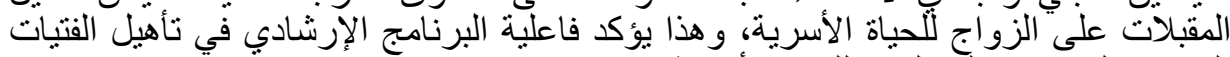
اليتيمات المقبلات على الزيلت الزاج للحياة الأسرية.

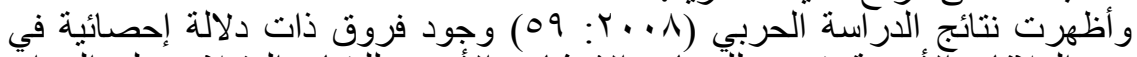

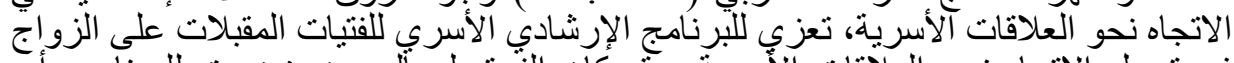

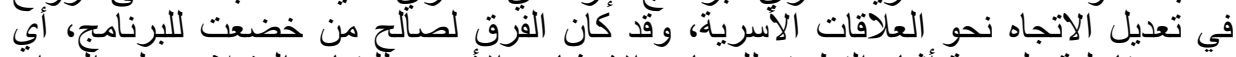

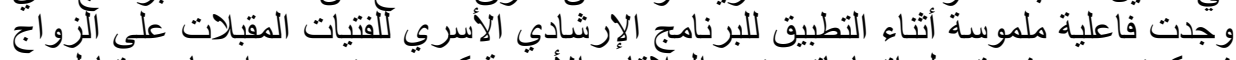

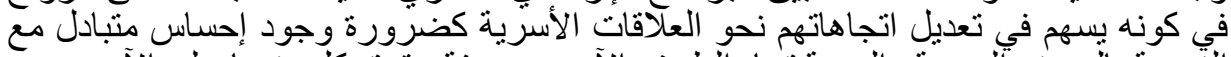

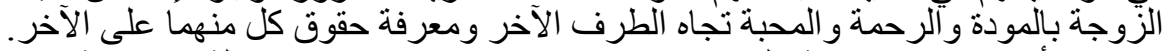

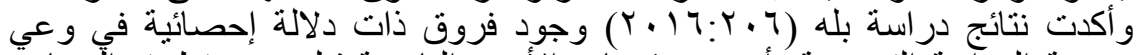
الطالبات عينة الدرأسة التجريية بأسية بأس ومقومات الأسرة الناجحة قبل وبعد نطبيق التبرنامج

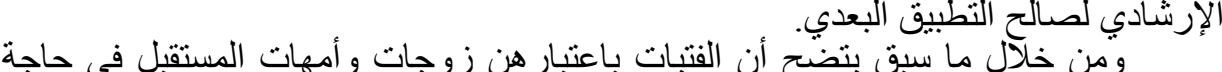

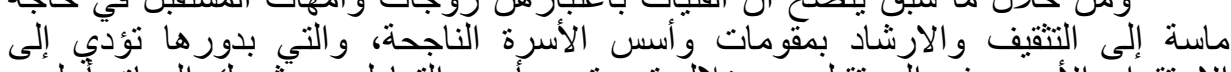

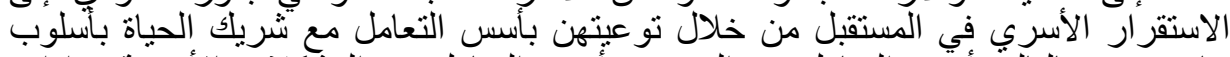

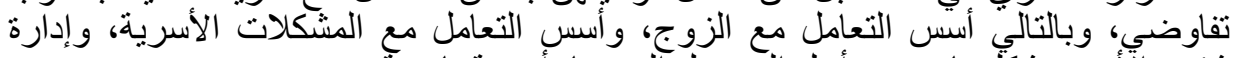

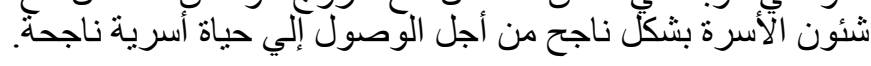

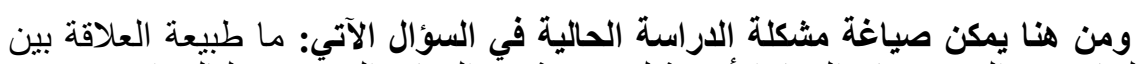

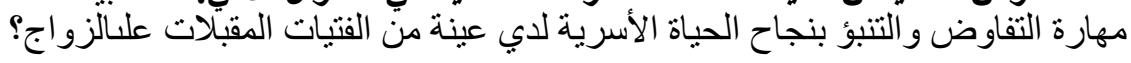

تهاف الدراسة الحالية بصفة رئيسة إلى دراسة مهارة التفاوض بأبعادها الأربعة (الوعي بمهارة أهداف الاراسة

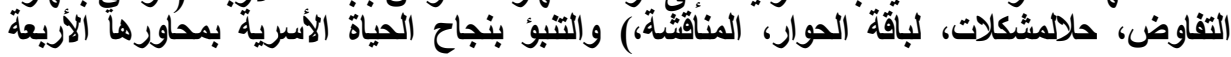




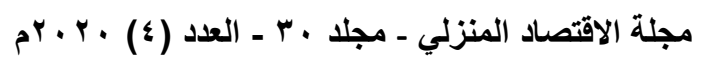

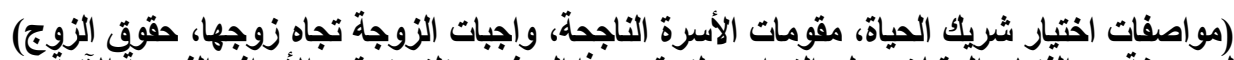

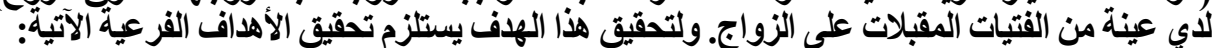

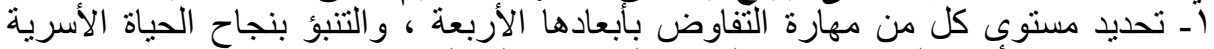

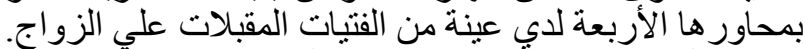

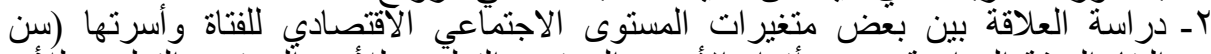

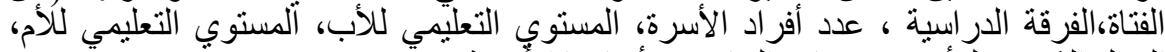

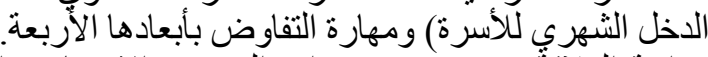

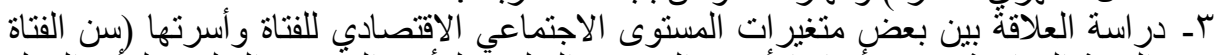

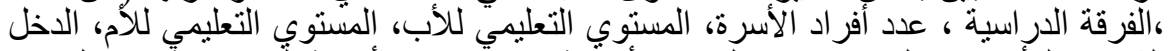

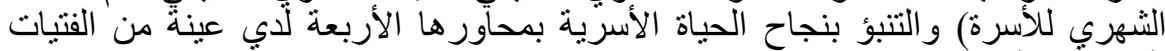

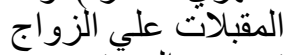

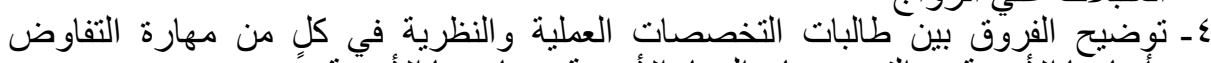

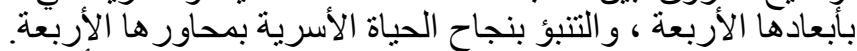

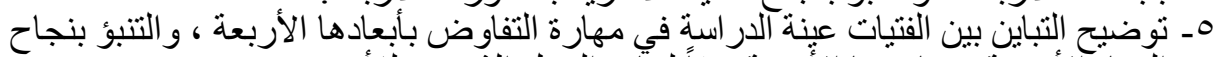

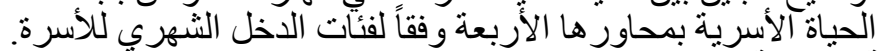

تكمن أهمية الدراسة في اتجاهين رئيسيين هما: -

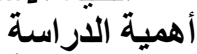

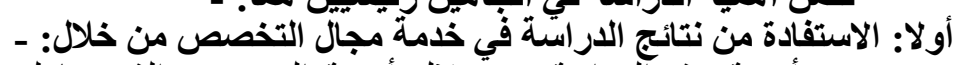

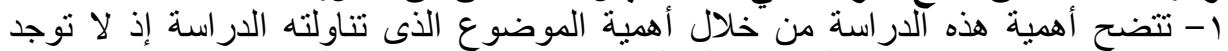

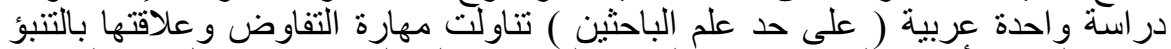

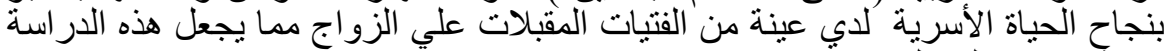

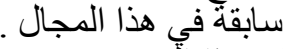

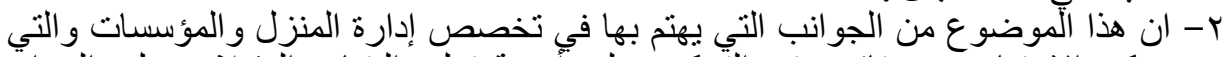

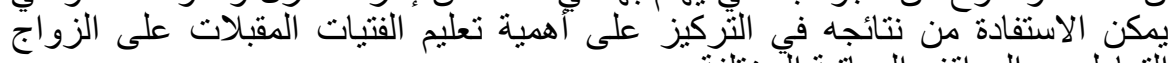

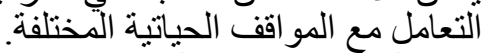

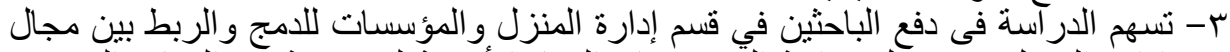

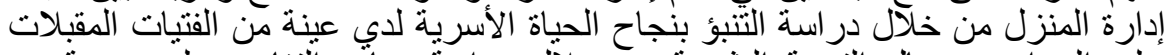

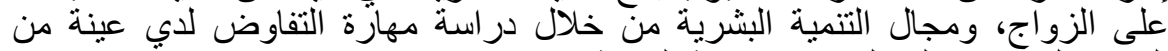

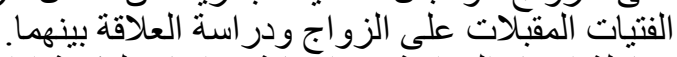

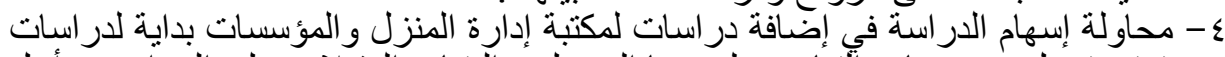

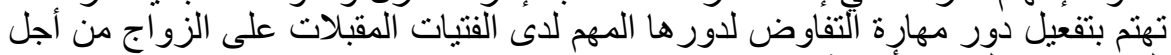
التنبؤ بنجاح الحباة الأسرية.

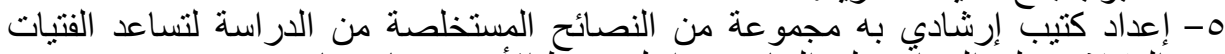

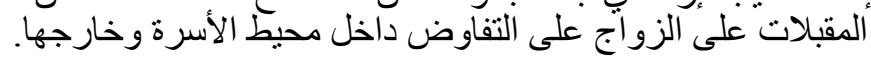

ثانيا: الاستفادة من نتائج الدراسة في خدمة المجتمع المحلى من خلال: - ـ

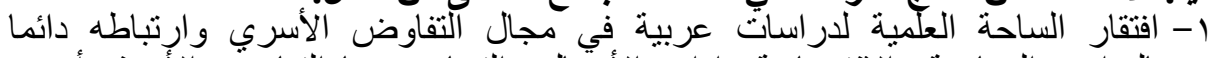

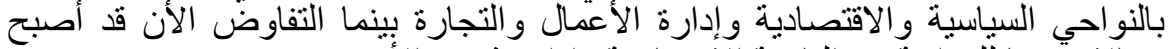

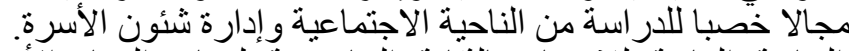

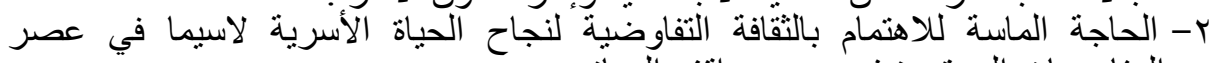
المفاوضات المستمرة في جميع مو اقف الحياة. 


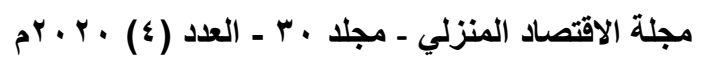

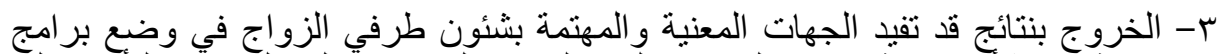

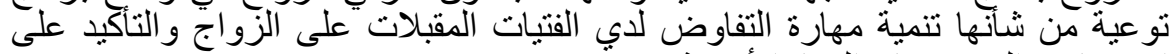
اهمينها في التنبؤ بنجاح الحياة الأسرية. ع- تدعيم مجهود الجهات المعنية بشئون الفتاة بالكتئ التيب الإرشادي المستخلص من الدراسة

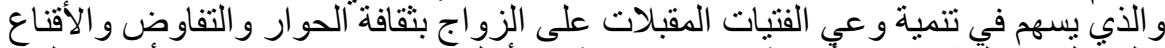

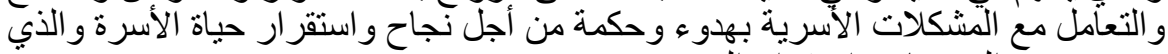

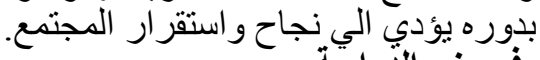

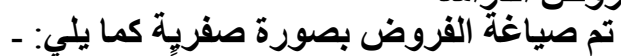

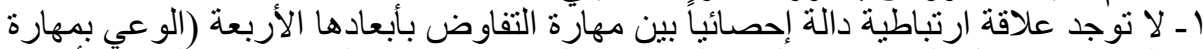

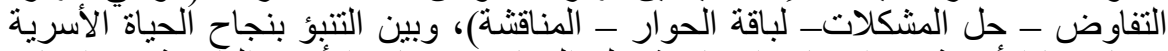

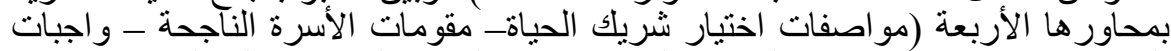

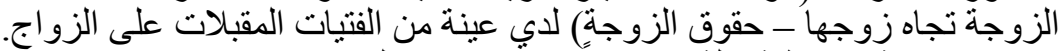

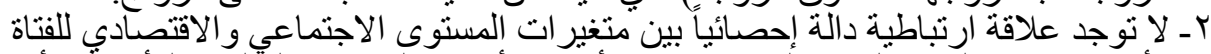

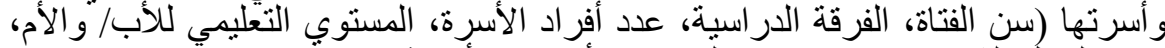

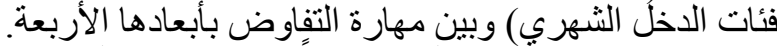

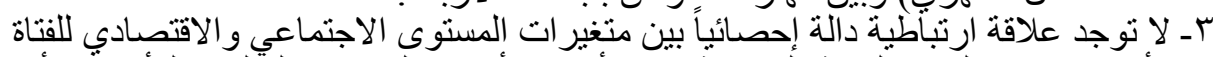

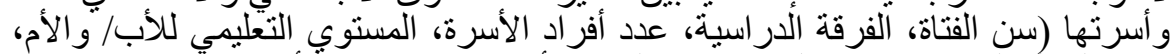

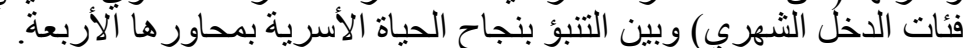

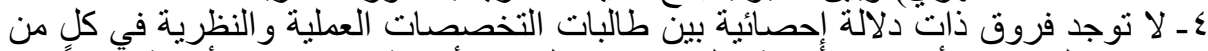

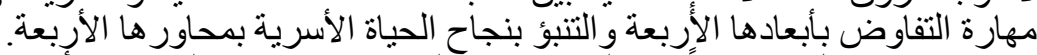

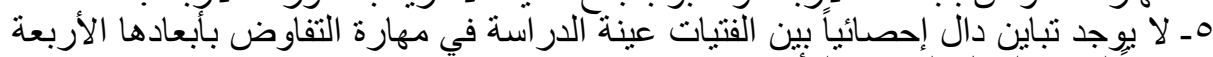
و وفقا لفئات الدخل الثهري لنالأسرة.

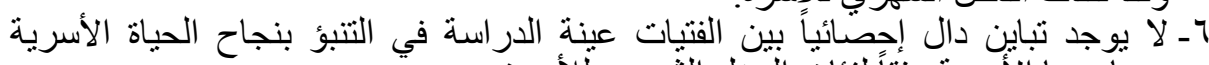

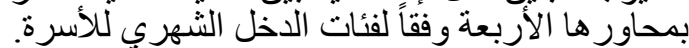

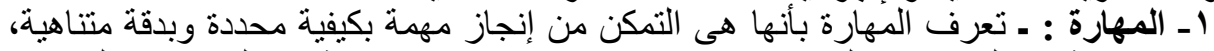

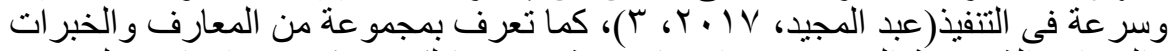

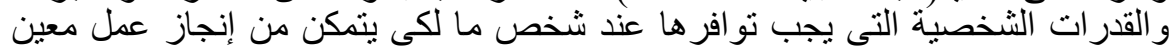
.(Alison Doyle,2019:1))

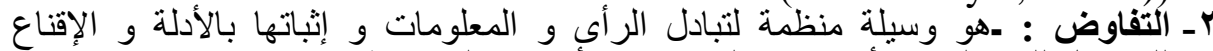

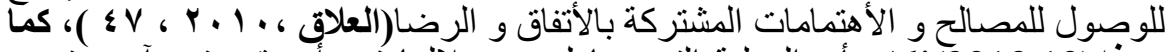

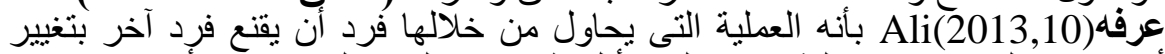

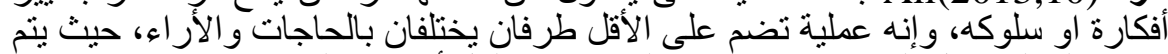

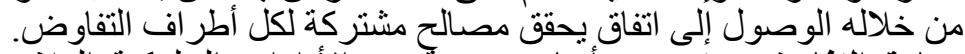

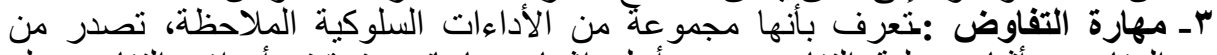

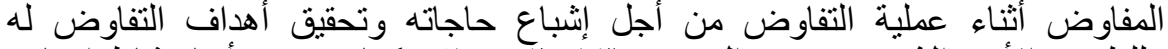

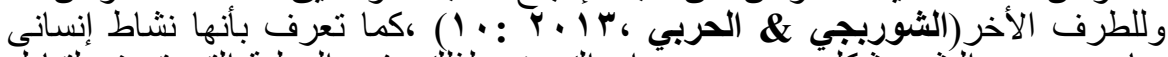

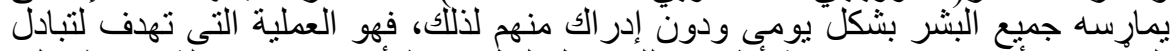

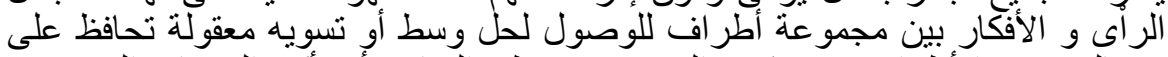

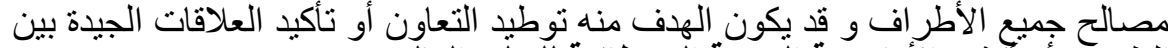

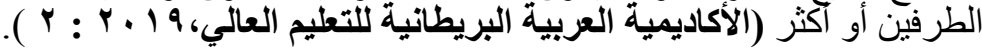




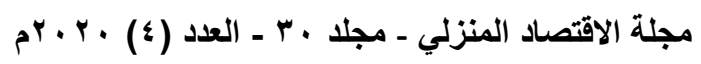

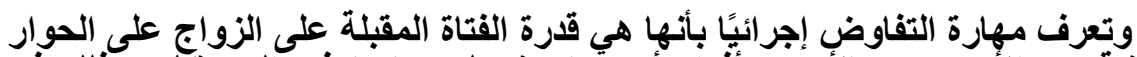

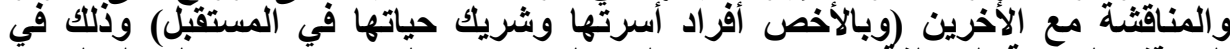

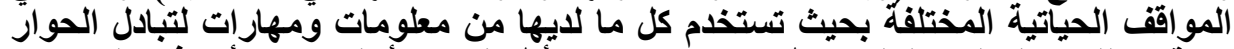

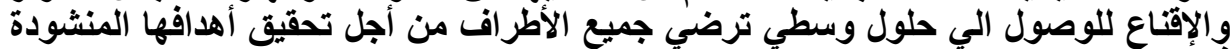

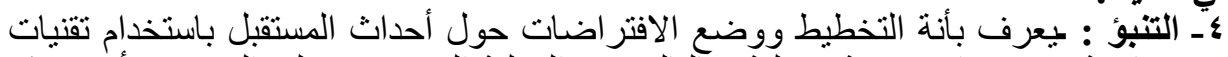

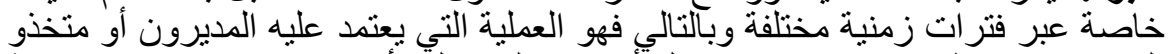

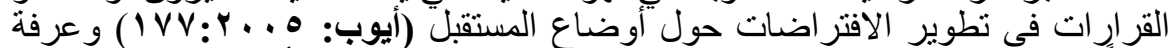

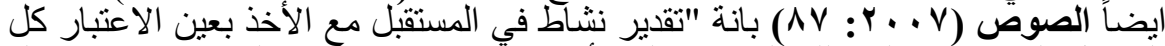

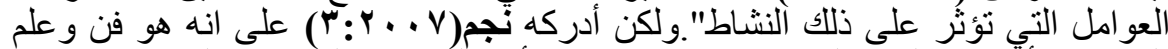

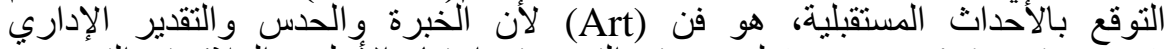

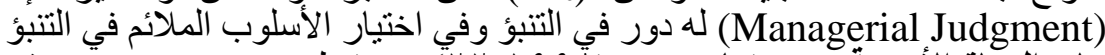

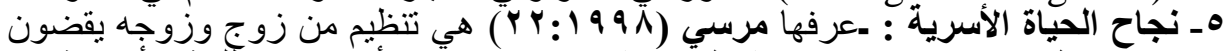

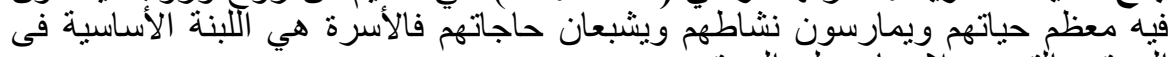

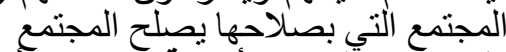

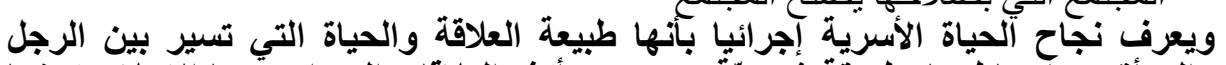

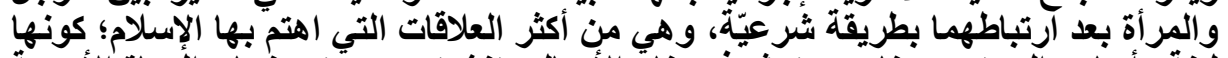

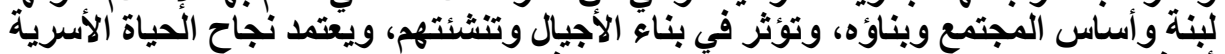

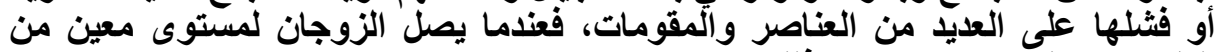

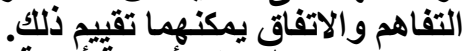

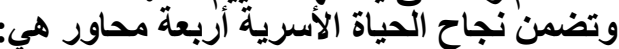

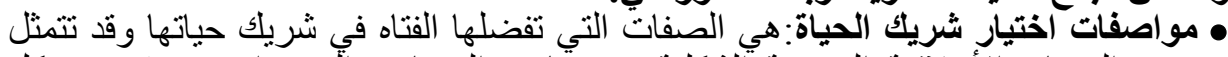

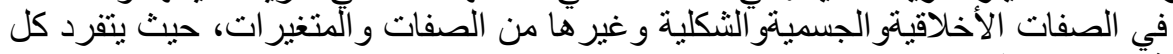
شخص بصفات تميزه عن غيره.

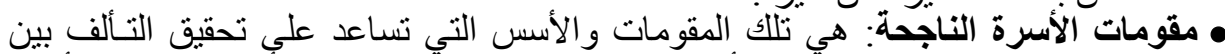

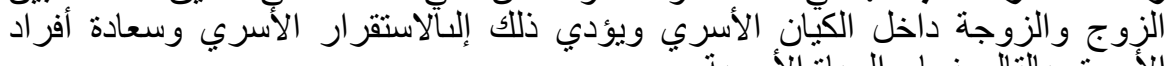
الأسرة وبالتالي نجاح الحياة الأسرية.

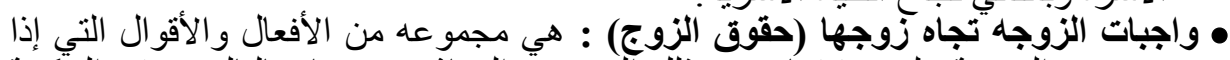

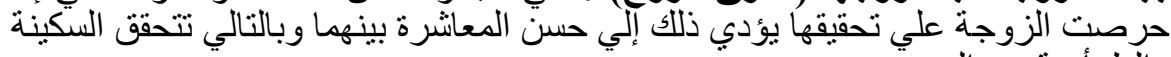
و الطمأنينة بين الزوجين.

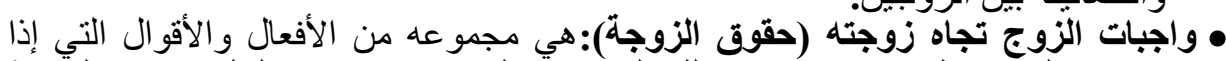

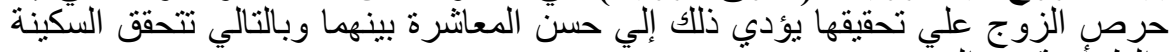

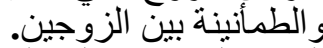

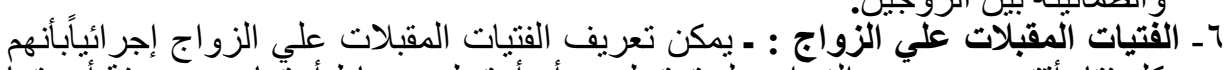

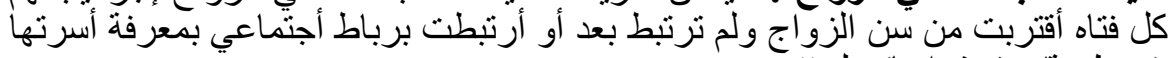
(مخطوبة/ عقد قر انها) ولم تنزو الزوج بعد.

ثنانياً: منهج الاراسة

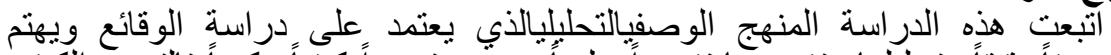

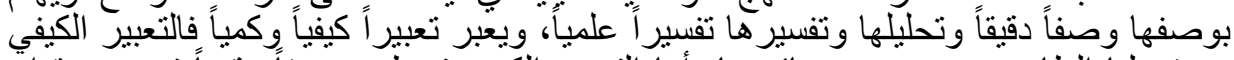

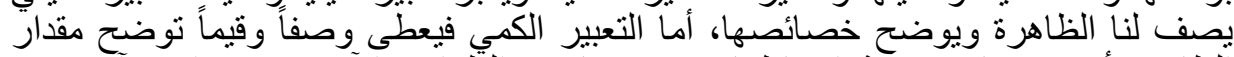

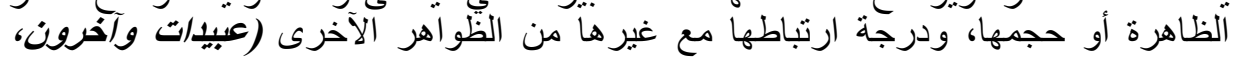




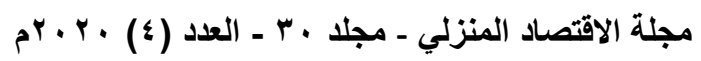

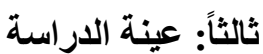

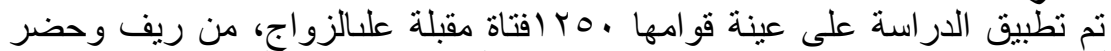
محافظة المنوفية ومن مستويات اجتماعية و اقتصادية مختلفة، وتم اختيار العينة بطريقة صنية صدفية

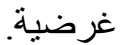

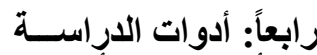

من أجل تحقيق أهداف الداسـة الدراسة و التحقق من صحة الفروض قام الباحثين بإعداد مجموعة من

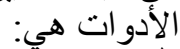

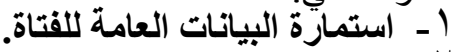

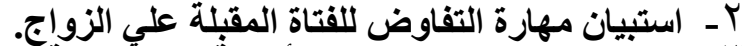

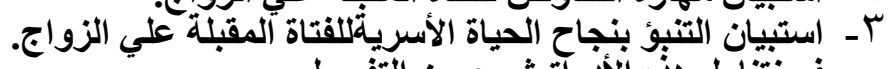

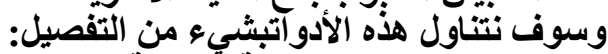

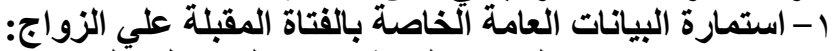

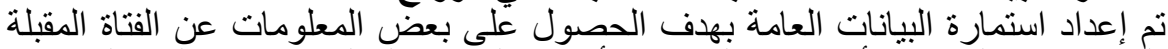

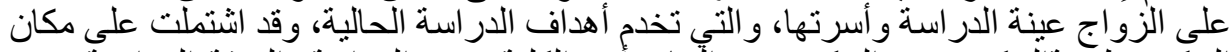

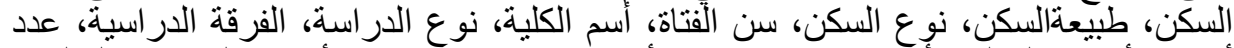

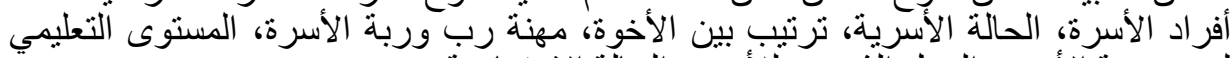

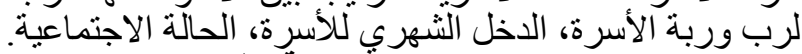

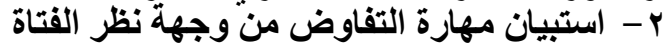

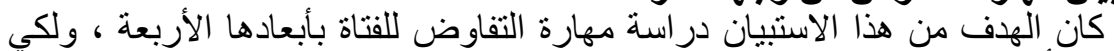

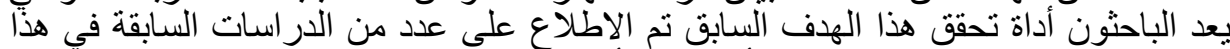

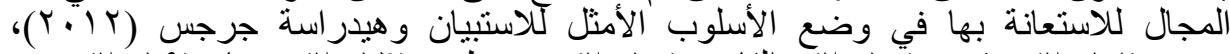

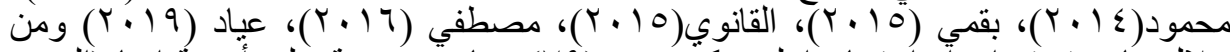

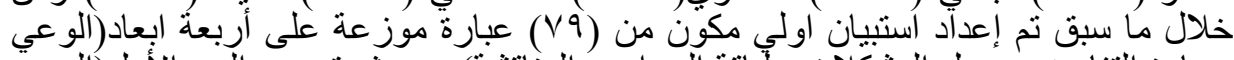

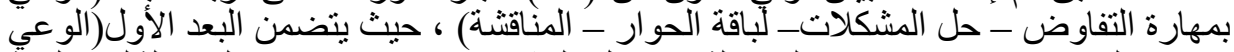

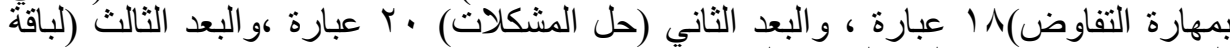

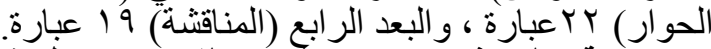

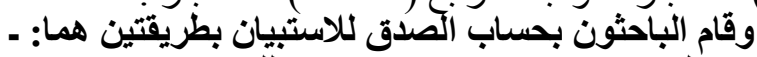

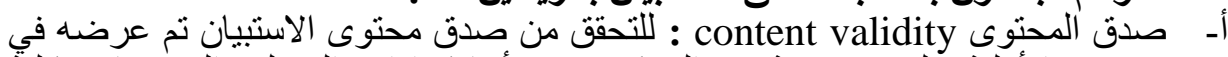

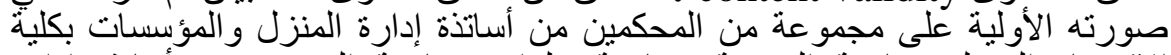

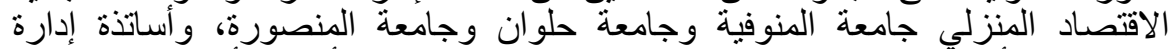

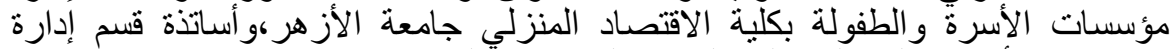

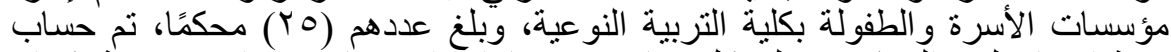

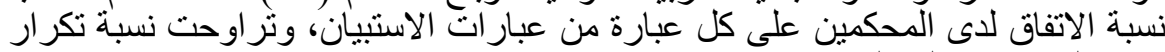

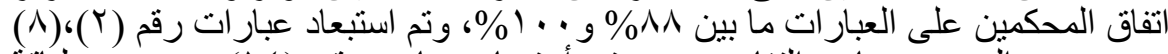

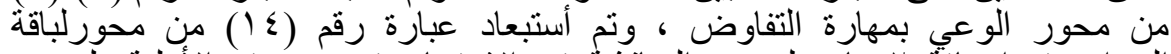

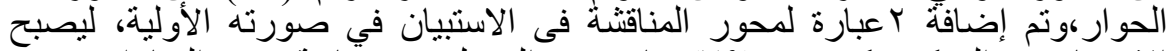

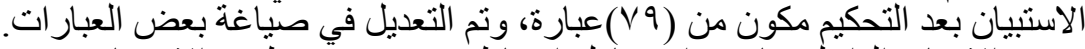

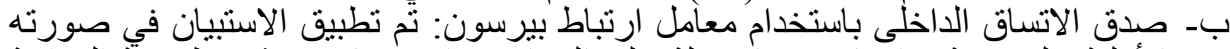

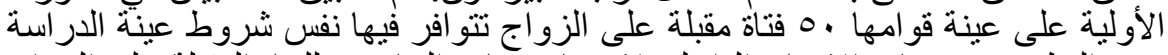

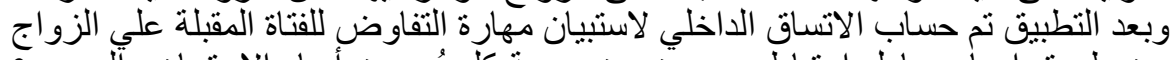

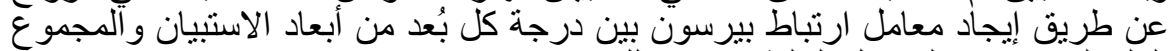

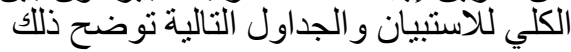




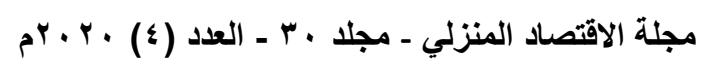

جدول ( 1) معامل ارتباط بيرسون لعبارات كل بعد من أبعاد مهارة التفاوض،

\begin{tabular}{|c|c|c|c|c|c|c|c|}
\hline \multicolumn{2}{|c|}{ المناقشة } & \multicolumn{2}{|c|}{ لباقة الحوار } & \multicolumn{2}{|c|}{ حل المشكلات } & \multicolumn{2}{|c|}{ الوعي بمهارة } \\
\hline $\begin{array}{c}* .67 .0 \\
*\end{array}$ & 1 & $* *, ، 00 \mu$ & 1 & $* * .01$. & 1 & **. ، & 1 \\
\hline $\begin{array}{c}* \text { * ، } \leqslant Y Y \\
*\end{array}$ & r & ו ו , * * & r & $* *$, . $\leqslant 9 \%$ & r & **. . & r \\
\hline $\begin{array}{c}* \text {. } 0 Y Y \\
*\end{array}$ & $r$ & $* *, 6 \leq 71$ & $r$ & $* * .6711$ & $r$ & $.6 .1 \mathrm{~V}$ & $r$ \\
\hline $\begin{array}{c}* \text { * r } 00 \\
*\end{array}$ & $\varepsilon$ & $.60 \%$ & $\varepsilon$ & $* *$, , $\{11$ & $\varepsilon$ & **.0T & $\varepsilon$ \\
\hline $\begin{array}{c}* .600 \\
*\end{array}$ & • & $* *$, , $0 \wedge$. & 0 & $* *$, . $\leq \leqslant \leq 7$ & 0 & **, ، & 0 \\
\hline $\begin{array}{c}\text { *, rTा } \\
*\end{array}$ & 7 & $* .6 .7 r_{-}$ & 7 & $* *$, , r & 7 & $* *$, เ $\leqslant 97$ & 7 \\
\hline $\begin{array}{c}*_{*} \text { ، } \lesssim \wedge \wedge \\
*\end{array}$ & V & $* * .671$. & V & $* * .6194$ & V & $* *$, , $1 \leq \leq$ & $v$ \\
\hline $\begin{array}{c}* ., 0 . r \\
*\end{array}$ & $\Lambda$ & $* *$, , & $\Lambda$ & . . ro & $\Lambda$ & $* *, 00 \leq 7$ & $\Lambda$ \\
\hline $\begin{array}{c}* .67 \leqslant 9 \\
*\end{array}$ & 9 & $* *, ، 1 \wedge r$ & 9 & $* * .6 .9 Y_{-}$ & 9 & $* *$, , $Y \leq 1$ & 9 \\
\hline $\begin{array}{c}*_{* 6} \cdot 19 \\
*\end{array}$ & 1. & $* * .674$ & 1 . & $* * ., 00 \mathrm{~V}$ & 1. & $* *$. ، $\leqslant$ r. & 1. \\
\hline $\begin{array}{c}* .0 Y T \\
*\end{array}$ & 11 & $* * .6710$ & 11 & $* *, ، \Xi Y Y$ & 11 & $* *$, ، $\Sigma \cdot r$ & 11 \\
\hline $\begin{array}{c}* \text { *. I YO } \\
*\end{array}$ & Ir & $* *$, เ $\leq 7 \leq$ & Ir & $* *$, , rq & Ir & $* *, .01 Y$ & Ir \\
\hline $\begin{array}{c}* \text { * r TOr } \\
*\end{array}$ & ir & $* *$, ، $\leqslant \vee 7$ & Ir & $* *, ،, \wedge \varepsilon$ & IT & $* *$, ، $\leqslant 9 r$ & ir \\
\hline $\begin{array}{c}* .097 \\
*\end{array}$ & $1 \varepsilon$ & $* *, ، 10 \mathrm{~V}$ & $1 \varepsilon$ & $* *$, , $\diamond \vee 4$ & $1 \varepsilon$ & $* *$. ، $\leq 9 \leq$ & $1 \varepsilon$ \\
\hline $\begin{array}{c}* .60 . \\
*\end{array}$ & 10 & $* *$, ، $\leqslant V$. & 10 & $* *$. ، $\varepsilon .0$ & 10 & **., orr & 10 \\
\hline $\begin{array}{c}* .6 \leq 77 \\
*\end{array}$ & 17 & $* *$, , 0 r $q$ & 17 & $* * .677 V$ & 17 & $* * .079$ & 17 \\
\hline $\begin{array}{c}* \text { *. } \\
* 9\end{array}$ & 18 & $* *$. . 094 & iv & $* * ., 1 \vee V$ & iv & $* *$, เ $\leqslant 77$ & 18 \\
\hline $\begin{array}{c}* ., 0 . r \\
*\end{array}$ & 11 & $* * .67,1$ & 11 & $* *$, ، $\leqslant \vee q$ & 11 & **, ، & 11 \\
\hline $\begin{array}{c}* \text { * r } Y V \leq \\
*\end{array}$ & 19 & $* *$, ، $\{1\}$ & 19 & $* *, \quad 0 \leq \leqslant$ & 19 & & \\
\hline & & $* *$, , & $r$. & $* *, \sigma r \wedge \varepsilon$ & $r$. & & \\
\hline & & $* *,, r \wedge V$ & YI & & & & \\
\hline & & $* * .6079$ & YY & & & & \\
\hline
\end{tabular}

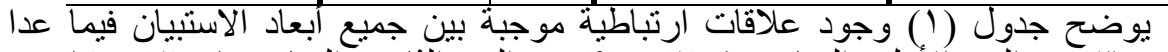

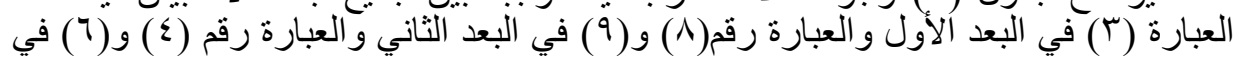




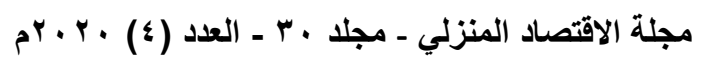

البعد الثالث نم حذفهما وبذلك نجد أن الاستبيان صادق في المتغيرات الخاصة به ويقيس الذي

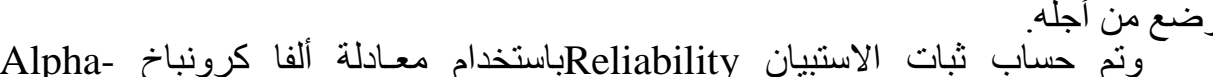

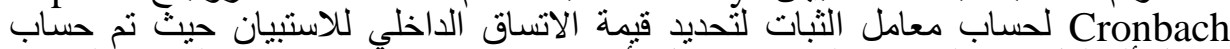

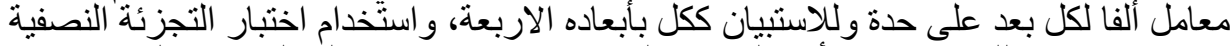

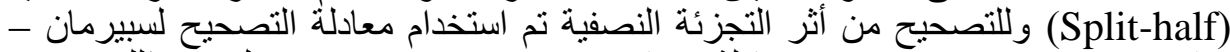

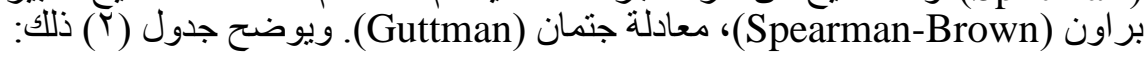

جدول (Y) اختبار معامل الفا كرونباخ، والتجزئة النصفية لاستبيان مهارة التفاوض من وجهة نظر الفتاة

\begin{tabular}{|c|c|c|c|c|}
\hline \multicolumn{2}{|l|}{ التجزئة النصفية } & \multirow{2}{*}{ كرونباخ الفا } & \multirow{2}{*}{ العبارات } & \multirow[b]{2}{*}{ 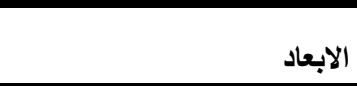 } \\
\hline سبيرمان برون & ل جتمان & & & \\
\hline .VYT & $.6 V 7 Y$ & $.6 \mathrm{~V} 00$ & IV & الكوعي بمهارة التفاوض \\
\hline . $6 \leqslant 5$ & $\cdot 6 \mathrm{~V} \leqslant 0$ & $.6 \times 79$ & in & حل المَنْكلاتَ \\
\hline . ‘AY. & . ‘AY. &.$\triangleleft \wedge .0$ & r. & لباقَة الحوار \\
\hline. $\mathrm{VV} \odot \mathrm{V}$ & - $6 \mathrm{~V} \leqslant 1$ & . & 19 & المناقثئة \\
\hline .6199 & .61999 &. .947 & $\overline{\nabla \varepsilon}$ & إجمالي استبيان مهارة التفاوض \\
\hline
\end{tabular}

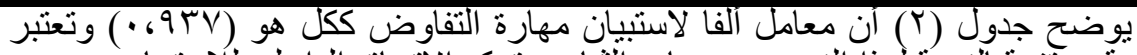

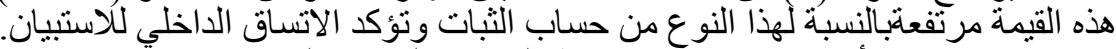

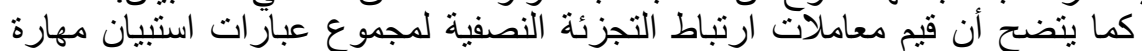

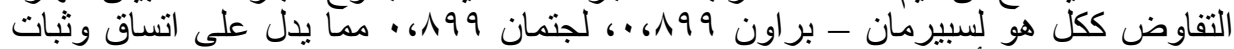

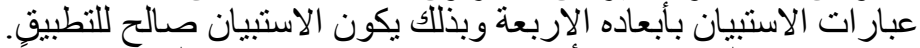

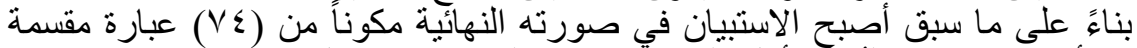

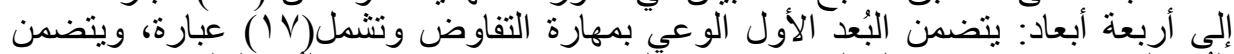

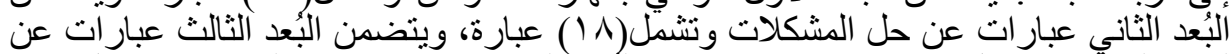

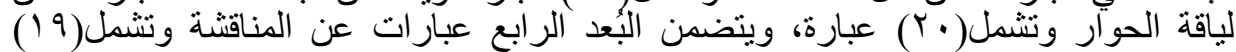

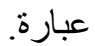

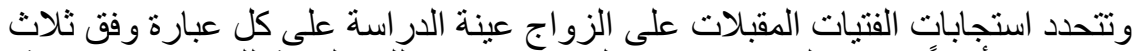

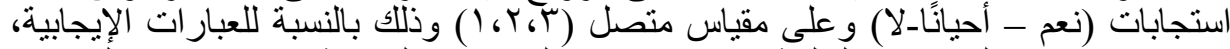

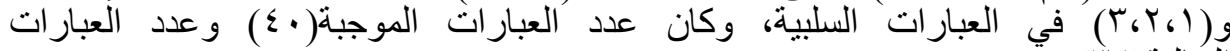

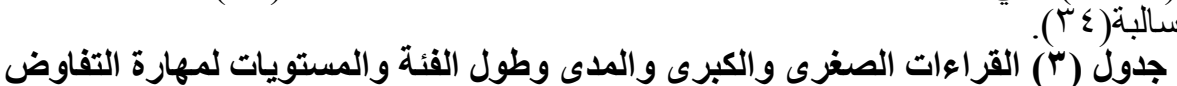

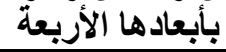

\begin{tabular}{|c|c|c|c|c|c|c|c|c|}
\hline مرتفع مستوى & متوستوي & منخفضت & الفئة & المدى & الكبرى القرة & الصغرى القرة & العبارات & الأبعاد \\
\hline$(01-\varepsilon \mu)$ & $(\varepsilon r-r \Delta)$ & $(Y \wedge-Y V)$ & $\Lambda$ & $Y \varepsilon$ & 01 & YV & IV & الوالتقاوضي بمهارة \\
\hline$(\theta \leqslant-\leqslant \theta)$ & $(\varepsilon \varepsilon-r V)$ & $\left(r_{q}-r_{q}\right)$ & $\Lambda$ & Yo & $0 \leqslant$ & rq & 11 & حل المشكلات \\
\hline$(7 \cdot-0 \cdot)$ & $(\leqslant 9-\varepsilon 1)$ & $(\varepsilon \cdot-r Y)$ & 9 & YN & 7. & MY & r. & لباقَة الحوار \\
\hline$(0 \curlyvee-\varepsilon \Lambda)$ & $(\leqslant V-\varepsilon \cdot)$ & $(r q-r r)$ & $\Lambda$ & YE & 07 & Tr & 19 & المناقشُة \\
\hline$\left(Y\left|Y_{-}\right| \wedge \overline{ }\right)$ & $(110-17 \cdot)$ & $(1 \otimes 9-1 \% \varepsilon)$ & rq & $\vee \wedge$ & YIr & IT & $V \varepsilon$ & إجمالي مهارة \\
\hline
\end{tabular}




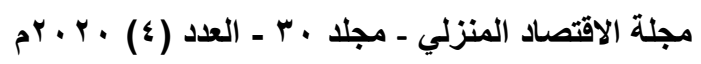

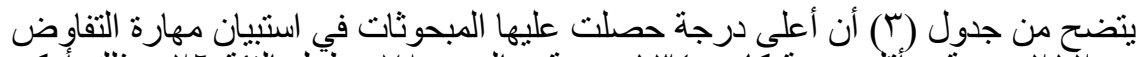

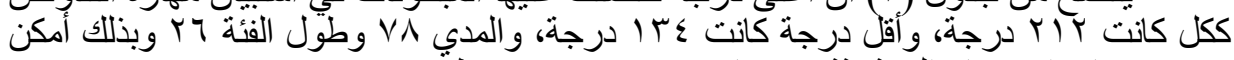

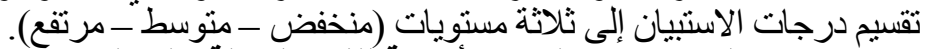

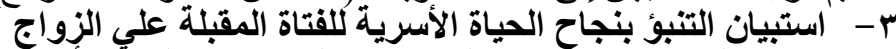

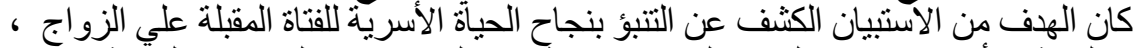

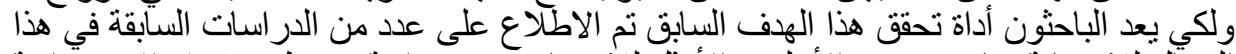

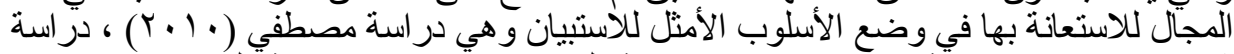

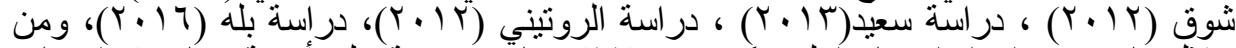

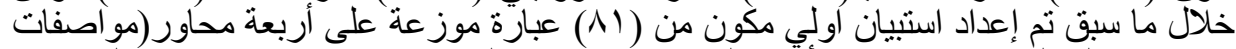

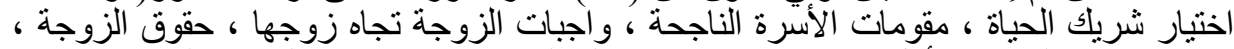

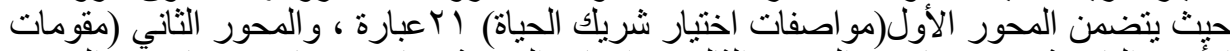

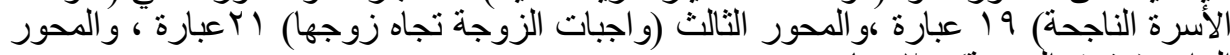

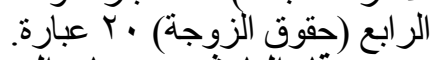

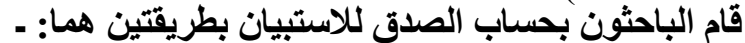

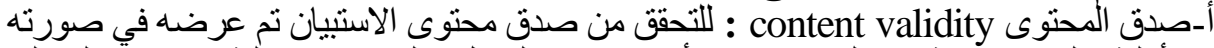

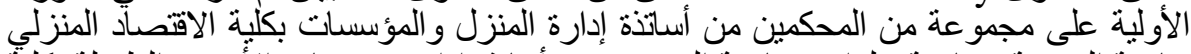

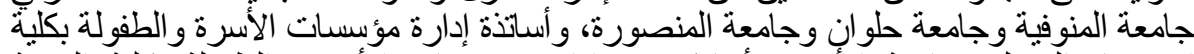

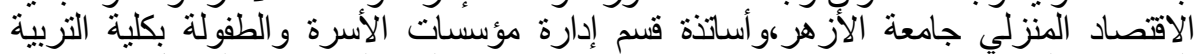

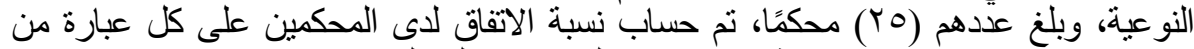

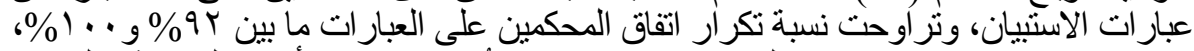

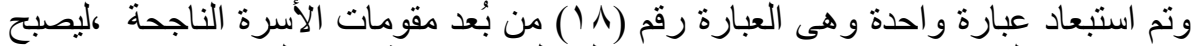

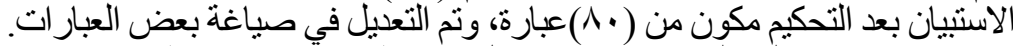

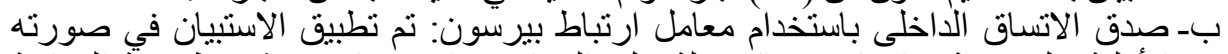

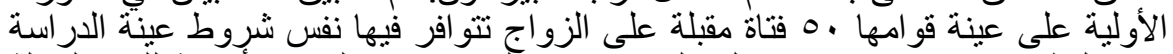

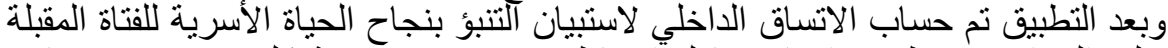

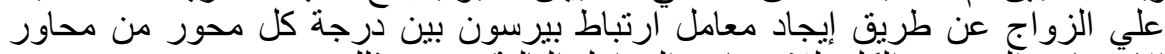

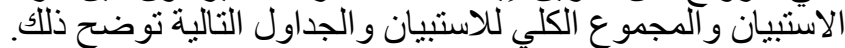

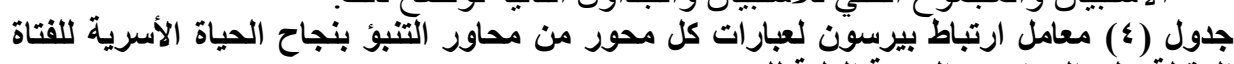

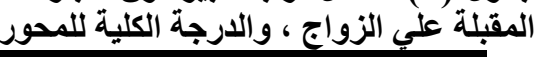

\begin{tabular}{|c|c|c|c|c|c|c|c|}
\hline \multicolumn{2}{|c|}{ حقوق الزوجة } & \multicolumn{2}{|c|}{ واجبات لزوجها تجاه } & \multicolumn{2}{|c|}{ مقومات الأسرة الناجحة } & \multicolumn{2}{|c|}{ مواصفات احتيار شريك } \\
\hline$* *, 6 \vee \vee \leqslant$ & 1 & $* *$, . $\leqslant \vee q$ & 1 & $* * .6710$ & $T$ & $* * .671$. & 1 \\
\hline$* * .6 \vee 10$ & T & $* * .679$. & T & $* * .67 .1$ & Y & $* *, .0 \vee q$ & T \\
\hline$* * .670$. & $r$ & **.،7rq & $\mu$ & $* * . ، 7 \wedge \wedge$ & $r$ & **., & $\mu$ \\
\hline$* *$, , YO . & $\varepsilon$ & $* * .617 \%$ & $\varepsilon$ & $* *, ، 0 \leq 0$ & $\varepsilon$ & $* * .67 V$. & $\varepsilon$ \\
\hline **. & • & **, , r T. & 。 & $* * .6791$ & 。 & ס שד. . *** & 0 \\
\hline$* * .6790$ & 7 & $* *, 6 \leqslant 0 V$ & 7 & $* *, .7 \leq r$ & 7 & $* *, ، 0 \Delta Y$ & 7 \\
\hline$* *, 6 r \wedge Y$ & $\mathrm{~V}$ & $* * ., 7 V$. & $\mathrm{V}$ & $* *, ، 00 \mathrm{~V}$ & $\mathrm{~V}$ & $* *$, . TVY & $\mathrm{V}$ \\
\hline$* *, ، \Delta \wedge \wedge$ & $\Lambda$ & $* *, ، 7 \leqslant r$ & $\Lambda$ & $* *, ، V \otimes r$ & $\Lambda$ & $* * .67 \vee \wedge$ & $\Lambda$ \\
\hline$* *+، \varepsilon \Gamma V$ & 9 & $* * .67 \% 0$ & 9 & $* * \cdot 6 \vee 10$ & 9 & $* *+67 V Y$ & 9 \\
\hline$* *$, . V & 1. & $* *, ، \leqslant \Gamma$ & 1. & $* * .677$ & 1. & $* * .67 \Lambda \varepsilon$ & 1. \\
\hline$* * .671 \mathrm{~V}$ & 11 & $* * .60,1$ & 11 & $* * \cdot 6 \mathrm{~V} \cdot \Lambda$ & 11 & $* * .6 \% q$. & 11 \\
\hline$* * .6 \& 99$ & TY & $* * .6099$ & Tr & $* * .67 \vee \Lambda$ & TY & $* *, ، \varepsilon \mid r$ & Tr \\
\hline$\% * .6711$ & TT & $* * .6791$ & $1 \pi$ & $* *, 6 \leqslant \leqslant 9$ & $\pi$ & $* * ., 0 \wedge 7$ & $1 T$ \\
\hline
\end{tabular}




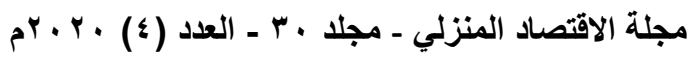

\begin{tabular}{|c|c|c|c|c|c|c|c|}
\hline \multicolumn{2}{|c|}{ حقوق الزوجة } & \multicolumn{2}{|c|}{ واجبات لزوجها تجاه } & \multicolumn{2}{|c|}{ مقومات الأسرة الناجحة } & \multicolumn{2}{|c|}{ مواصفات احتيار شريك } \\
\hline$* *, 6 V, \theta$ & $1 \varepsilon$ & $* * .6797$ & $1 \leq$ & $* * .699 \mathrm{~V}$ & TE & $* * ., Y \odot V_{-}$ & $1 \varepsilon$ \\
\hline **. . ، Y & 10 & $* * .67 .0$ & 10 & $* *, ، 0, \mu$ & 10 & $* \% .679$. & 10 \\
\hline$* * . ، \leqslant 94$ & 17 & $* \% .6707$ & 17 & $* *, 00 \leqslant$ & 17 & $* * .67 \%$ & 17 \\
\hline$* * .67 .7$ & IV & $* * .67 V$. & IV & $* *, 6 V Y q$ & IV & $* *$, , Y०४ & IV \\
\hline$* *, 6 \leq \leqslant \leq$ & 11 & $* *$, , ०9 & $1 \wedge$ & $* *, 6 \leqslant \Lambda \vee$ & $1 \wedge$ & $* * .6 \vee 19$ & 11 \\
\hline$* * .67 \%$ & 19 & $* * .6070$ & 19 & & & $* * ., Y \vee 0$ & 19 \\
\hline$* *, 6 \leqslant I V$ & Y. & $* * .67 \leq \leq$ & Y. & & & $* *, 6 \leqslant 90$ & $r \cdot$ \\
\hline & & $* * .6097$ & YI & & & $* * .6770$ & YI \\
\hline
\end{tabular}

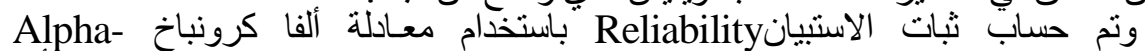

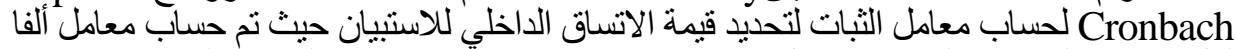

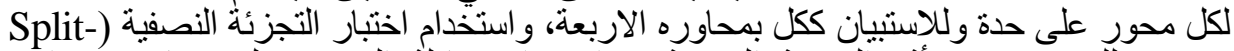
(half (Spearman-Brown)

جلول (ه) اختبار معامل الفا كرونباخ، والتجزئة النصفية لاستبيان التنبؤ بنجاح الحياة

\begin{tabular}{|c|c|c|c|c|}
\hline \multicolumn{2}{|c|}{ التجزئة النصفية } & & & \multirow[b]{2}{*}{ 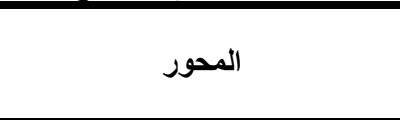 } \\
\hline سببيرمان & جتمان & كرونباخ & العبارات & \\
\hline $.6 \Lambda .0$ & $.6 \Lambda .0$ & .6117 & r. & مواصفات اختيار شريك الحياة \\
\hline $.69 \cdot Y$ & $\cdot 69 \cdot r$ & $.69 \cdots$ & 11 & مقومات الأسرة الناجحة \\
\hline .6107 & $\cdot . \wedge 01$ & 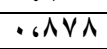 & YI & واجبات الزوجة تجاه زوجها \\
\hline $.6 \wedge 91$ & $\cdot 6 \wedge \wedge 9$ & .6179 & 19 & حقوق الزوجة \\
\hline$\cdot 69 \leq V$ & $.09 \leq 7$ & .6971 & $\vee \wedge$ & إجمالي التنبؤ بنجاح الحياة الأسرية \\
\hline
\end{tabular}

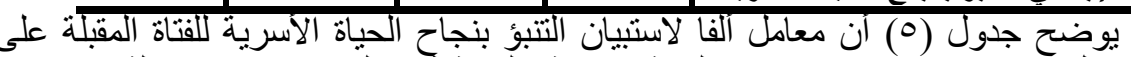

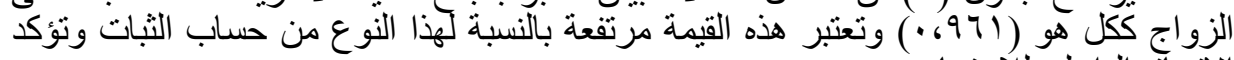

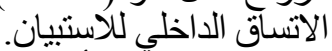

كما يتضح أن قيم معاملات ارتباط التجزئة النصفية لمجموع عبار ات استبيان التنبؤ بنجاح

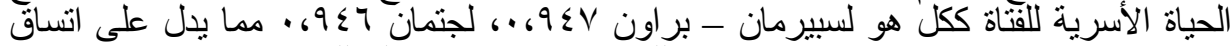

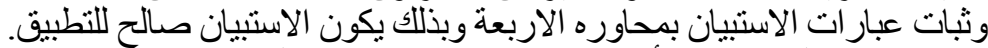

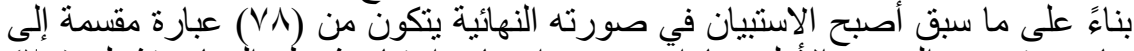

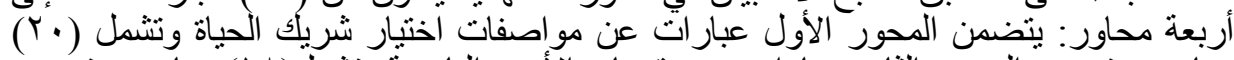

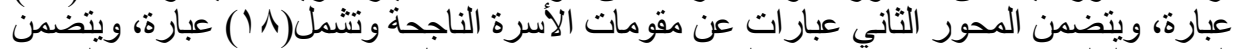

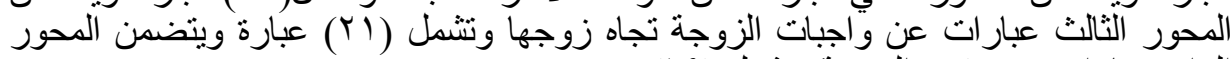
الرابع عبار ات عن حقوق الزوجة وتنشمل (9 (1). 


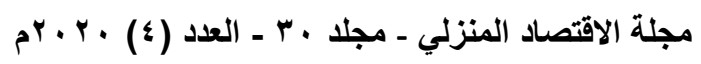

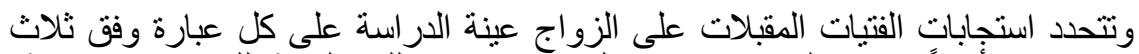

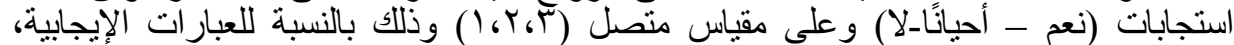

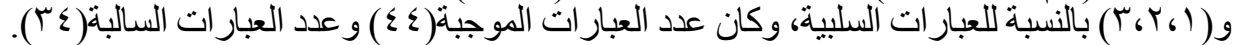
جذول (†) القراءات الصغرى والكبرى والمدى وطول الفئة والمستويات لتتبؤ بنجاح الحياة الاسرية بمحاور ها الأربعة المراع

\begin{tabular}{|c|c|c|c|c|c|c|c|c|}
\hline مستوي مرتفع & متوستوي & 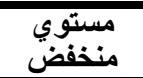 & طولي & المدي & الكبرى ألقة & الصغراءة & العدد العد & المحور \\
\hline$(09-0 \cdot)$ & $(\leqslant 9-\leqslant 1)$ & $(\varepsilon \cdot-r r)$ & 9 & $r v$ & 09 & rr & $r$. & الحياة \\
\hline$(0 \leq-\leq 7)$ & $(\varepsilon \theta-r V)$ & $\left(r^{M}-Y \Lambda\right)$ & 9 & Yq & $0 \leq$ & YA & 11 & مقومات الأسرة الناجحة \\
\hline$(7 r-0 \varepsilon)$ & $(O r-\varepsilon \varepsilon)$ & $(\varepsilon r-r \varepsilon)$ & 1. & rq & 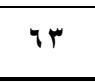 & צ & r & زوجها (حقوق الزوجة تجاه \\
\hline$(\diamond \vee-\leqslant q)$ & $(\varepsilon \wedge-\varepsilon \cdot)$ & $\left(r q-r^{\prime}\right)$ & 9 & rq & ov & r & 19 & زوجتبه (حقوق الززوجة تُجاه \\
\hline$(Y Y \wedge-19 \wedge)$ & $(198-179)$ & $(17 \wedge-1 \leq \cdot)$ & rq & $\wedge \wedge$ & rrA & $1 \leq$. & $\wedge \vee$ & الجياة الأسرية التبوئ بنجاح \\
\hline
\end{tabular}

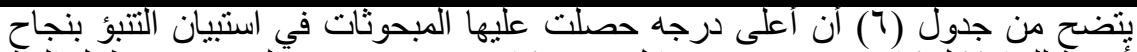

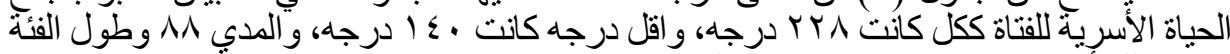
qr و بذلك أمكن تقسيم درجات الاستييان إلى ثلاثة مستويات (منخفض - منوسط - مرتفع).

$$
\text { خامساً: إجراءات تطبيق أدوات البحث على العينة }
$$

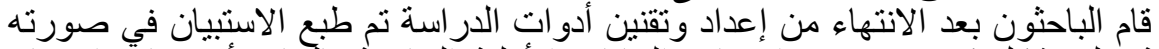

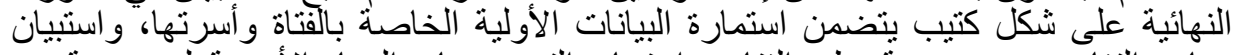

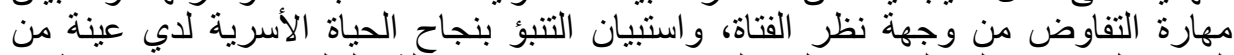

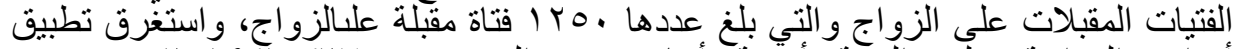

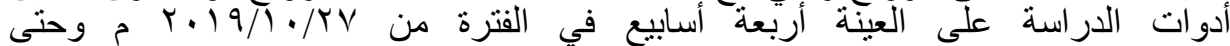

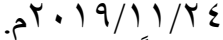
سنادساً: المعاملات الإحصائية المستخدمة في الإراسة

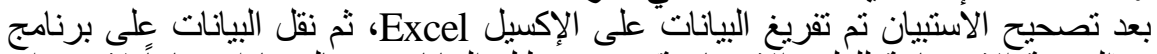
SPSS

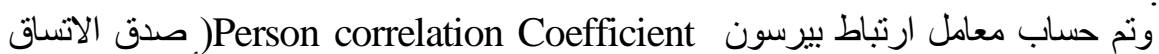
النتائج.

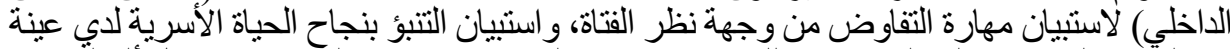

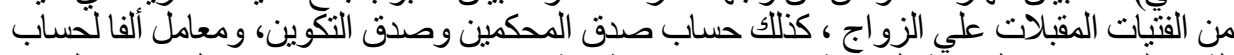

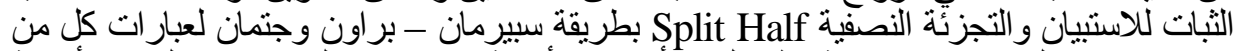

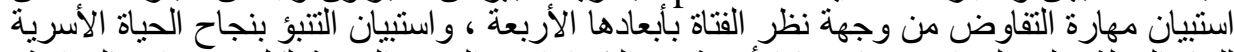

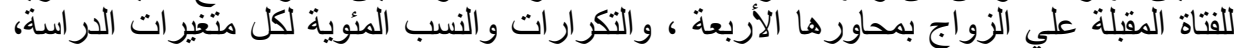

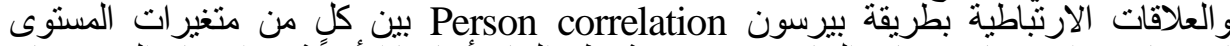

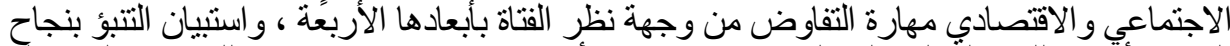

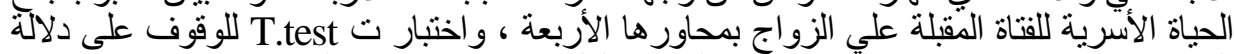

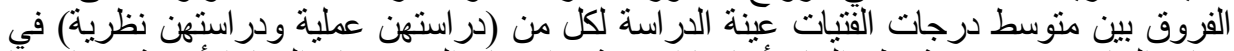

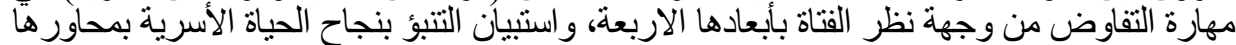
الاربعة، وباستخدام تحليل التباين في اتجاه واحد ANOVA للوقوف علي دلالة التئة التباين بين الفتيات 


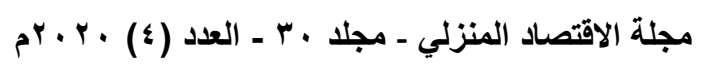

عينة الدراسية في مهارة التفاوضٍ من وجهة نظر الفتاة بأبعادها الأربعة، واستبيان التتبؤ بنجاح الحياة

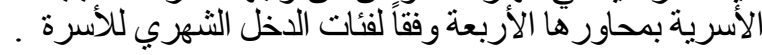

نتائج الاراسة الميدانية أولا: وصف عينة البحث

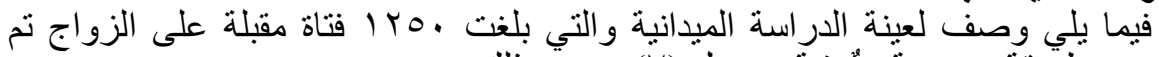

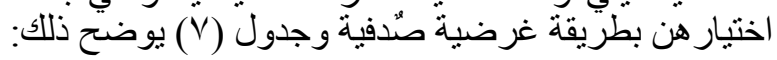

جدول (V) الخصائص الاجتماعية والاقتصادية للفتيات القبلات على الزواج عينة البحث

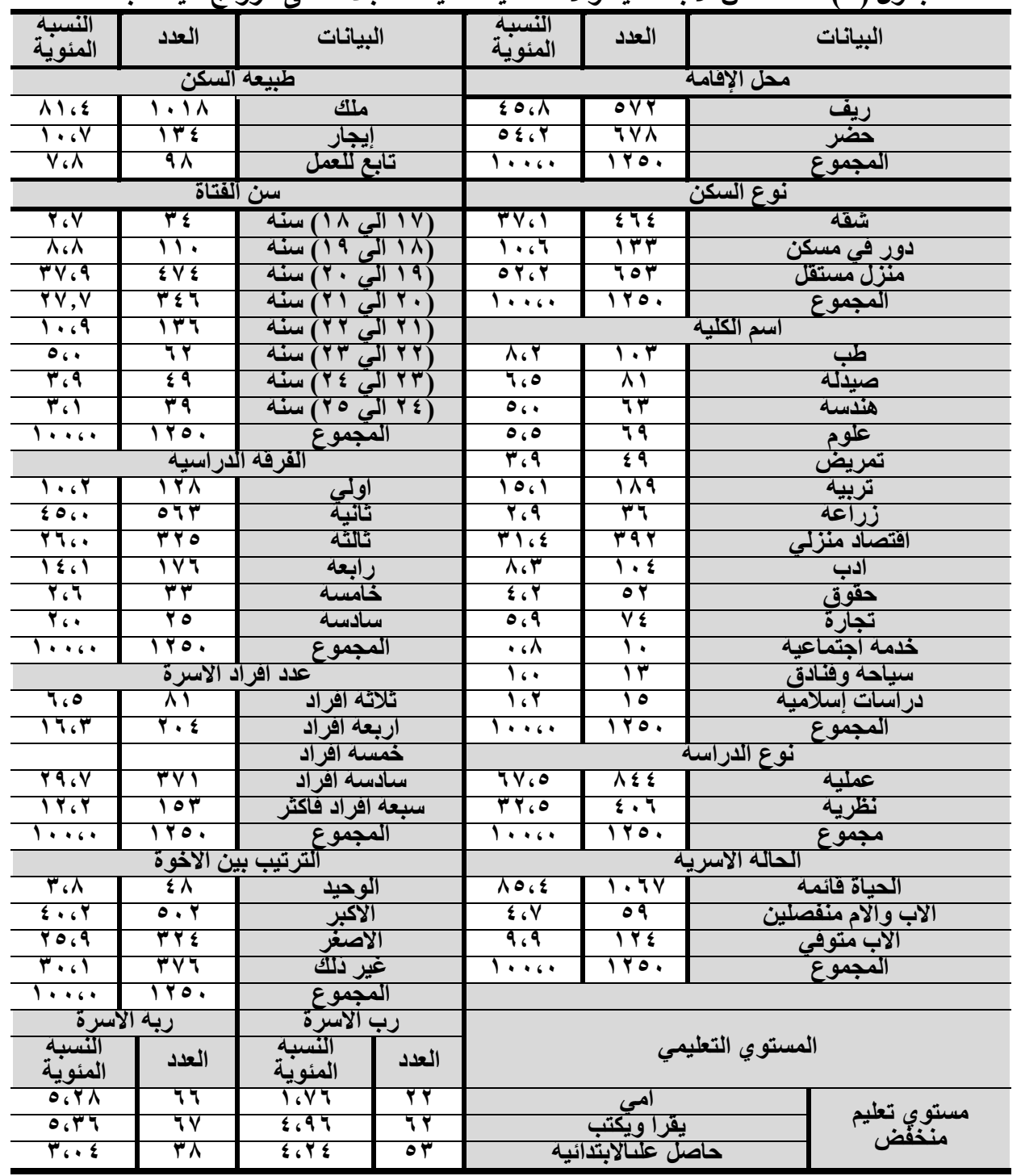




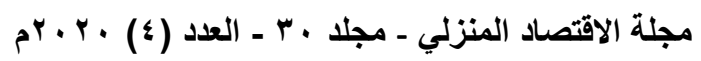

\begin{tabular}{|c|c|c|c|c|c|c|}
\hline المئوية & العدد & \multicolumn{2}{|c|}{ البيانات } & المئوينة & العدد & \multirow{4}{*}{ مستوّيط تعليم } \\
\hline$r .7 \Lambda$ & 27 & $\varepsilon_{6 V Y}$ & 09 & \multirow{2}{*}{\multicolumn{2}{|c|}{ 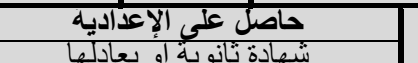 }} & \\
\hline M.人E & एवर & P7.07 & TYY & & & \\
\hline P. .99 & TqT & 19649 & TE & \multicolumn{2}{|c|}{ 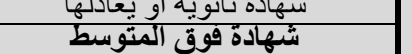 } & \\
\hline Y7، $\varepsilon$ & r. & ro, & $\varepsilon \Gamma \wedge$ & \multicolumn{2}{|c|}{ حاصل على مؤهل جامعي } & 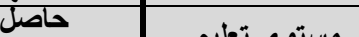 \\
\hline Y & 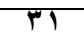 & $Y_{6} \cdot 1$ & rq & \multicolumn{2}{|c|}{ دراسات عليا(ماجيسنتير) } & دراساً \\
\hline .699 & Tr & T.PN & 19 & \multicolumn{2}{|c|}{ لدراسات عليأدكتور اه) } & دراس \\
\hline $1 \cdots, \cdots$ & T120. & $1 \cdots, \cdots$ & TYO. & & & المجموع \\
\hline \multicolumn{4}{|c|}{ رباه الأسرةز } & \multicolumn{2}{|c|}{ رب الاسرة } & \multirow{2}{*}{ وظيفة رب وربة الأسرة } \\
\hline \multirow{2}{*}{\multicolumn{2}{|c|}{ ألَّبه المئوياه }} & \multirow{2}{*}{\multicolumn{2}{|c|}{ 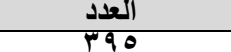 }} & الْنسبه & العدد & \\
\hline & & & & $\sum \pi, 0$ & $0 \leqslant \leqslant$ & وظظفه حكومبيه \\
\hline \multicolumn{2}{|c|}{$r . V$} & \multicolumn{2}{|c|}{$\leqslant 7$} & IT,V & 109 & فَظاع خاص \\
\hline \multicolumn{2}{|c|}{0,1} & \multicolumn{2}{|c|}{$7 \varepsilon$} & 1961 & $T \leqslant \Lambda$ & اعمّال حرةً \\
\hline \multicolumn{2}{|c|}{ T.V } & \multicolumn{2}{|c|}{ एद } & Trus & $19 \mathrm{~V}$ & على المعانّت \\
\hline \multirow{2}{*}{\multicolumn{2}{|c|}{$\begin{array}{l}\text { T6r } \\
0 \leqslant 67\end{array}$}} & \multicolumn{2}{|c|}{ is } & 1,9 & $\pi$ & منتوفي \\
\hline & & \multirow{2}{*}{\multicolumn{2}{|c|}{ 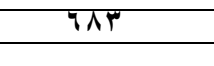 }} & $1 . \mathrm{V}$ & Tा & بدون عمل \\
\hline \multirow{2}{*}{\multicolumn{4}{|c|}{ الحاله الاجتماعيه }} & \multicolumn{2}{|c|}{$1 \ldots$} & المجموع \\
\hline & & & & \multicolumn{3}{|c|}{ فئَّات الاخل الشُهري } \\
\hline$T V_{6} \Lambda$ & हV & \multicolumn{2}{|c|}{ | مخطوبه } & $11_{6} \cdot$ & TYO & أل من · . . P جنيه \\
\hline 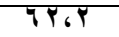 & VVI & \multicolumn{2}{|c|}{ غير مخطوبه } & T9,1 & TVT & \multirow{2}{*}{ 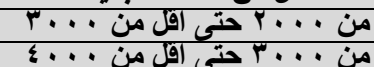 } \\
\hline \multirow[t]{8}{*}{$1 \cdot \cdot 6$} & $1 \% 0$ & \multicolumn{2}{|c|}{ ألمجموع } & 10,9 & 199 & \\
\hline & & & & 1769 & $10 \mathrm{~V}$ & 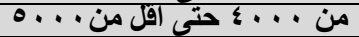 \\
\hline & & & & 9.9 & Tार & من . . • حتي اقل من . . \\
\hline & & & & $0, \varepsilon$ & 71 & 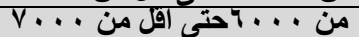 \\
\hline & & & & P,T & Tq & 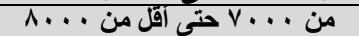 \\
\hline & & & & T.V & Tा & 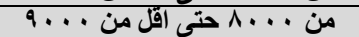 \\
\hline & & & & $\varepsilon, \Gamma$ & $0 \leq$ & 1 9. . . . \\
\hline & & & & $1 \cdots$ & Iro. & 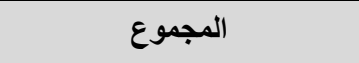 \\
\hline
\end{tabular}

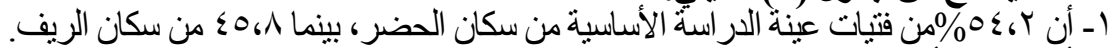

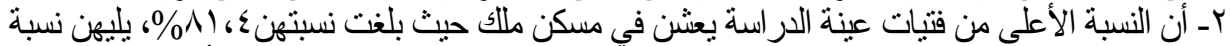

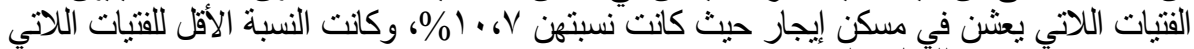

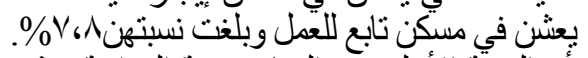

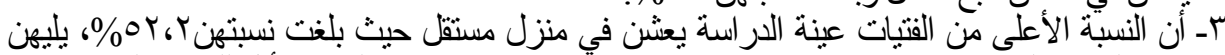

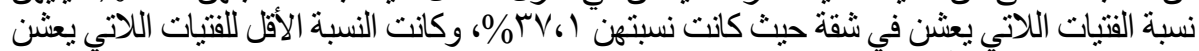

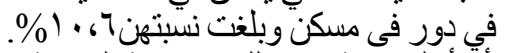

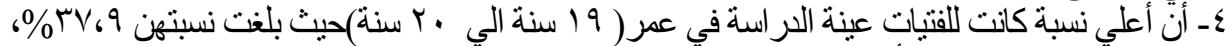

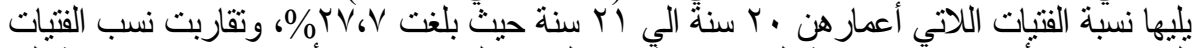

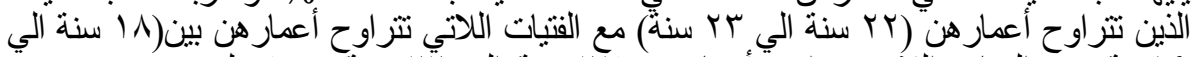

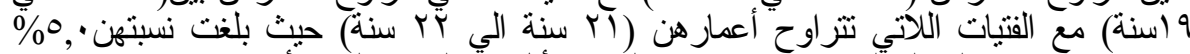

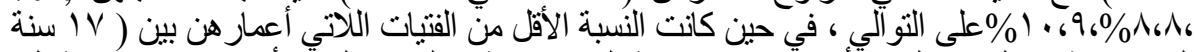

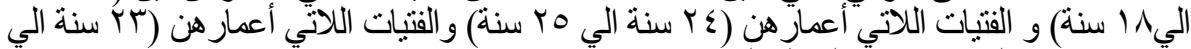

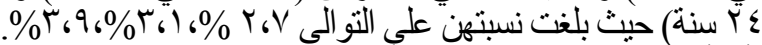

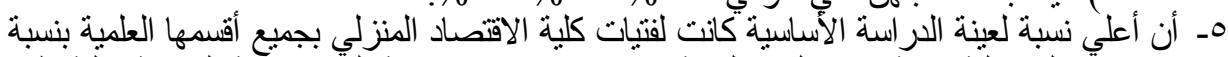

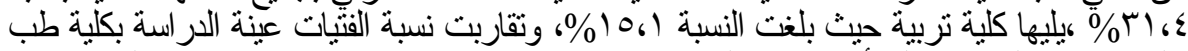

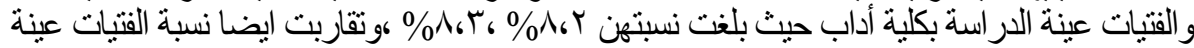
الدراسة بكلية حقوق والفتبات عبنة الدر اسة بكلية هنسة وفتبات عبنة الدراسة كلية العلوم و فنتات عينة 


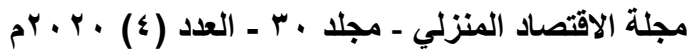

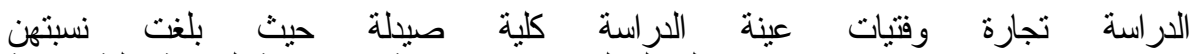

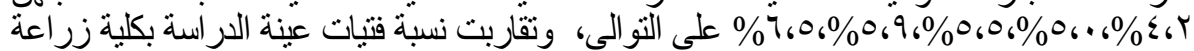

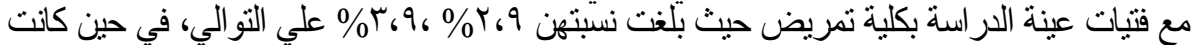

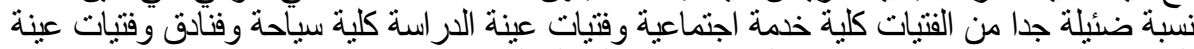

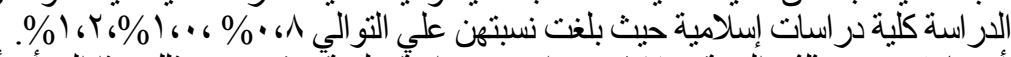

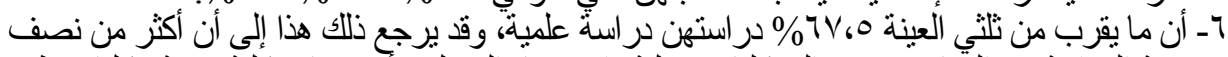

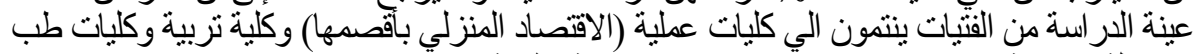

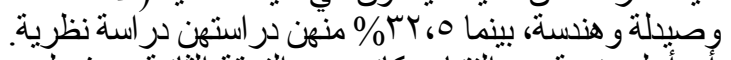

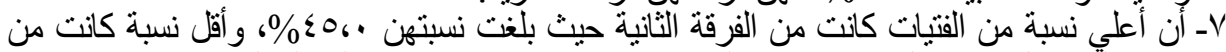

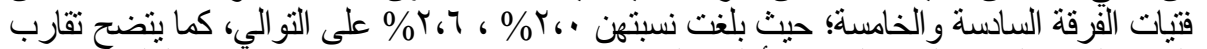

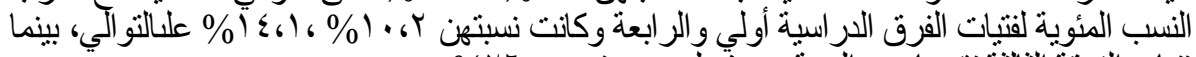

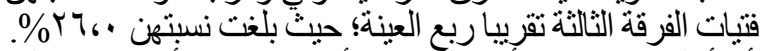

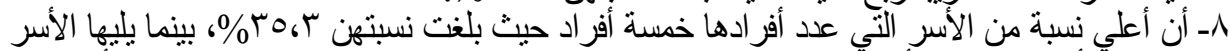

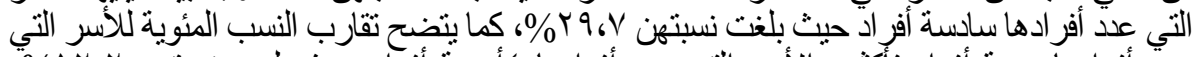

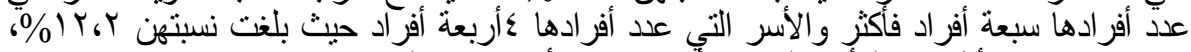

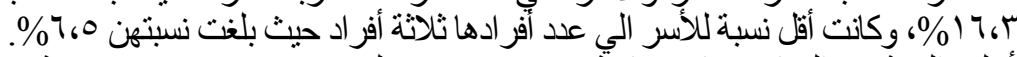

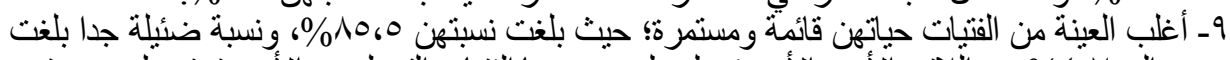

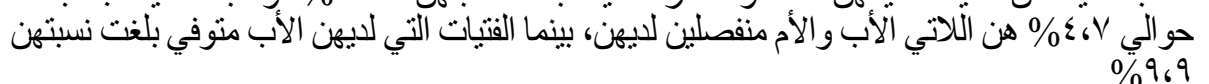

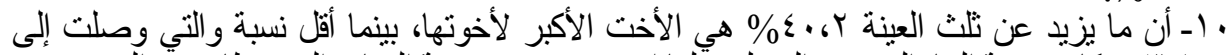

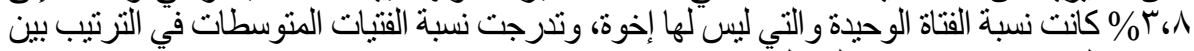

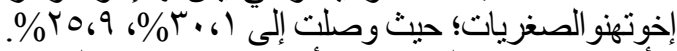

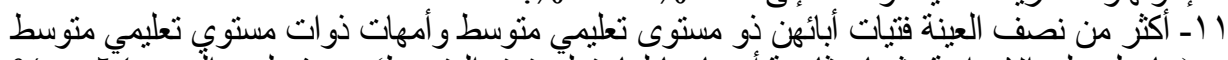

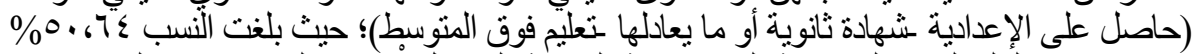

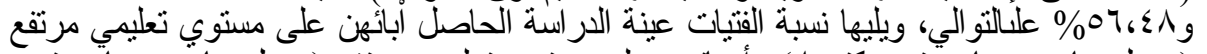

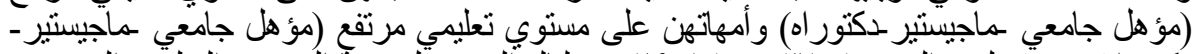

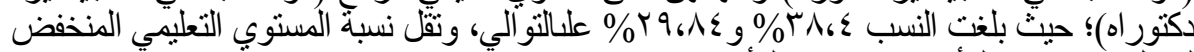

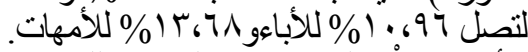

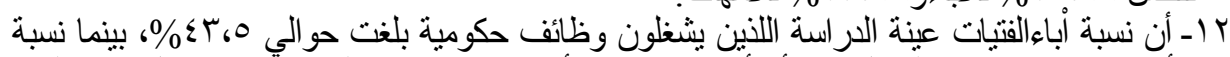

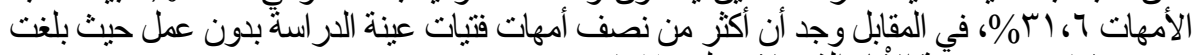

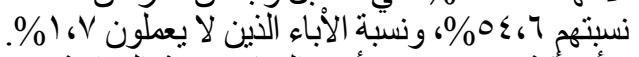

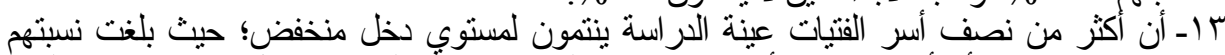
كبr.V

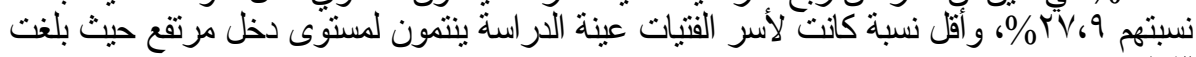
$\%{ }^{\lambda, r}$

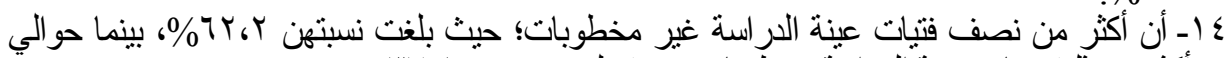

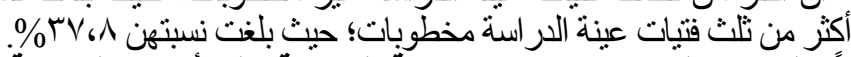

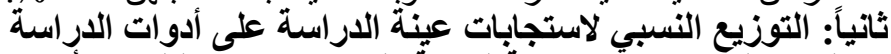

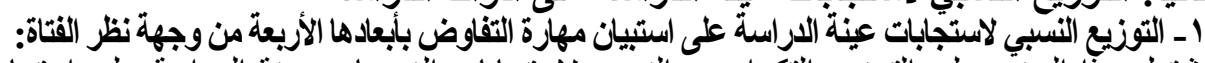

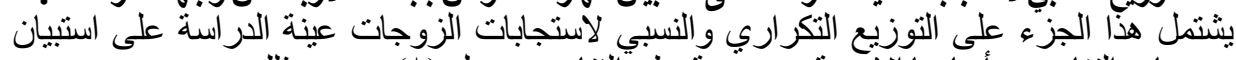

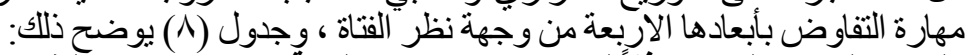

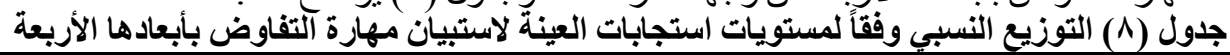

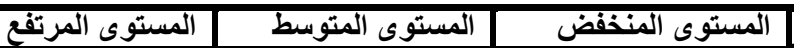




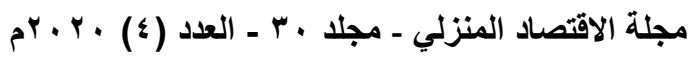

\begin{tabular}{|c|c|c|c|c|c|c|}
\hline$\%$ & العدد & $\%$ & العدد & $\%$ & العدد & |لابعاد \\
\hline TA, YY & $\sum \sqrt{q q}$ & \&9,YY & $0 \vee 9$ & 10,49 & T9Y & الوعى مهارة التفاوض \\
\hline$\varepsilon V_{6}, \varepsilon$ & $\Delta \wedge \Lambda$ & $r \Lambda_{G} Y \xi$ & $\varepsilon \vee \wedge$ & $1 \varepsilon_{6} V Y$ & $1 \wedge \varepsilon$ & حل المشُكلات \\
\hline OY, 17 & $70 Y$ & $r 0,7 \Lambda$ & \& «7 & $1 Y 617$ & TOY & لباقَة الحوار \\
\hline$r 4, r Y$ & $\leqslant 0 \leqslant$ & $\leqslant T_{6} \cdot \varepsilon$ & OHN & Y.، T & YON & المناقشتة \\
\hline$\sum Y_{6} 17$ & OYV & rras & $\xi 1 \wedge$ & $Y \leqslant 6 \varepsilon$ & $r .0$ & إجمالي مهارة التفاوض \\
\hline
\end{tabular}

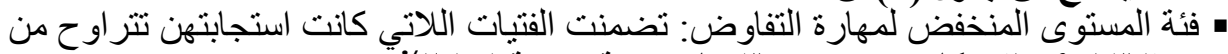

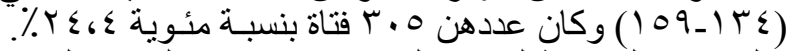

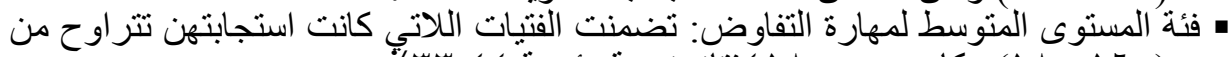

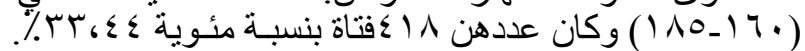

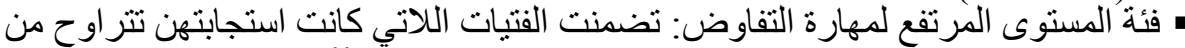
ا

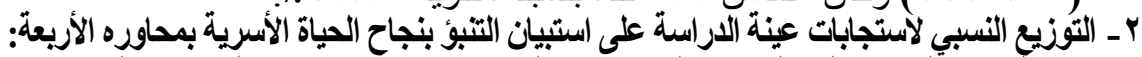

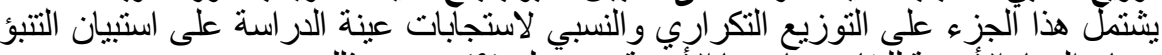

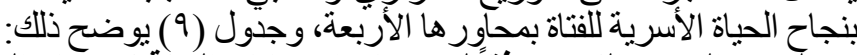

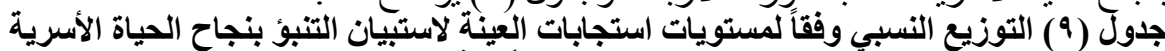

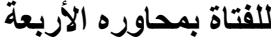

\begin{tabular}{|c|c|c|c|c|c|c|}
\hline \multicolumn{2}{|c|}{ المستوى المرتفع } & \multicolumn{2}{|c|}{ المستوى المتوسط } & \multicolumn{2}{|c|}{ المستوى المنخفض } & \multirow[t]{2}{*}{ البيان } \\
\hline$\%$ & 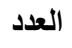 & $\%$ & العدد العد & $\%$ & 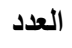 & \\
\hline VI، & तqय & TV، $\varepsilon \varepsilon$ & YIN & $11,1 \mathrm{r}$ & $1+9$ & مواصفات اختيار شريك الحياة \\
\hline VI.9Y & 199 & IY. & 17. & $10, Y \Lambda$ & 191 & مقومات الحياة الأسرية \\
\hline $77 . \wedge \Lambda$ & ATY & Y... & Yo. & $1 \mathrm{TH} / \mathrm{T}$ & $17 \varepsilon$ & واجبات الزوجة تجاه زوجها \\
\hline$V 1.47$ & $\Lambda 9 Y$ & 17.78 & $Y \cdot \Lambda$ & $1 r_{6}$ & 10. & حقوق الزوجة \\
\hline$V_{Y}, \Lambda$ & 91. & $V_{6} \cdot \varepsilon$ & $\overline{\wedge \Lambda}$ & $Y .617$ & YOY & إجمالي التنبؤ بنجاح الحياة الاسرية \\
\hline
\end{tabular}

• فئة المستوى المنخفض للتنبؤ بنجاح الحياة الأسرية: تضمنت الفنتيات اللاتي كانت استجابتهن

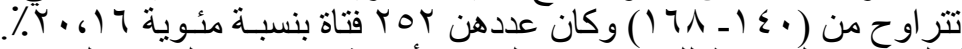

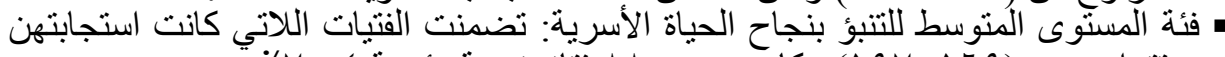

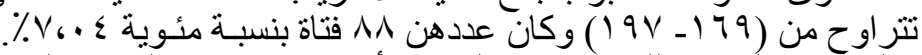

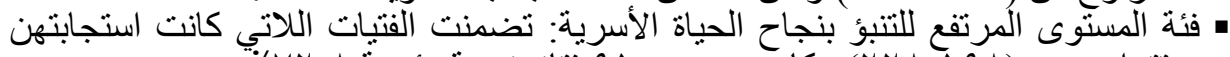

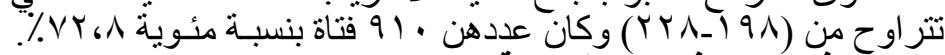

ثالثاً: النتائج في ضوح فو فروض الأراسة 1- النتائج في ضوض فوء الفرض فرض الأول

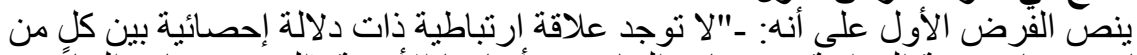

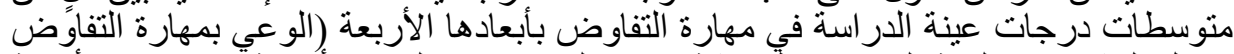

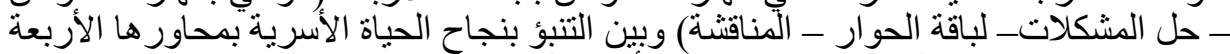

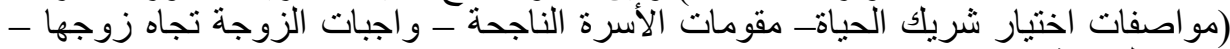

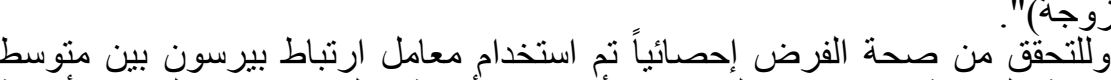

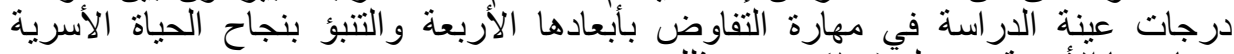

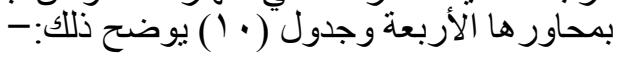




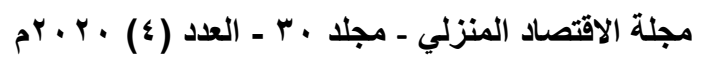

جدول(· 1 ) معامل ارتباط بيرسون بين مهارة التفاوض بأبعادها الأربعة والتبؤ بنجاح الحياة الأسرية

\begin{tabular}{|c|c|c|c|c|c|}
\hline التفاوض & المناقثشة & لباقة الحوار & المشكلات & الواعثَّي بمهارة & \\
\hline$* * \cdot 6 \cdot 4$ & $* * .670$. & $* * .674 \mathrm{~V}$ & **.6TYY & $* * .6079$ & مو اصفات آختبار شريك الحياة \\
\hline$* * .6 \mathrm{V04}$ & $* * \cdot 6 v \cdot 1$ & $* * .6 \%$ & $* * .6744$ & $* * .671 \leqslant$ & مقومات الاسرة" الناجِحة \\
\hline$* * .6 \vee 4$ & $* * .6791$ & $* * .6999$ & $* * .6704$ & $* * .4 .4$ & واجبات الزوجة تجاه زوجها \\
\hline$* * .699 \mathrm{~V}$ & **.67\% & $* * .64 \leqslant 9$ & **.67. & $* * .0 \mathrm{VT}$ & حقوق الزوجة \\
\hline **.,VAY & **.6VYO & **.6VTY & $* * .679$ & **.6747 & التنبؤ بنجاح الحياة الأسرية \\
\hline
\end{tabular}

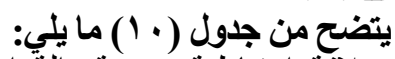

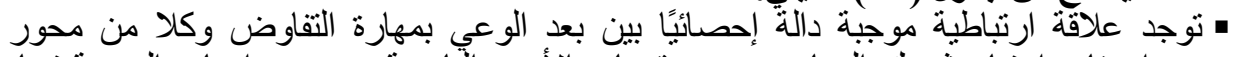

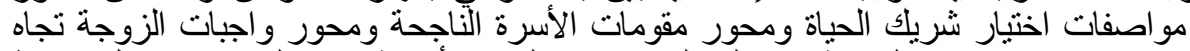

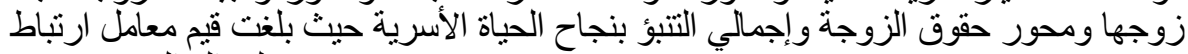

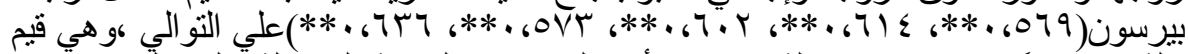

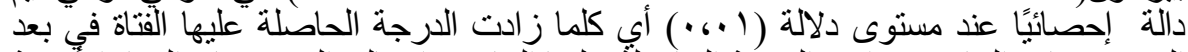

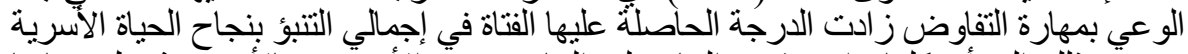
ويرجع ذلك إلي أن كلما زانت قدرة الفتاة علي التفاوض مع الأخرين وبالأخص شريك حياتها زادت نسبة نجاح الحياة الأسرية المستقبلية .

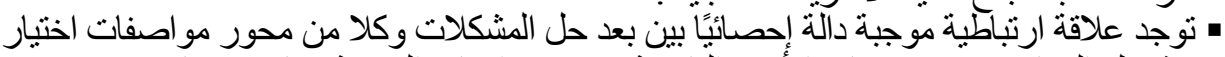

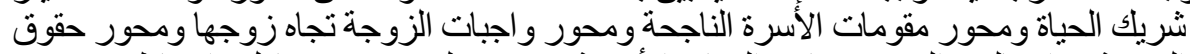

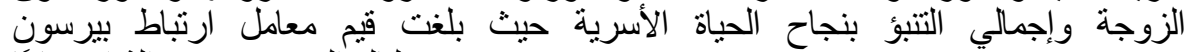
(2)

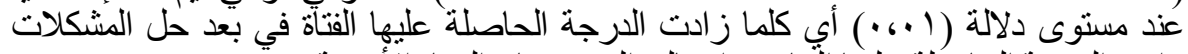

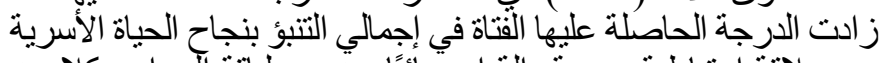

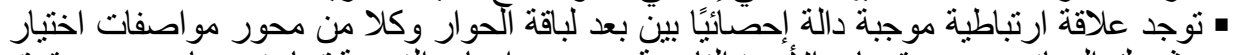

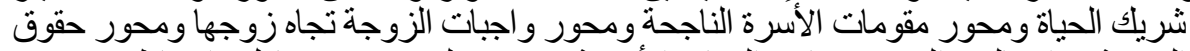

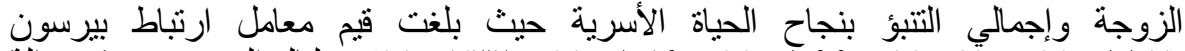

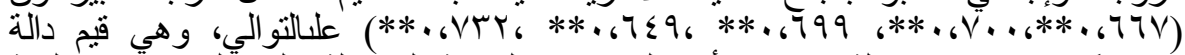

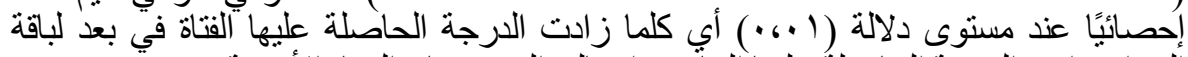

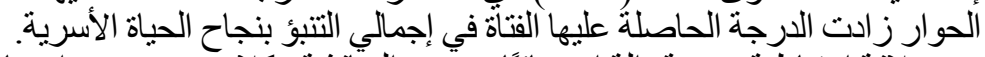

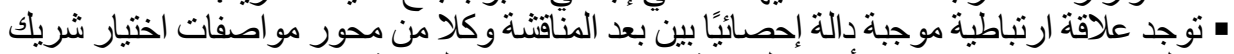

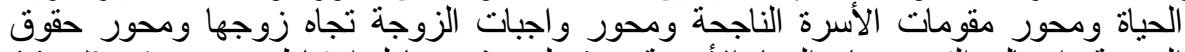

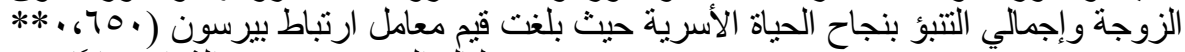

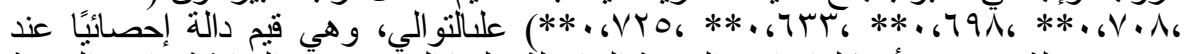

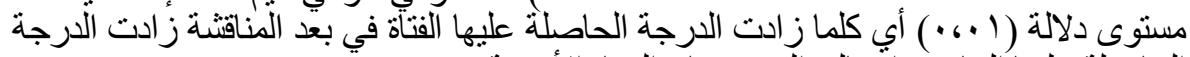

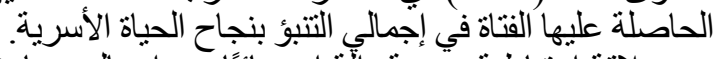

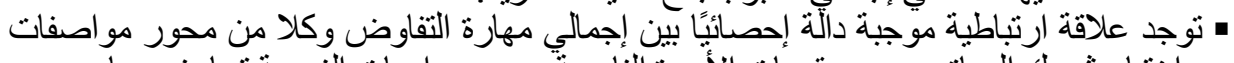

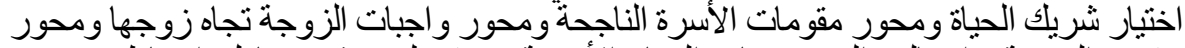

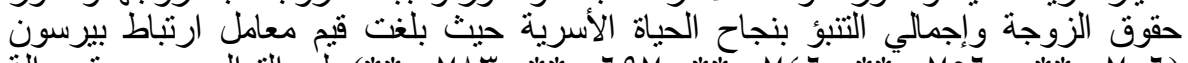

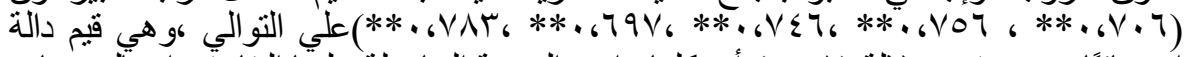

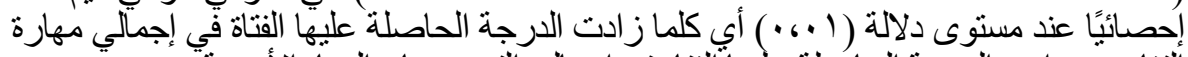
ألتفاوض ز ادت الدرجة الحاصلة عليها ألفتاة في إجمالي الثنبؤ بنجاح الحياة الأسرية. 


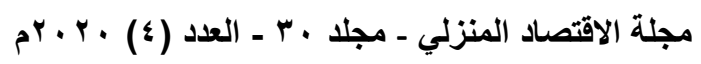

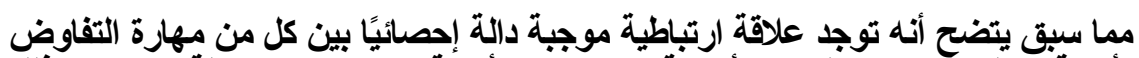

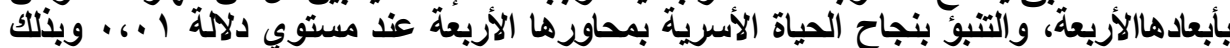

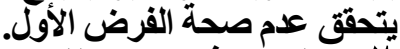

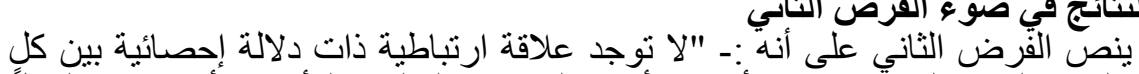

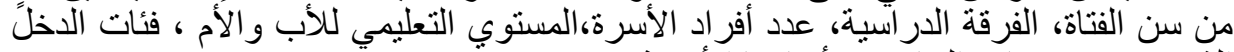

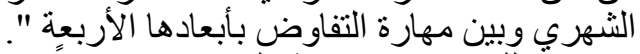

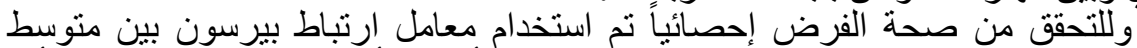

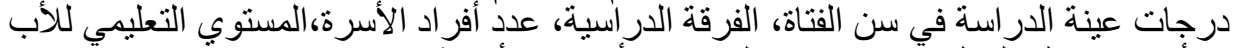

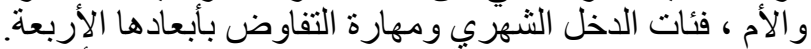

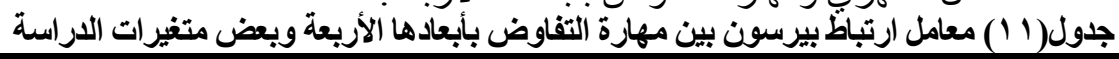

\begin{tabular}{|c|c|c|c|c|c|}
\hline التفاوضارة & المناقشة & لباقة الحوار & حل المشكلات & الوعي بمهارة & \\
\hline$* *, 61, r$ & $* * .61+1$ & $* * \ldots, 1 \wedge 9$ & $* * .690$ & $* * \ldots, \ldots \leqslant$ & سن الفتاة \\
\hline$\cdot 6+1 \varepsilon$ & $\cdot 6 \cdot \varepsilon \cdot$ & $\cdots \cdot 1$ & $\cdots+1$ & $\cdot 6 \cdot 11$ & الفرقة الدراسية \\
\hline$* *, 61 \leq V$ & $* * ., 1 Y \mu$ & $* * ., 1 Y$ & $* *, .1 \leq$ & $* *, 61 \leq \varepsilon$ & عدد أفراد الاسرةة \\
\hline $.6+10$ & $\cdot 6 \cdot T_{-}$ & $\cdot 6 \cdot \leqslant \Lambda$ & $\cdot 6+1 \leqslant$ & $\cdot 6 \cdot 19$ & مستوي تعليم الآب \\
\hline$\cdot 6 \cdot \leqslant V_{-}$ & $*_{.6}+7 Y_{-}$ & $\cdot 6 \cdot 1 V_{-}$ & $.6 .01-$ & $\cdot 6 \cdot \leqslant Y_{-}$ & مستوي تعليم الام \\
\hline$* *, 61 Y T_{-}$ & $* * \cdot 610 \Lambda_{-}$ & $* * .6 .99-$ & $* * .611 V_{-}$ & $* * \cdot 61,1-$ & فئَات ألاخل الشهري \\
\hline
\end{tabular}

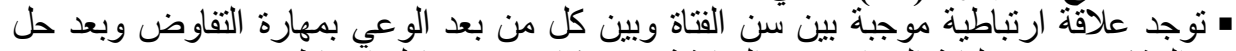

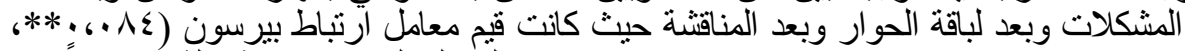

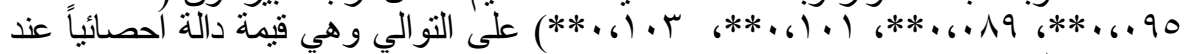

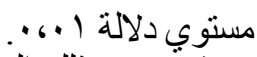

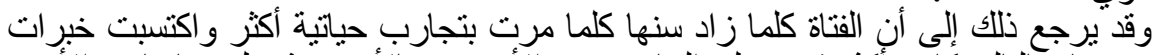

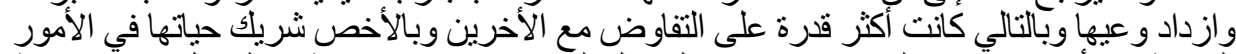

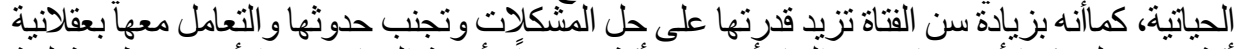

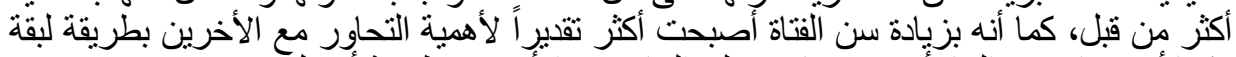

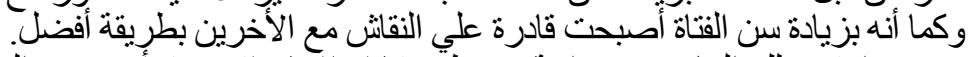

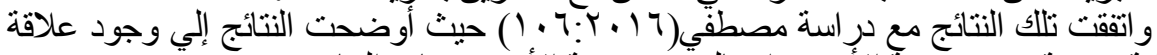
ارتباطية موجبة بين سن ربةّ الأسرة وإجمالي وعي ربة الأسرة بمهارة التفاوض.

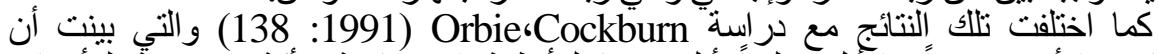
الأشخاص الأصغر سناً والآجل تعليماً أقل دعما للأنظمة الاجتماعية وأكثر عرضة لناذزمات

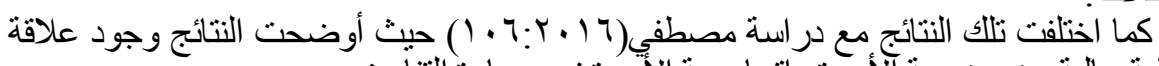
والمشكلات.

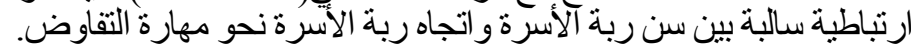

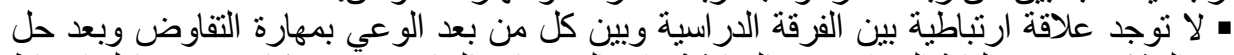

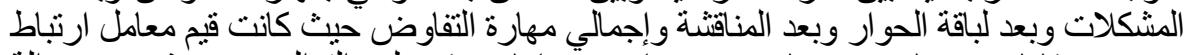

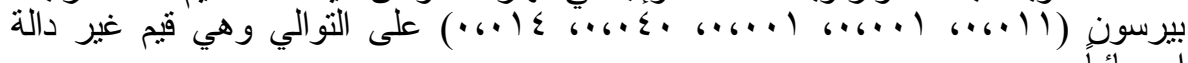
احصائياً. • توجد علاقة ارتباطية موجبة بين عدد أفراد الأسرة وبين كل من بعد الوعي بمهارة التفاوض وبعد حل المشكلات وبعد لباقة الحوار وبعد المناقثة وإجمالي مهارة التفاوض حيث حيث كانت قيم معامل 


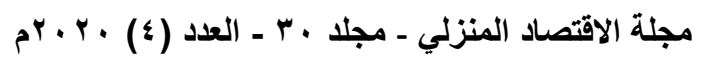

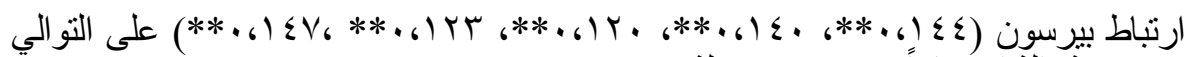

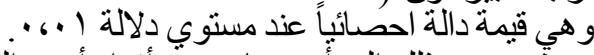

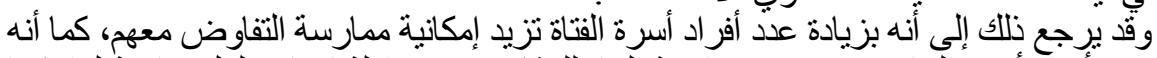

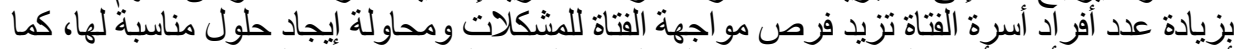

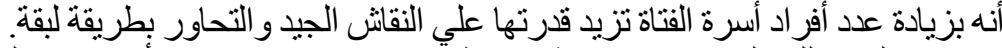

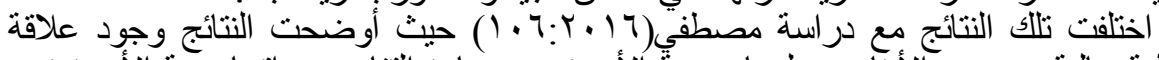

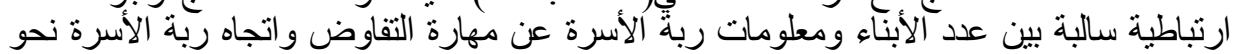

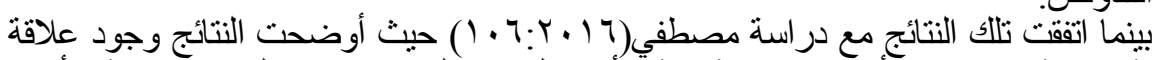

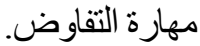

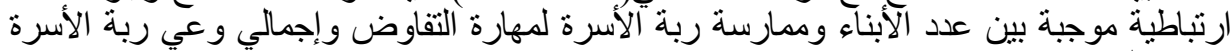

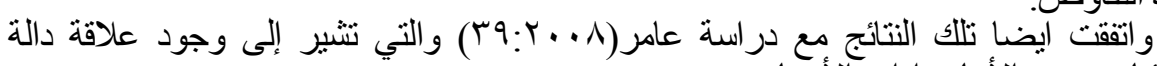

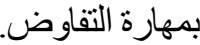

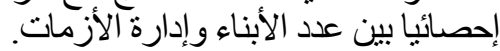

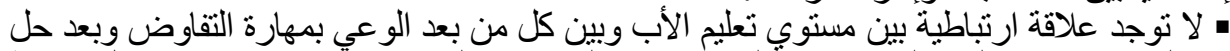

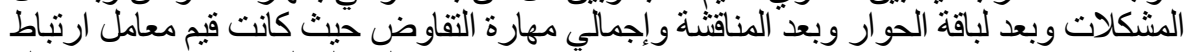

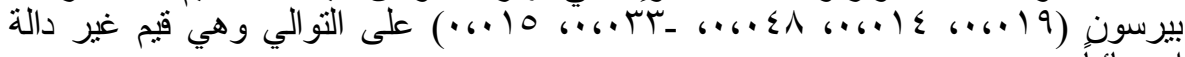

• توجد علاققة ارتباطية سالبة بين مستوى تعليم الأم وبين بعد المناقتشة حيث كانت قيمة معامل ارتباط

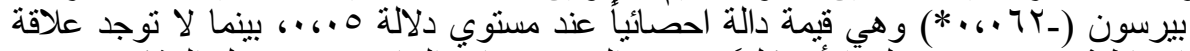

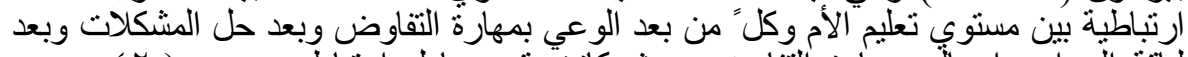

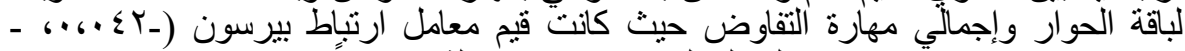
年

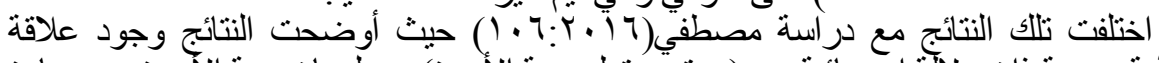

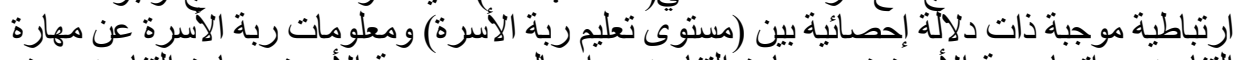
التفأوض واتجاه ربة الأسرة نحو مهارة التفاوض وإجمالي وعي ربة الأبرة الأسرة بمهارة التفاوض عند

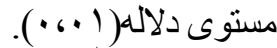

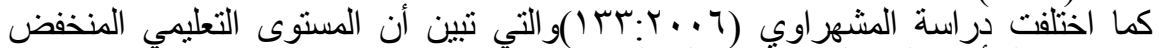

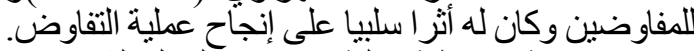

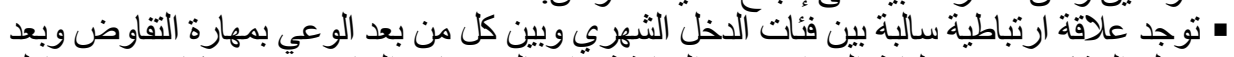

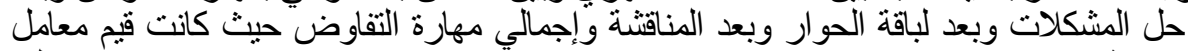

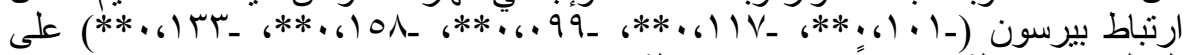

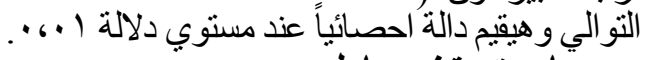

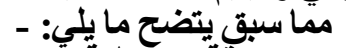

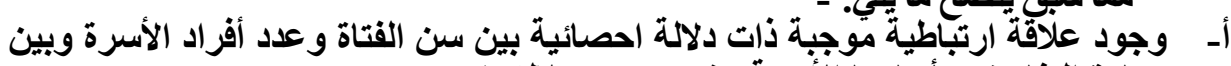

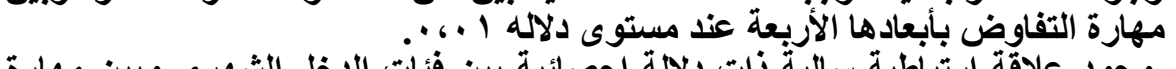

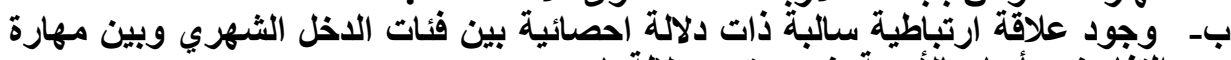

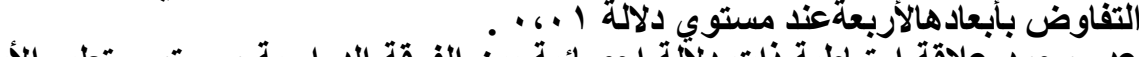

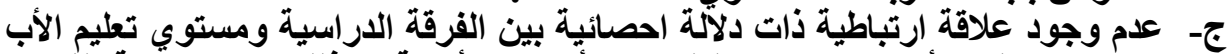

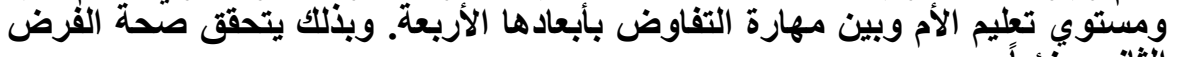

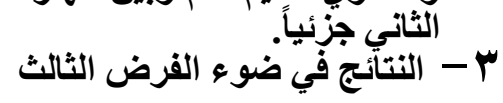




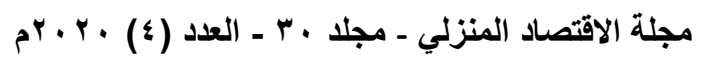

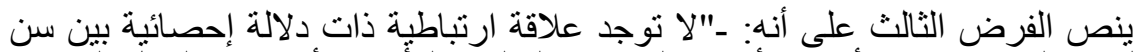

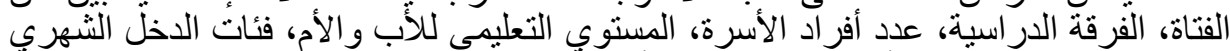

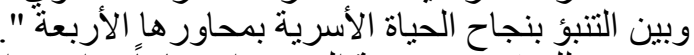

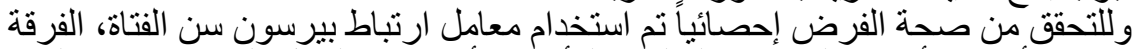

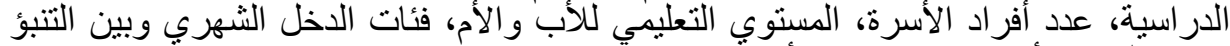

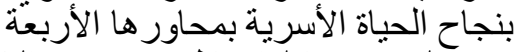
جدول(r أ) معامل أرتباط بيرسون بين التببؤ بنجاح الحياة الأسرية بمحاورها الأربعة وبعض متغيرات الأسراسة

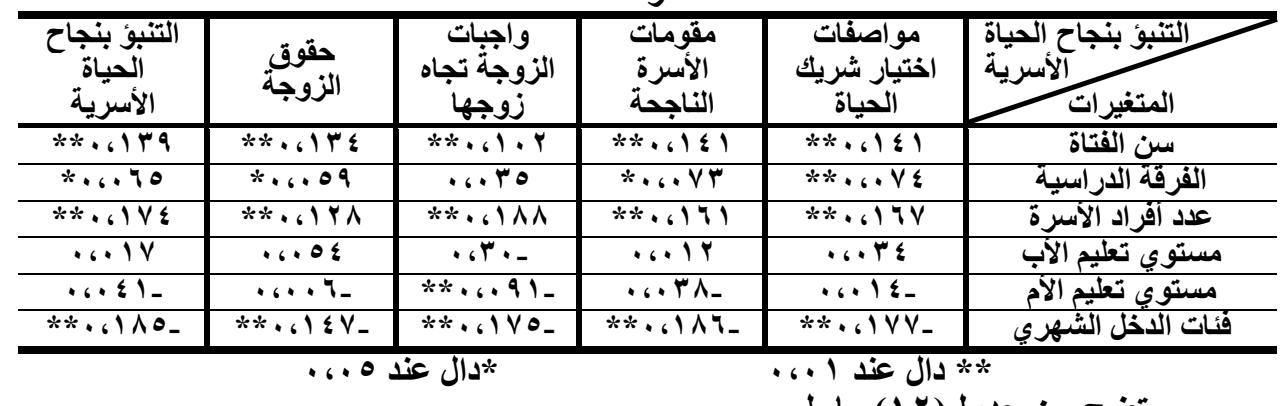

يتضح من جدول( ا l ) ما ما يلي

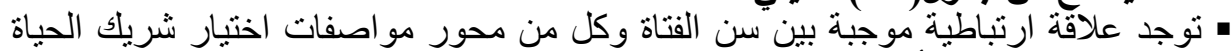

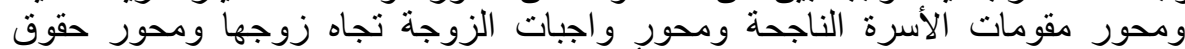

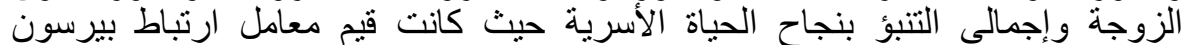

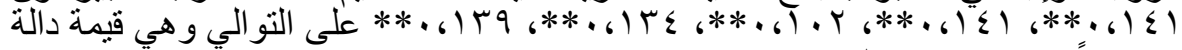

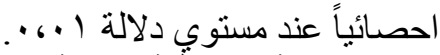

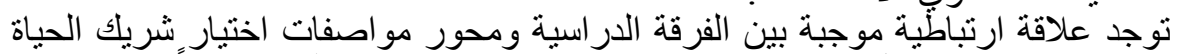

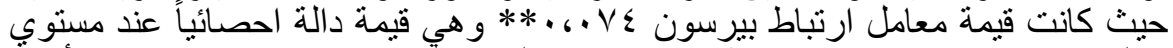

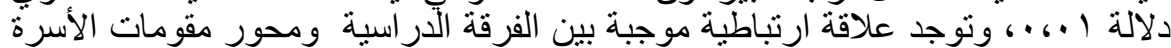

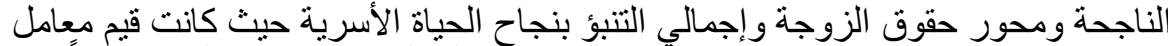

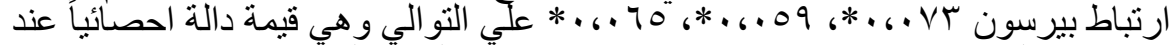

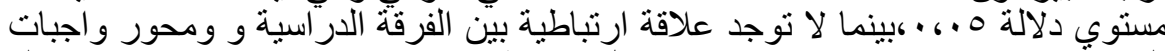

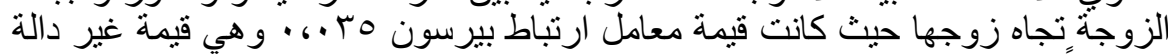

توجد علاقة ارتباطية موجبة بين عدد أفراد الأسرة وكل من محور مواصفات اختيار

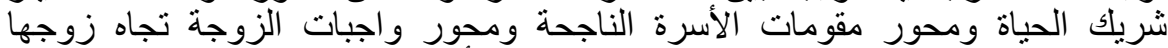

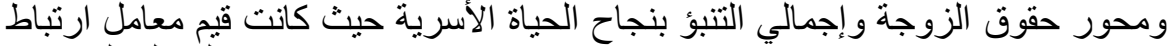

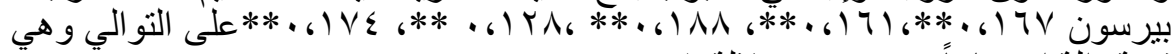

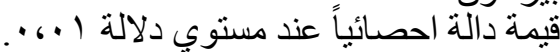

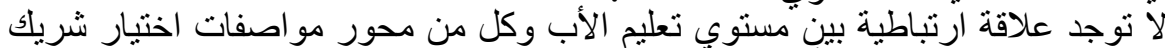

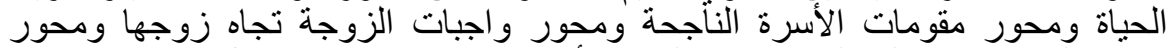

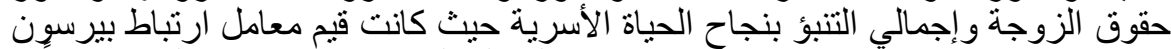

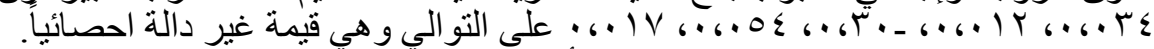

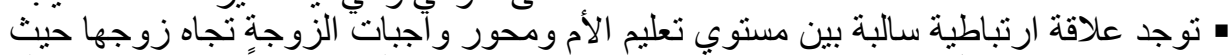

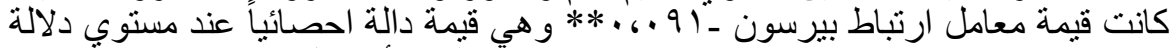

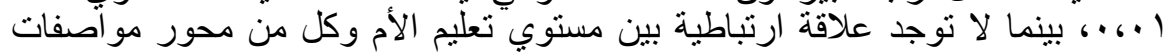




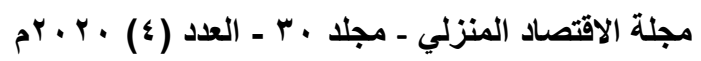

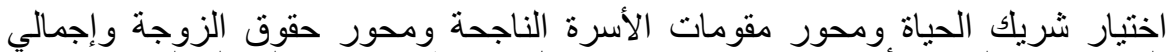

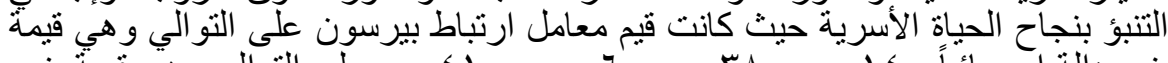

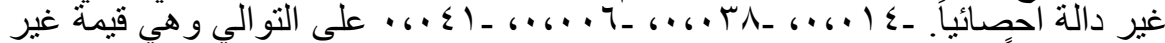
دالة احصائياً.

توجد علاقة ارتباطية سالبة بين فئات الدخل الثهري وكل من محور مو اصفات اختيار

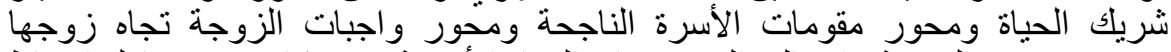

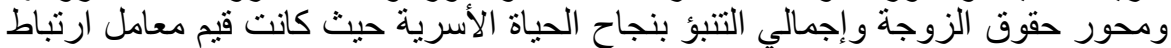

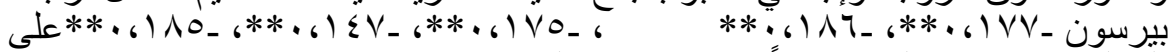

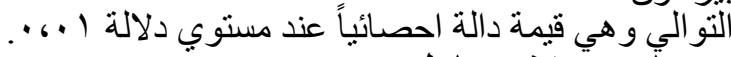

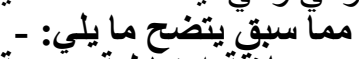

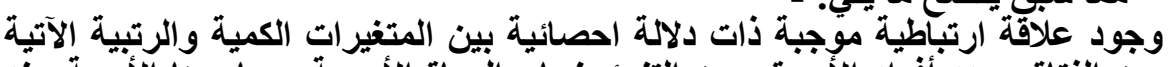

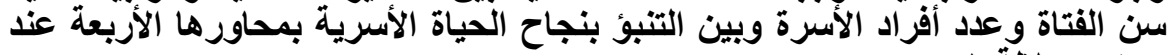

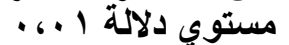
ب- وجود علاقة ارتباطية سالبة ذات دلالة احصائية بين المتغيرات الكمية والرتبية الآتية

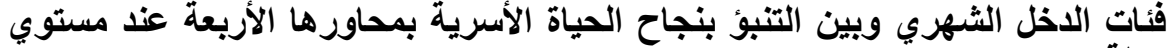

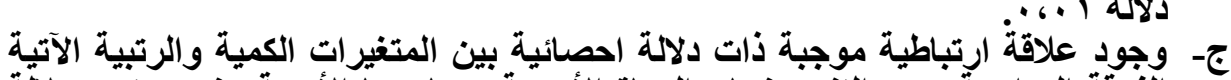

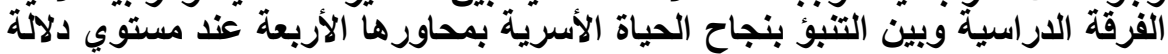

دـ عدم وجود علاقة ارتباطية ذات دلالة احصائية بين المتغيرات الكمية والرتبية الآتية

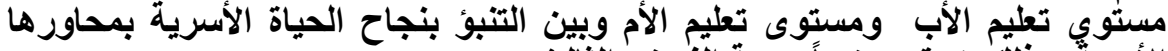

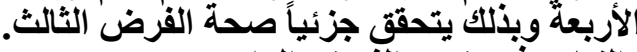

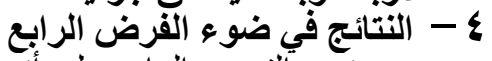

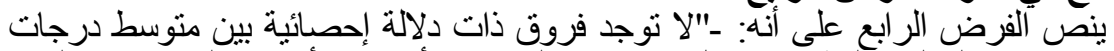

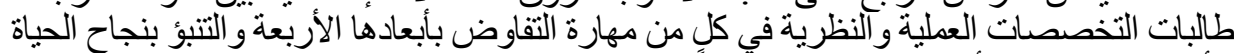

$$
\text { الأسرية بمحاور ها الأربعة ". }
$$

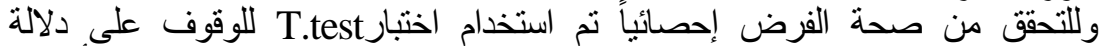

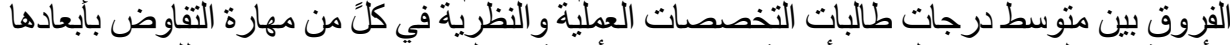

\begin{tabular}{|c|c|c|c|c|c|c|c|}
\hline \multirow{2}{*}{ مستوى } & \multirow[t]{2}{*}{ فيمة (ت) } & \multirow{2}{*}{ المتوسط بين } & \multicolumn{2}{|c|}{ نظرية ن=ף · ؛؛ } & \multicolumn{2}{|c|}{ عملية ن= ؟ ؟ 1} & \multirow[t]{2}{*}{ / البيان } \\
\hline & & & المعياري & الحستوسطي & المعياري & الحستوسط & \\
\hline غير دال & .6171 & . . 0 & $\varepsilon, \vee \wedge$ & 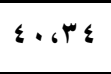 & \&، & \&. • & ألتفاوض الوعي بمهارة \\
\hline غير دال 90 ـأ & .6 .01 & $\cdots r$ & 0.19 & $\{r, \cdot \wedge$ & $0.1 \mathrm{~V}$ & « «, l. & بعد حل المشكلات \\
\hline غير دال & . .945 & 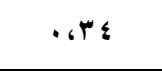 & O،八V & $\left\{\Lambda_{6}, 0\right.$. & 0.99 & $\varepsilon \wedge, \wedge \varepsilon$ & بعد لباقة الحوار \\
\hline غير دالز & - 6149 & . . $\varepsilon$ & $0.1 \%$ & \& & $0 . .1$ & \& \& & بعد المناقثُشة \\
\hline غير دال & - r & • ، & IA,VY & 1V7.4 & $1_{1} \wedge_{6}$. & IVV。. & مهارة التفاوض \\
\hline
\end{tabular}

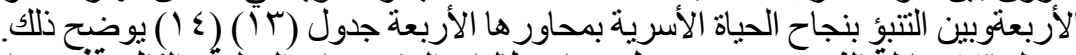

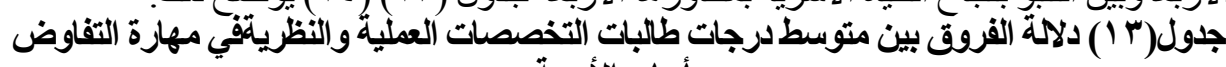
بأبعاده الأربعة 


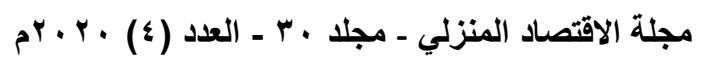

• لا توجد فروق ذات دلالة احصائية بين متوسط درجات طالبات التخصصات العملية و النظرية في

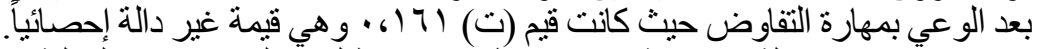

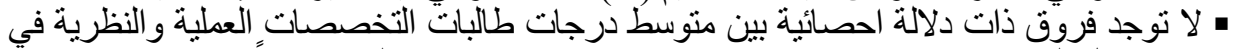

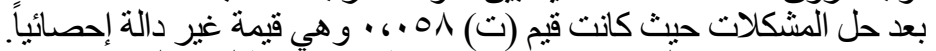

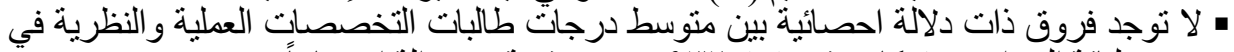

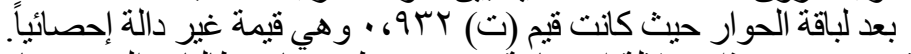

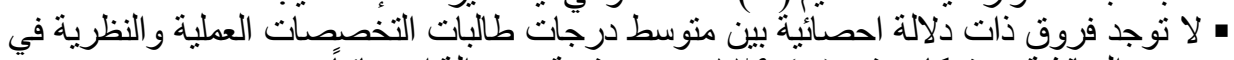

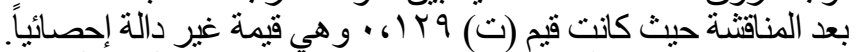

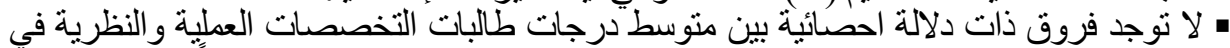

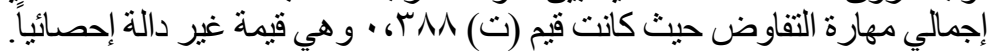

جدول(؟ 1) دلالة الفروق بين متوسطدرجات طالبات التخصصت العملية والنظرية في التتبؤ بنجاح الحياة

\begin{tabular}{|c|c|c|c|c|c|c|c|}
\hline \multirow[b]{2}{*}{ مستوية } & \multirow[b]{2}{*}{ قيمة (ت) } & \multirow[b]{2}{*}{ المتروقط بينت } & \multicolumn{2}{|c|}{ نظرية ن=" • •؛ } & \multicolumn{2}{|c|}{ عملية ن=؛ ؟ 1} & \\
\hline & & & الالاتحرافي & الحستوبط & الالانحراف & الحستوسطي & \\
\hline غير دال & . 61 r & . ... & $0 ، \wedge \varepsilon$ & 0.100 & $7,1$. & 0.60 . & مواصفكات الختيار \\
\hline غير دا"، & $\cdot$ c $\leqslant V \cdot-$ & .619 & 7.07 & $\leqslant 4, \wedge \leqslant$ & 9.69 & ะ4.70 & مقومات الأسترة \\
\hline غير دالز & $1,1 \cdot r_{-}$ & • $،: 0_{-}$ & 1,01 & A A & $7, \wedge$. & Or.q4 & واجباه زوجوجان \\
\hline غير دال & שדים. & . .99 & $7, \ldots$ & $\leqslant 9,00$ & 7.1. & $\leqslant 9,7 \leqslant$ & حقوق الزوجة \\
\hline غير دالز & . ، $\left\{1 r_{-}\right.$ & .009 & rrolr & $r+1, r r$ & $r \varepsilon_{6}, r$ & $r \ldots v r$ & الحياة الأسنجية \\
\hline
\end{tabular}

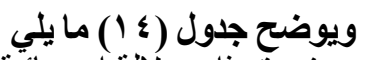

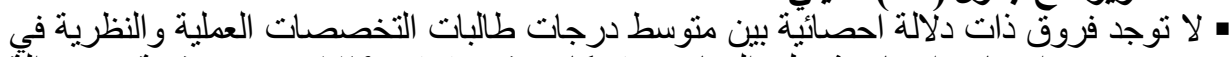

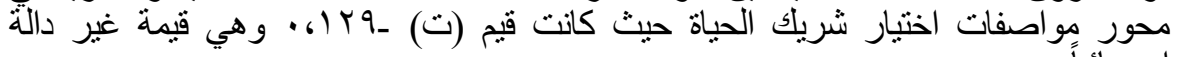
إحصائياً. • لا توجد فروق ذات دلالة احصائية بين متوسط درجات طالبات التخصصات العطلية و النظرية في

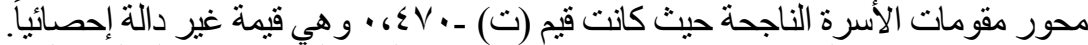

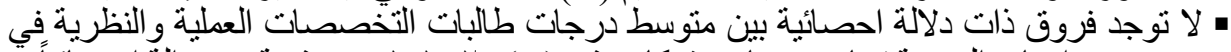

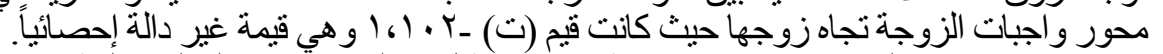

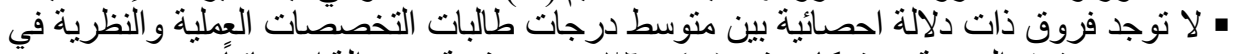

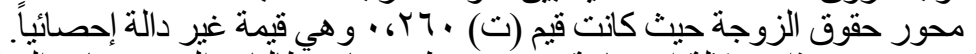

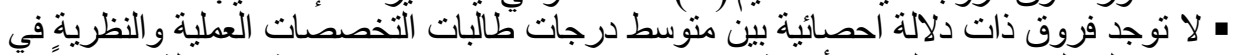

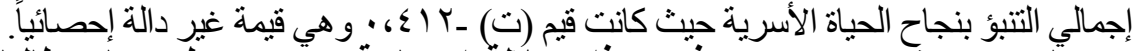

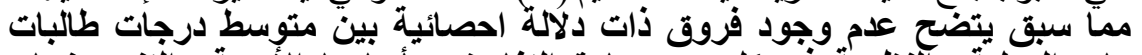

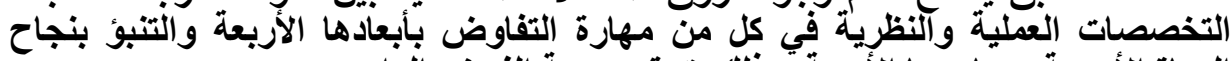
الحياة الأسرية بمحاور ها الأربعة ويذلتك يتحقى صحة الفرض الفرض الزرابع. 


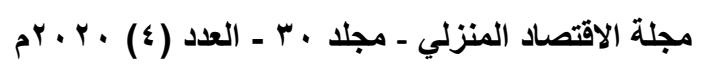

ينص الفرض الخامس على أنه: -"لا يوجد تباين دال إحصائياً بين الفنيات عينة الدراسة في

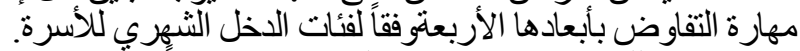

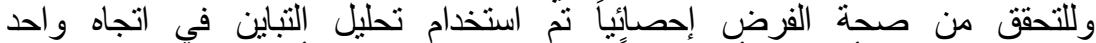

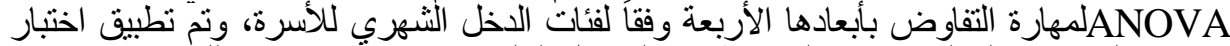
Tukey

جدول(ه 1 ) تحليل التباين في اتجاه واحد للفتيات عينة الدارسة في مهارة التفاوض بأبعادها الأربعة وفقاً

\begin{tabular}{|c|c|c|c|c|c|c|}
\hline مستوى الدلالة & قَّمة & المربعات & لدرجية & مجموع المربعات & مصدر التباين & \\
\hline 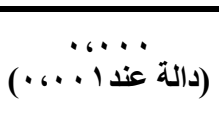 & 0,119 & $\begin{array}{l}\text { MA, rIV } \\
\text { rro. } 9 \leq\end{array}$ & $\begin{array}{c}1 \\
1 r \leq 1 \\
1 r \leqslant 9\end{array}$ & 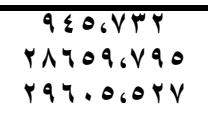 & داخلين المجموعات المبوعات & بمهارة الوعي \\
\hline 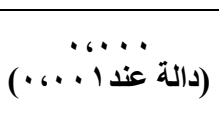 & 0 ،八11 & $\begin{array}{l}10 r_{61.1} \\
\text { rq, rq0 }\end{array}$ & $\begin{array}{c}1 \\
1 r \leqslant 1 \\
1 r \leqslant 9\end{array}$ & 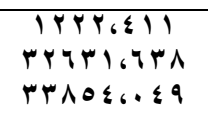 & دأخل المجموعات المجين & المشكلات حل \\
\hline 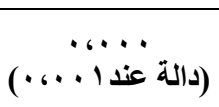 & \&.7\%. & $\begin{array}{l}17.6197 \\
7 \leqslant 67 .\end{array}$ & $\begin{array}{l}1 \\
1 r \leqslant 1 \\
1 r \leqslant 9\end{array}$ & 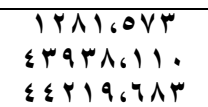 & داخلّل المجموعوعات المبن & بعد لباقة \\
\hline 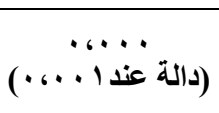 & 0.701 & $\begin{array}{l}\text { Trq.VAN } \\
r \leq 6 . \wedge\end{array}$ & $\begin{array}{l}1 \\
1 r \leq 1 \\
1 r \leq 9\end{array}$ & 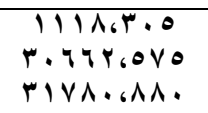 & داخلّ المجموعات المبل & بعد المناقشة \\
\hline 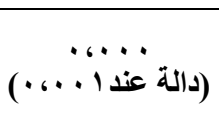 & T.Y.O & $\begin{array}{l}r 110,9 \mu 1 \\
r \leq 1, \ldots .0\end{array}$ & $\begin{array}{c}1 \\
1 r \leq 1 \\
1 r \leq 9\end{array}$ & 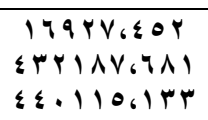 & داخل المجموعات المجوعات & التفاوض \\
\hline
\end{tabular}

جدول(7 1 ) المتوسطات الحسابية لدرجات الفتيات في مهارة التفاوض وفقًا لفئات الاخل الثهري

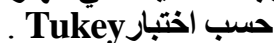

\begin{tabular}{|c|c|c|c|c|c|c|}
\hline إجماليّي استبيان & المناقشة بعدة & بعد لباقة & المشكلات حل & بعد اللوعي & العدد & فئات الدخل الشهري \\
\hline $18 V_{6} 04$ & $\varepsilon 0,1 \wedge$ & $\varepsilon \Lambda_{6} \vee 0$ & $\varepsilon r_{6} .9$ & $\leq \cdot, 0 \leqslant$ & rYo & أقل من ... . . جنية \\
\hline $1 \wedge 1, Y T$ & $\leqslant 0, \vee 9$ & $\varepsilon 9.90$ & \& \&, Yr & $\leqslant 1,40$ & rV & 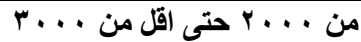 \\
\hline IVV.74 & ะ « : VV & $\leqslant \wedge, 9 \wedge$ & $\{r(\varepsilon)$ & $\leqslant \cdot ، \leqslant V$ & 199 & 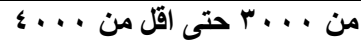 \\
\hline IVr.74 & ะ r.9 & $\leqslant V .7 Y$ & $\leq Y_{6} 1 \leqslant$ & rq.9Y & $10 \mathrm{~V}$ & من . . ع حتى اقل من . . . \\
\hline IVY, I. & $\varepsilon r, V V$ & $\leqslant V_{6} 11$ & $\leqslant r_{6} 1$. & r9,11 & IY & من . . . . حتى اقل من . . . \\
\hline $1796 \cdot 4$ & $\varepsilon Y_{6} \vee \wedge$ & $\sum V_{6} Y \wedge$ & $\varepsilon \cdot 6 \varepsilon 9$ & $r \Lambda_{6} \cdot r$ & 71 & 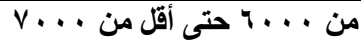 \\
\hline IVVG & $\leqslant \leqslant$ \& $\leqslant \wedge$ & $\leqslant 9,1 \leqslant$ & $\leqslant Y, 09$ & $\leqslant 1,61$ & rq & 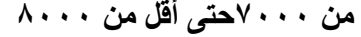 \\
\hline $1 V \cdot 69$. & $\varepsilon r, r \wedge$ & $\varepsilon V, r r$ & $\varepsilon \cdot 60 \mathrm{~V}$ & $r 9.7 r$ & Y & 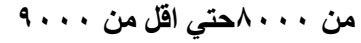 \\
\hline$|V \varepsilon 6 \wedge|$ & $\varepsilon \mu_{6} \cdot V$ & $\varepsilon \Lambda_{6} \leqslant \mu$ & $\varepsilon 46.9$ & $\varepsilon \cdot \sigma r Y$ & $0 \leqslant$ & ... . . ج جنية فأكثر \\
\hline
\end{tabular}

يوضح جدول (0 10)و(7 1 ) مايلي: - 


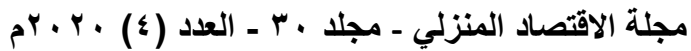

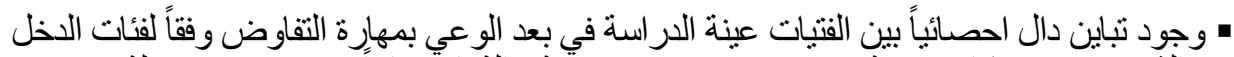

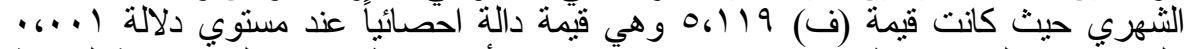

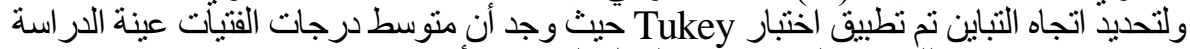

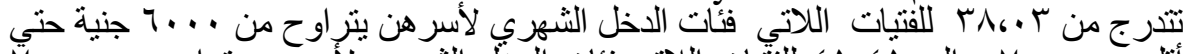

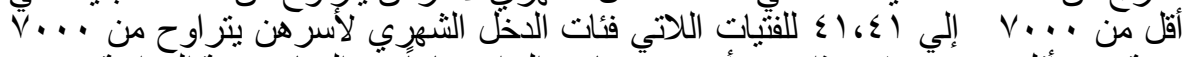

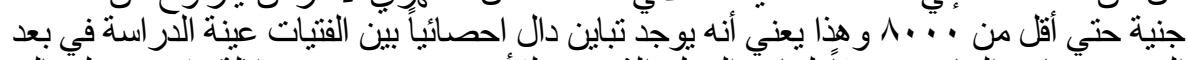

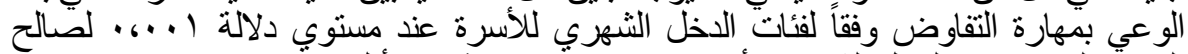

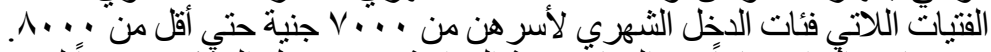

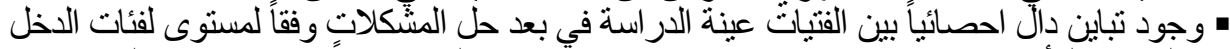

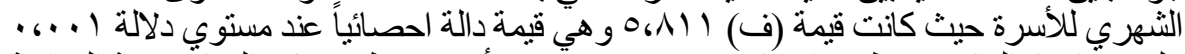

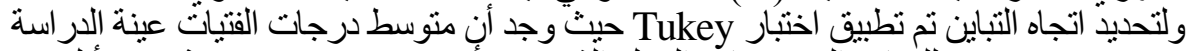

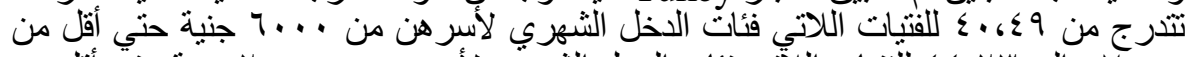

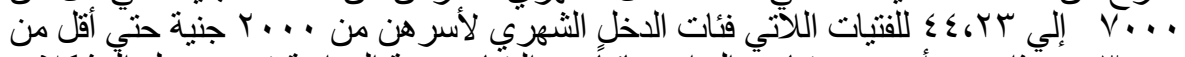

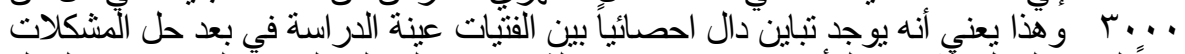

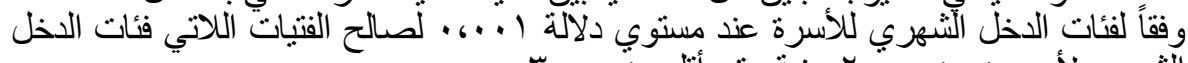

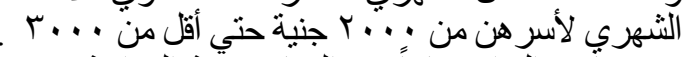

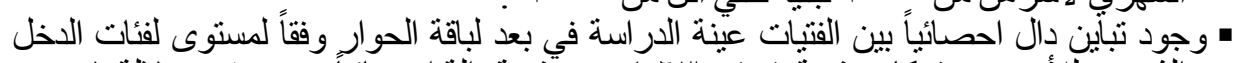

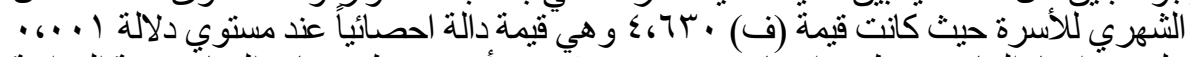

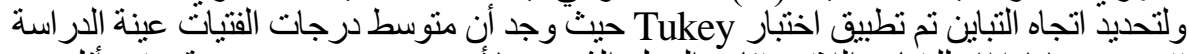

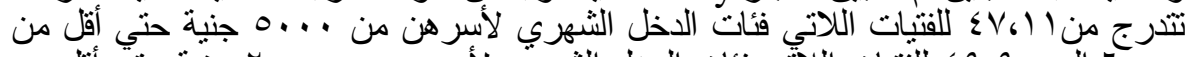

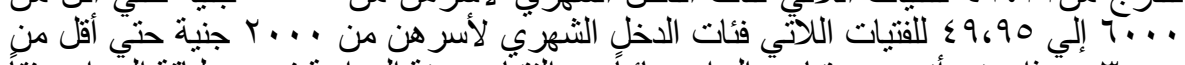

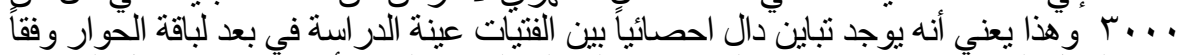

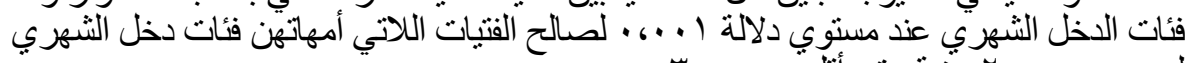

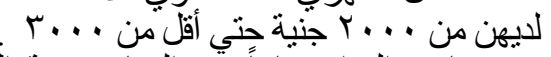

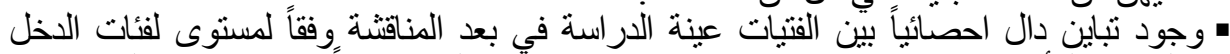

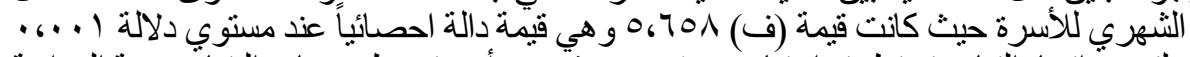

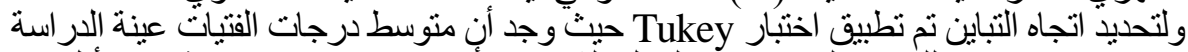

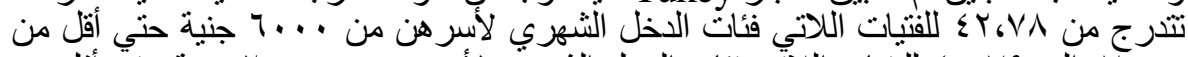

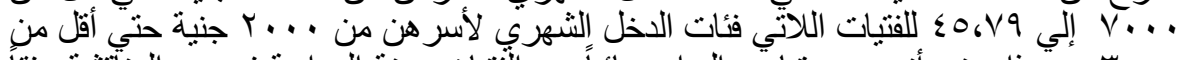

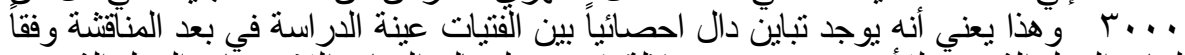

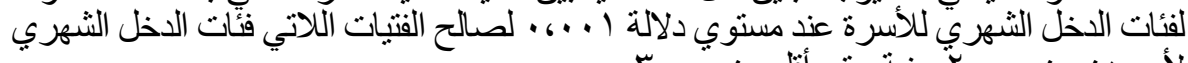

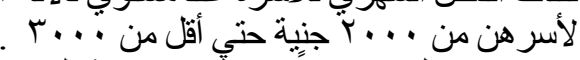

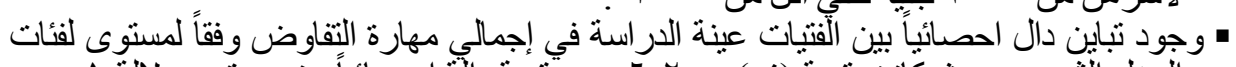

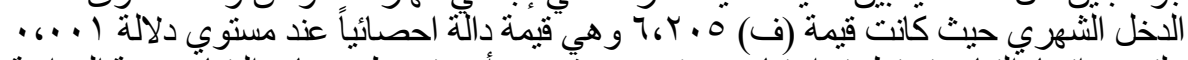

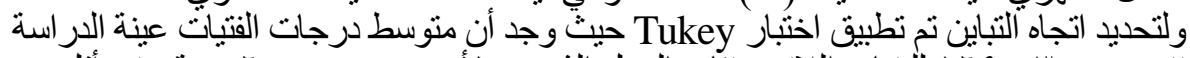

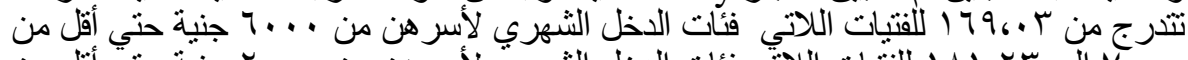

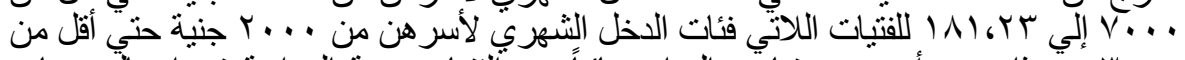

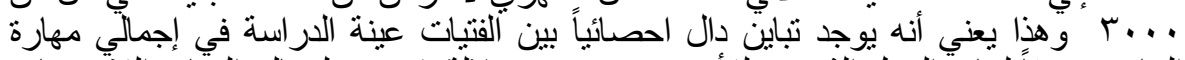

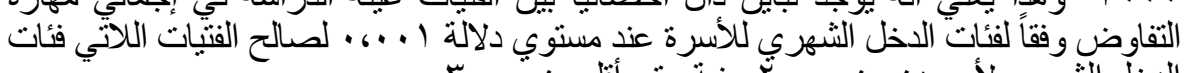

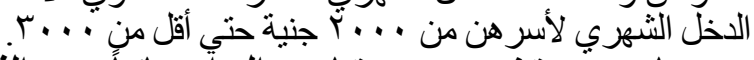

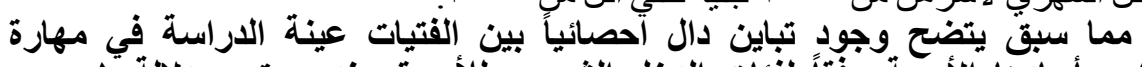

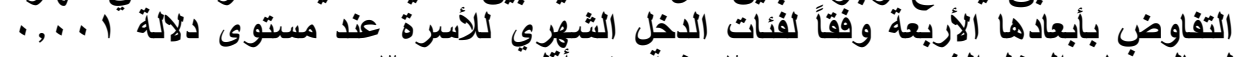

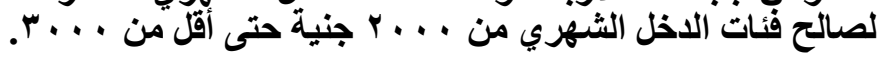




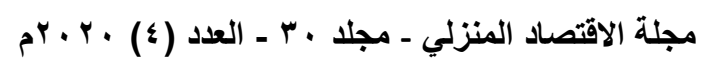

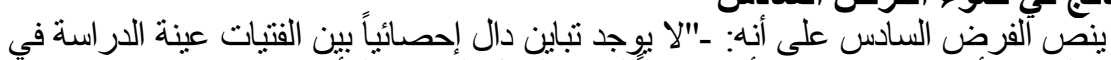

$$
7 \text { - النتائج في ضوء الفرض السادس النهاس }
$$

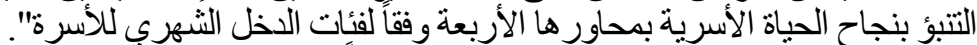

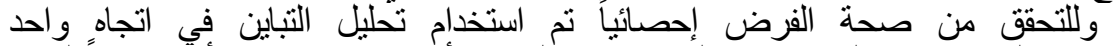
Aبين الفتيات عينة الدراسة في التنبؤ بنجاح الحياة الأسرية بمحاور ها الأربعة وفقاً لفئات

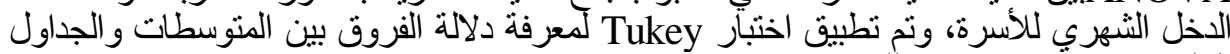

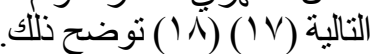

\begin{tabular}{|c|c|c|c|c|c|c|}
\hline مستوى الدلالة & قُمة & المربعات متوسط & الحرية & & عدر التباين & \\
\hline 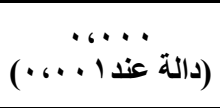 & $V_{G} Y \leq \varepsilon$ & $\begin{array}{l}r 01,9 V 1 \\
r \varepsilon, V A r\end{array}$ & $\begin{array}{c}\wedge \\
\mid r \leq 1 \\
1 r \leq q\end{array}$ & $\begin{array}{l}Y \cdot 106 V 41 \\
\varepsilon Y 17 \leqslant 64 \leqslant 0 \\
\varepsilon 011.611 r\end{array}$ & داخل المجمو المجموعات & مواصفات اخك الحي \\
\hline 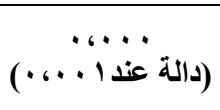 & $\Lambda_{6} \vee \vee \leqslant 7$ & $\begin{array}{l}r \vee 0, q \wedge \wedge \\
\varepsilon \curlyvee . q \wedge \wedge\end{array}$ & $\begin{array}{c}\wedge \\
\mid r \leq 1 \\
1 r \leq q\end{array}$ & 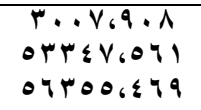 & داخل المجمو المجوعات & مقومات الأسرة \\
\hline 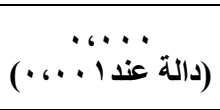 & $V . V \circ V$ & $\begin{array}{l}r r V_{6} I V . \\
\leqslant r 6 \leqslant 74\end{array}$ & $\begin{array}{c}\wedge \\
1 r \leq 1 \\
1 r \leq q\end{array}$ & $\begin{array}{l}\text { Yq9V، rOq } \\
0 \% 9 \& 161 . r \\
079496109\end{array}$ & داخل المجنّ المجموعات & واجبات زالزوجة \\
\hline (دالة عند ا • . . . • ) & 7.09. & $\begin{array}{l}r m \text { rquV } \\
\text { ro. \&qV }\end{array}$ & $\begin{array}{c}A \\
1 r \leq 1 \\
1 r \varepsilon q\end{array}$ & $\begin{array}{l}\mid \wedge V 16 \leqslant 9 \wedge \\
\varepsilon \varepsilon .0160 \leqslant q \\
\varepsilon 0 q Y Y_{6} . \varepsilon Y\end{array}$ & داخل المجنمو المجموعات & حقوق الزوجة \\
\hline 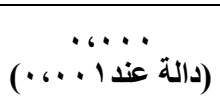 & 1,719 & $\begin{array}{l}\varepsilon \neg Y 0,90 \% \\
0 Y 7.710\end{array}$ & $\begin{array}{l}1 \\
\mid r \leq 1 \\
1 r \leq q\end{array}$ & 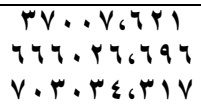 & داخل المجمو المجوعات & \\
\hline
\end{tabular}
جدول(IV) تحليل التباين في اتجاه واحد للفتيات عينة الدارسة في استبيان التتبؤ بنجاح الحياة الأسرية

جدول (1) المتوسطات الحسابية لارجات الفتيات في استبيان التتبؤ بنجاح الحياة الأسرية وفقًا لفئات

\begin{tabular}{|c|c|c|c|c|c|c|}
\hline 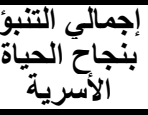 & الزوجة & تجاه زاجبات & الأسبوماث & 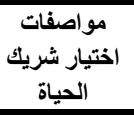 & العدد الع & فئـات الدخل الشهري للأسرة \\
\hline$r \cdot r_{6} \leqslant 1$ & $\varepsilon 9, \wedge 0$ & $0 \leqslant$ \& V & $\varepsilon 7.9 V$ & $0 \cdot ، \wedge \wedge$ & rYO & أقل من . . . ج جنية \\
\hline$Y \cdot 7, \wedge 0$ & $0.6 \wedge 7$ & 00 ชิ & $\varepsilon \Lambda_{6} \leqslant 7$ & 01610 & rvr & 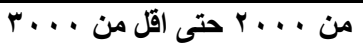 \\
\hline$r \cdot r, \wedge q$ & 0.617 & $0 \leq 69$ & $\varepsilon V_{6} 19$ & 01617 & 199 & 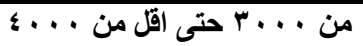 \\
\hline 197679 & $\varepsilon \Lambda_{6} \vee \mu$ & ०Y،八q & $\varepsilon 0,0 V$ & $\varepsilon 9.07$ & $10 \mathrm{~V}$ & من . . ع حتى اقل من . . . \\
\hline $19 \varepsilon 6 V Y$ & $\varepsilon \Lambda_{6} Y V$ & 01691 & $\leq 0, \varepsilon 1$ & $\varepsilon 96.7$ & IrE & من . . . حتى اقل من . . . \\
\hline $1 \wedge 96.1$ & $\leqslant 7,0$. & 0161. & $\varepsilon M_{6} \varphi_{0}$ & $\left.\varepsilon \Lambda_{6}\right) \nsucc$ & 71 & 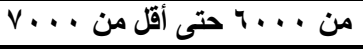 \\
\hline 191679 & $\& 9.7 \%$ & $0 r_{6} \leq 1$ & $\varepsilon 7_{6} \cdot r$ & $\varepsilon 967 r$ & rq & 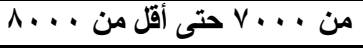 \\
\hline 194.9. & $\varepsilon 7.90$ & ० Y ४9० & $\varepsilon \varepsilon, 1 \leqslant$ & $\varepsilon \wedge, \wedge \neg$ & Y & من ... . حتى اقل من ... \\
\hline 194689 & $\leqslant \Lambda_{6} 0 \leqslant$ & $0 Y_{6} \cdot 7$ & $\varepsilon r_{6} \wedge q$ & $\varepsilon V_{6} 9 \wedge$ & $0 \leq$ & . . . . ج جنية فأكثر \\
\hline
\end{tabular}

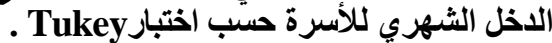




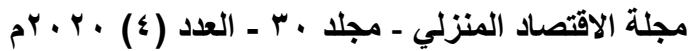

• وجود تباين دال احصائيًا بين الفنيات عينة الدراسة في محور مواصفات اختبار شريكِ الحياة وفقاً

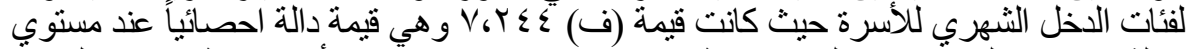

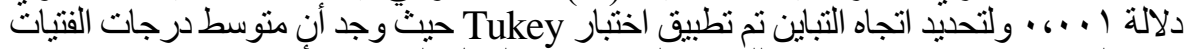

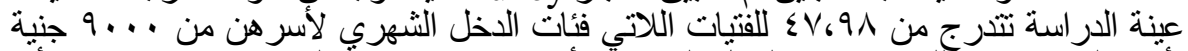

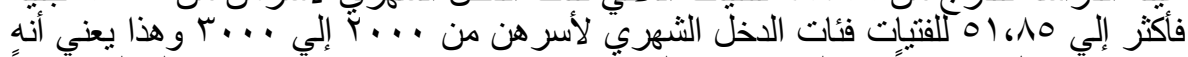

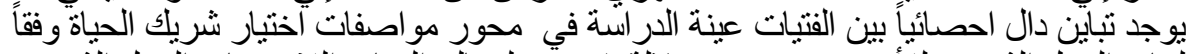

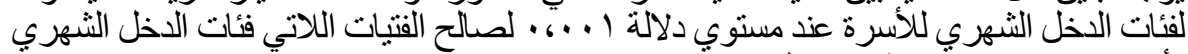

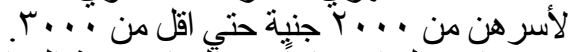

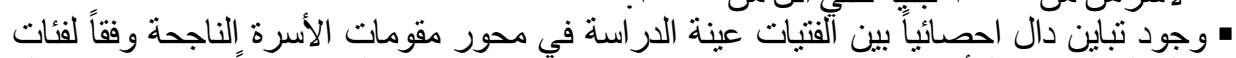

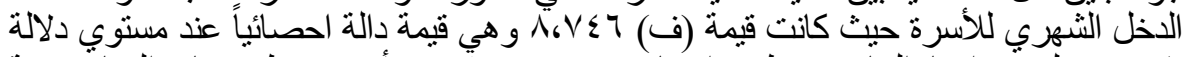

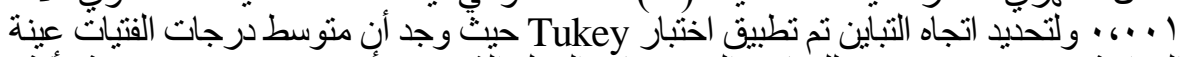

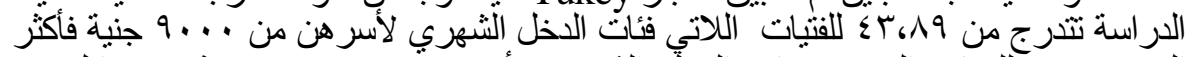

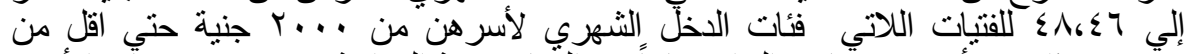

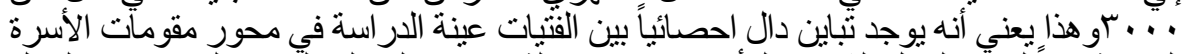

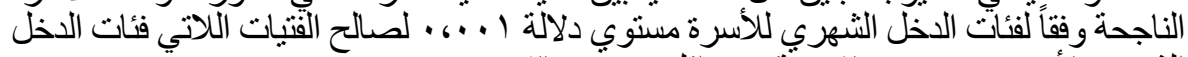

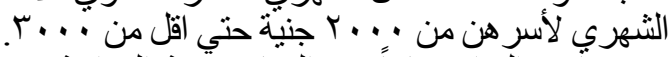

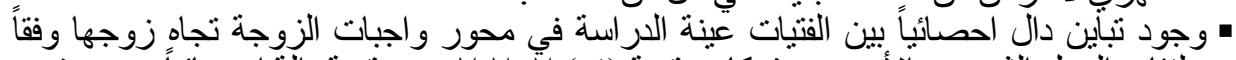

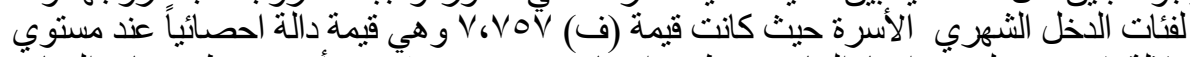

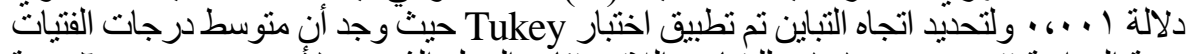

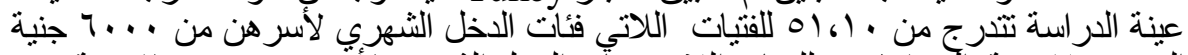

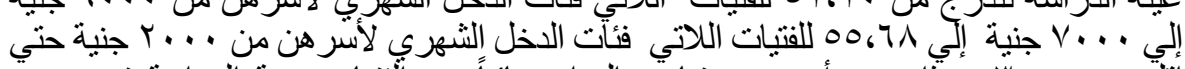

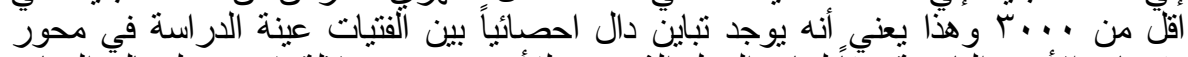

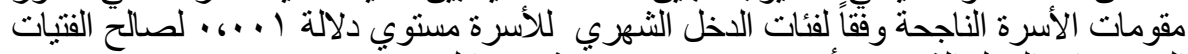

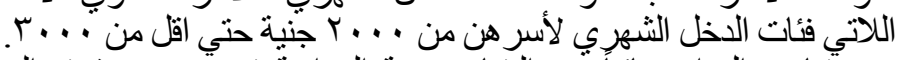

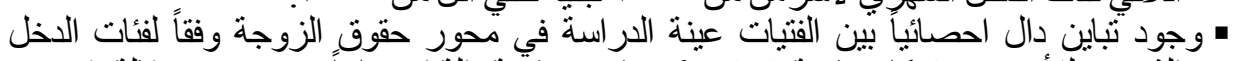

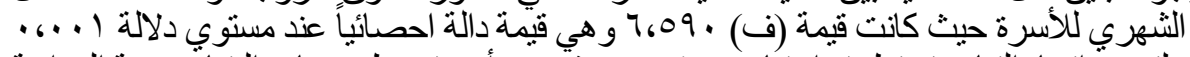

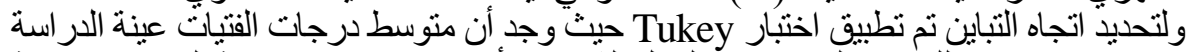

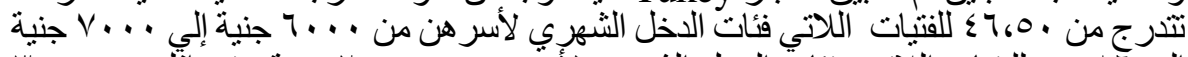

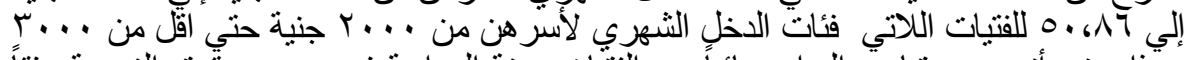

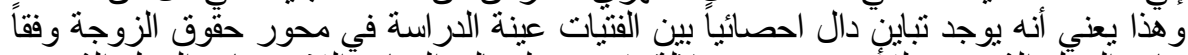

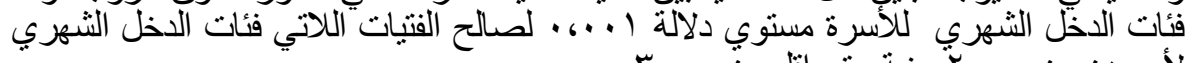

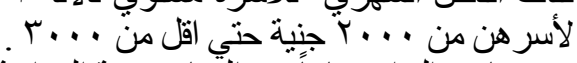

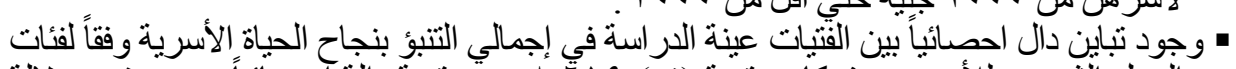

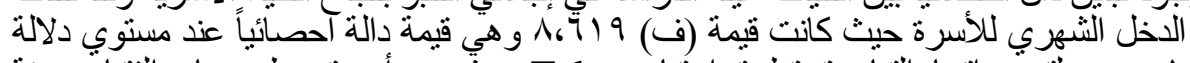

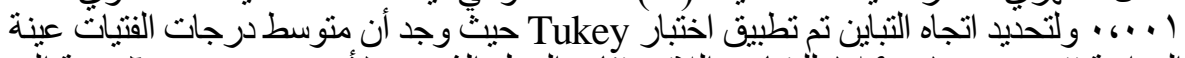

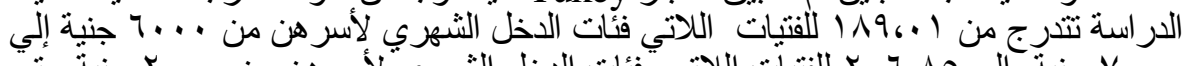

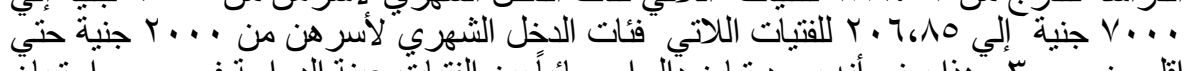

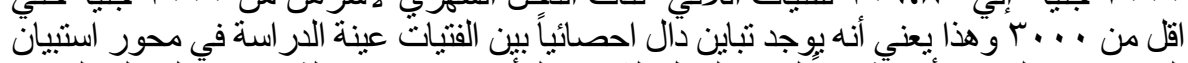

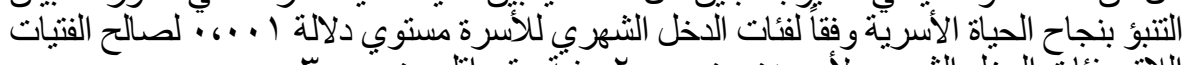

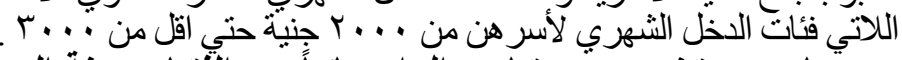

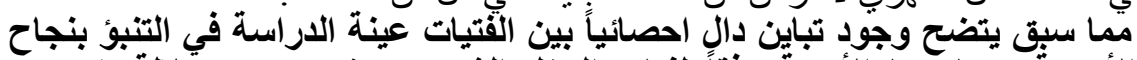

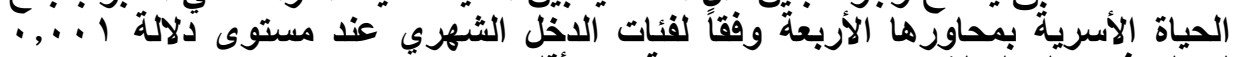

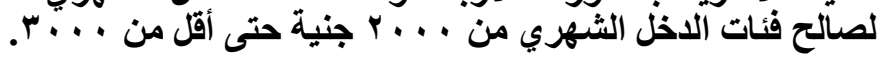




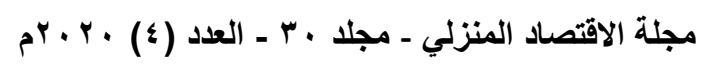

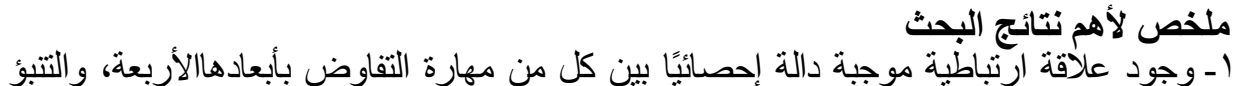

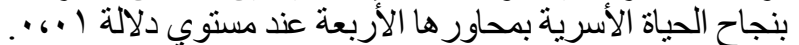

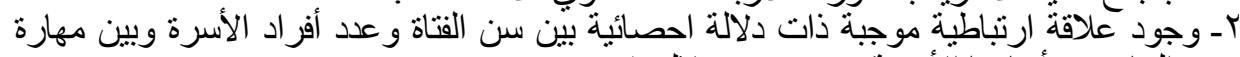

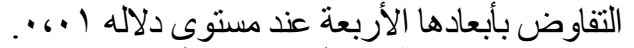

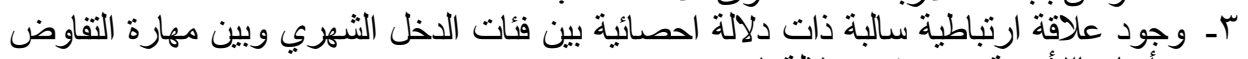

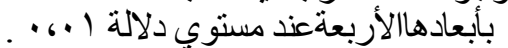
ع - عدم وجود علاقة ارتباطية ذات دلالة الحابلة الحصائية بين الفرقة الدراسية ومستوي تعليم الأب ومستوي

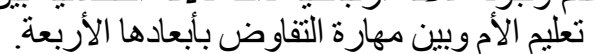
هـ وجود علاقة ارنباطية موجبة ذات دلالة الحابة الحصائية بين سن الفتاة و عدد أفراد الأسرة وبين التتبؤ

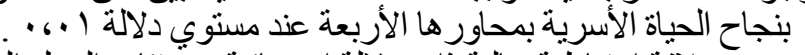

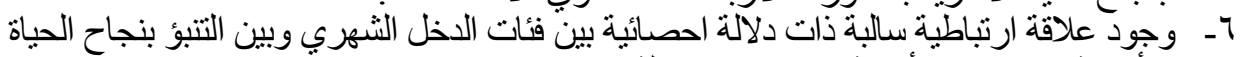

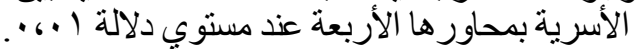

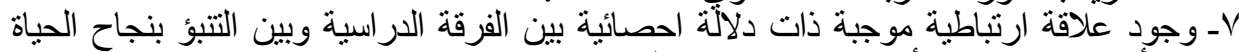

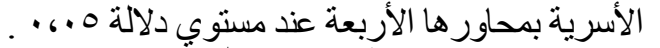

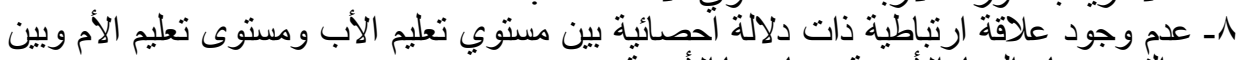

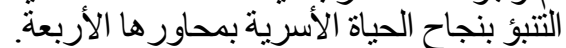

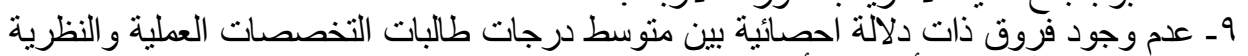
في مهارة التفاوض بأبعادها الأربعة.

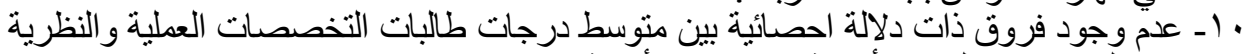

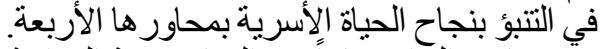

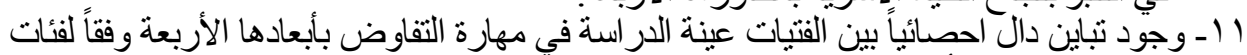

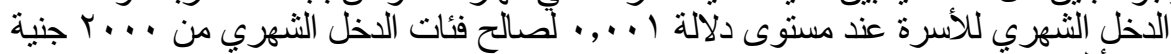

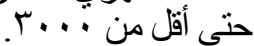
r ا ـوجود نتباين دال الحصائياً بين الفتيات عبنة الدراسة في التنبؤ بنجاح الحياة الأسرية بمحاورها

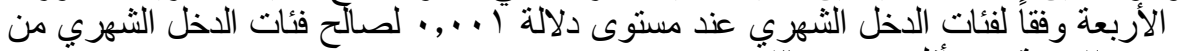

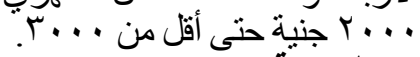

\section{من خلال ما تم التوصل إليه من نتائج يوصي الباحثون بما يلي:}

توصيات الدراسنة

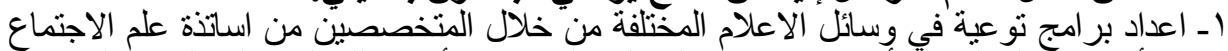

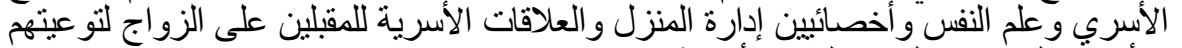
بالأسباب التي تؤدي لنجاح الحياة الأسرية.

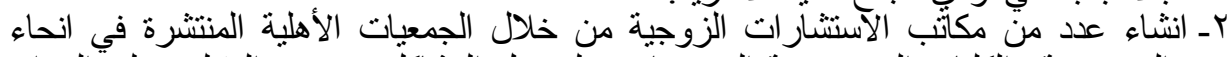

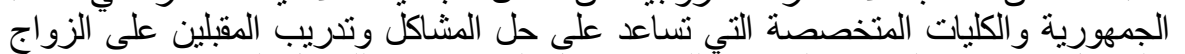

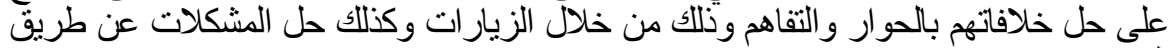

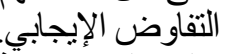

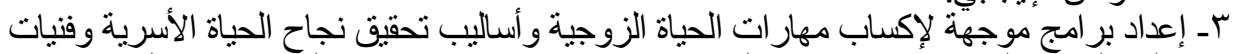

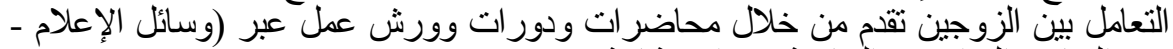

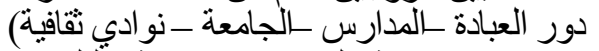

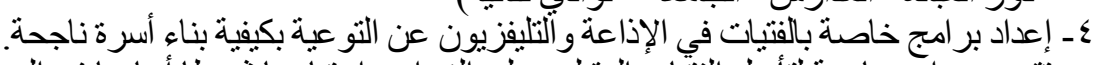

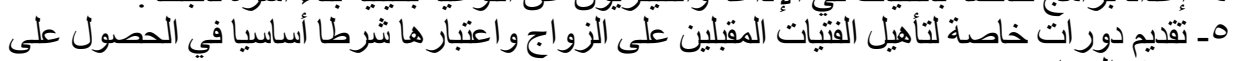

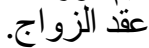




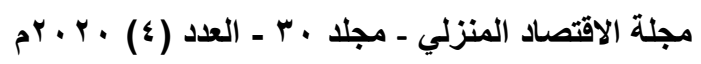

جـ الاستعانة بخريجات الاقتصاد المنزلي بصفة عامة وخريجة قسم إدارة المنزل و المؤسسات بصفة

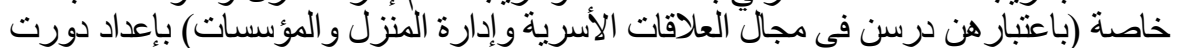

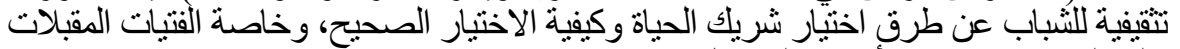

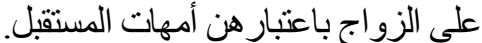

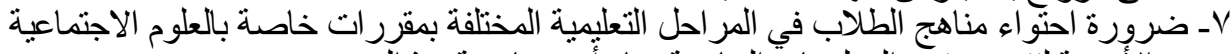

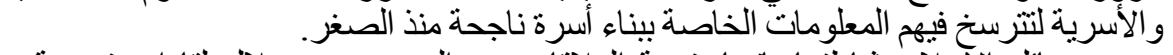

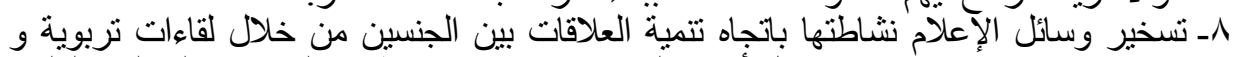

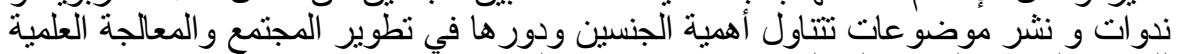
للمفاهيم الخاطئة التي يحملها الجنسان إز اء بعضية الجنهما البعض.

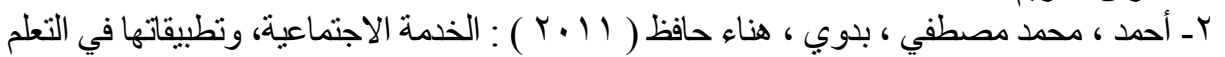
ور عاية الثباب ، المكتب الجامعي الحليث ، الطبعة الر ابعة، الإسكندرية.

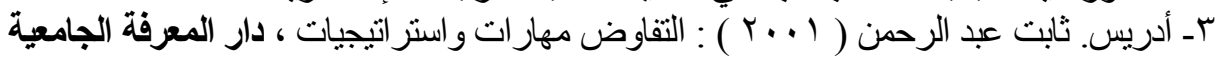

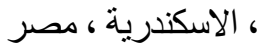

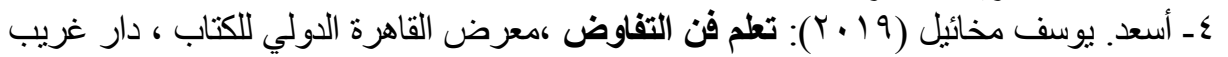

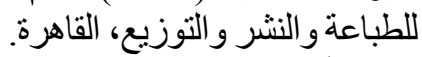

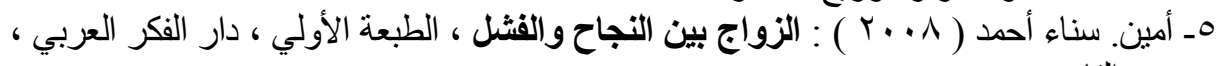

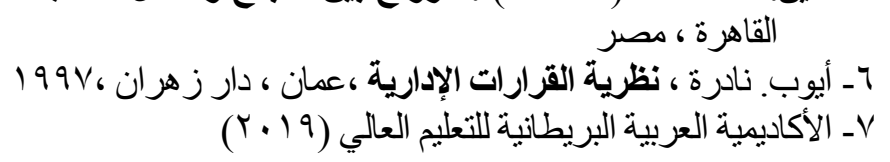

\section{(www/http://abahe.uk/ negoti}

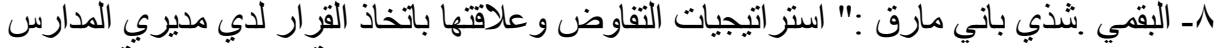

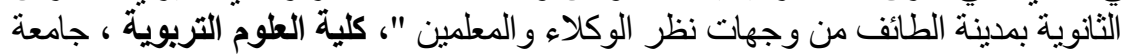

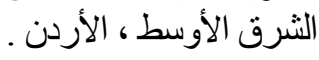

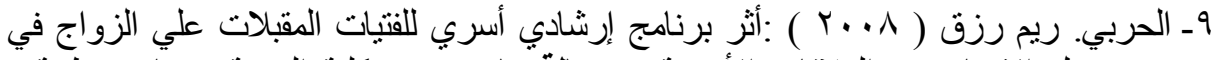

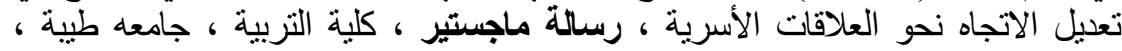
السعودية.

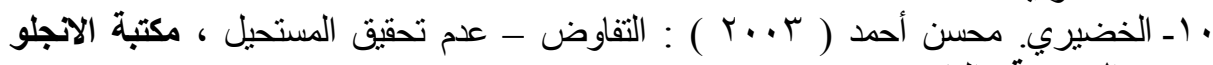

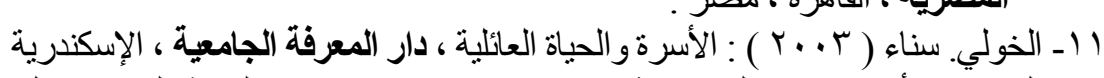

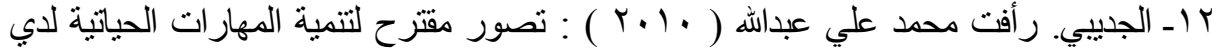

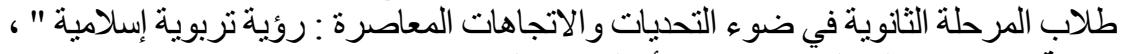

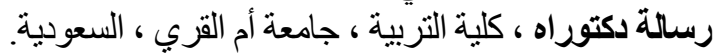

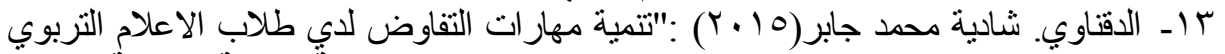

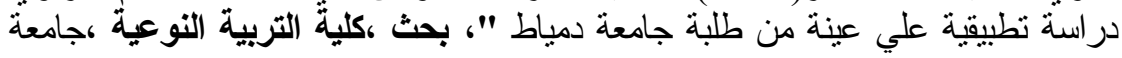




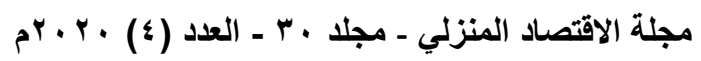

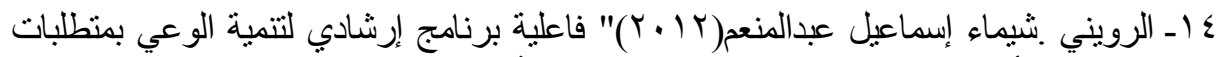

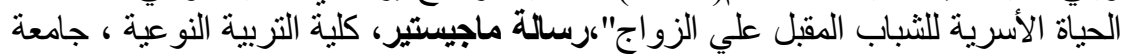
كفر الثيخ.

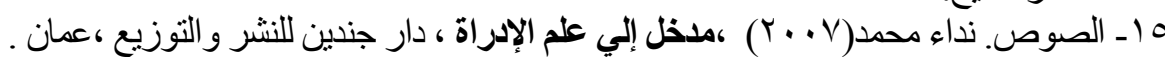

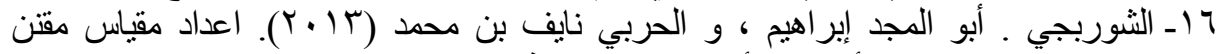
لمهار ات التفاوض ، أستخدام أسلوب التثرير الذاتي ـ درارات تربوية و نفسية (مجلة كلية

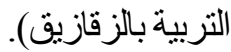

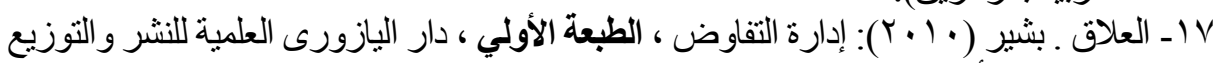

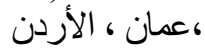

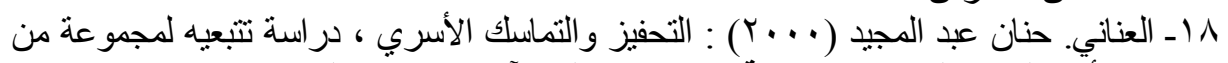

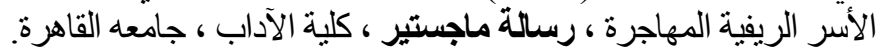

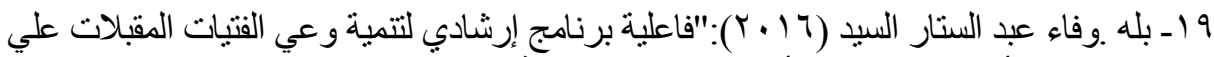

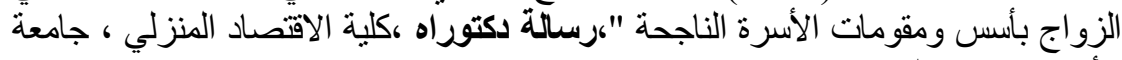
الأز هر ،جامعة المنوفية.

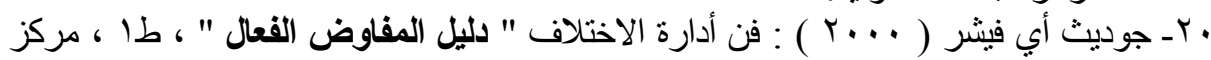

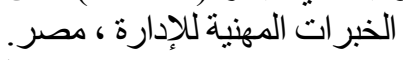

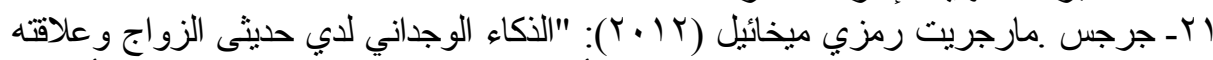

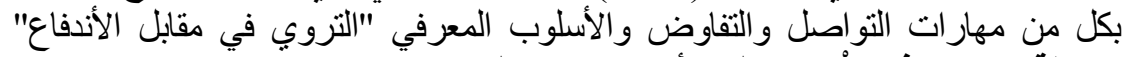

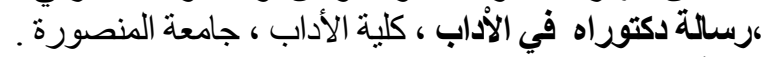

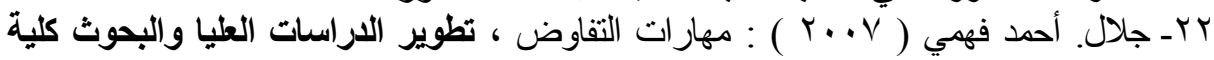

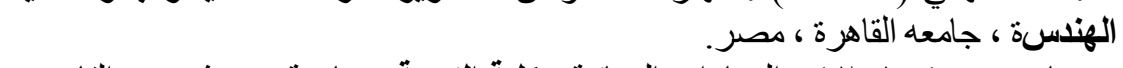

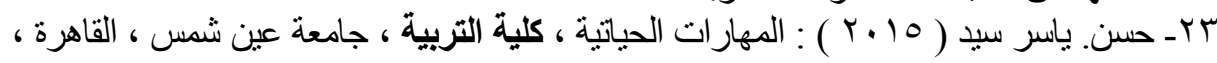

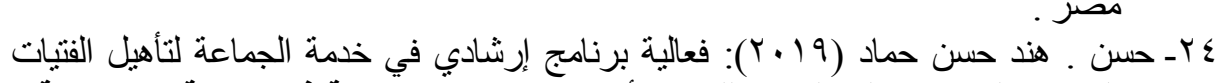

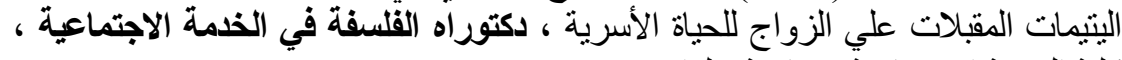

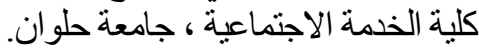

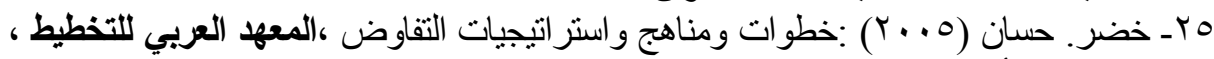

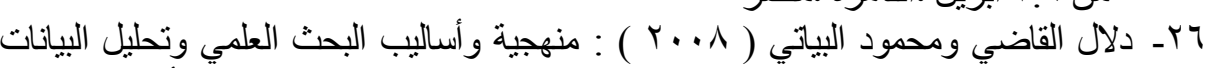

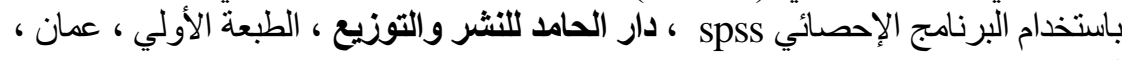

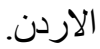

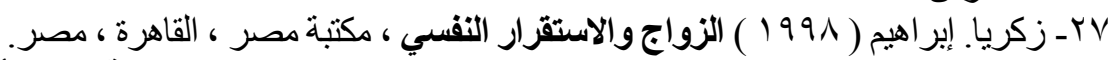

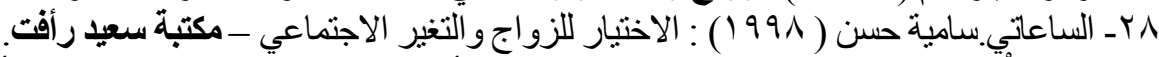

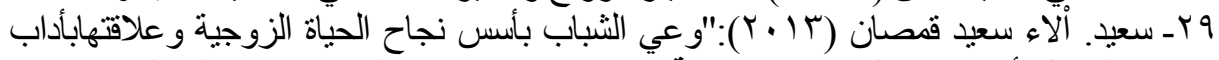

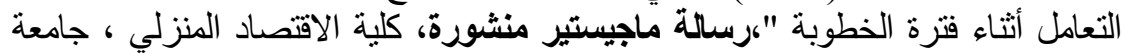
المنوفية

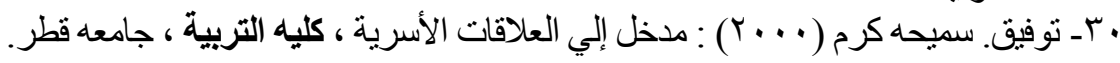




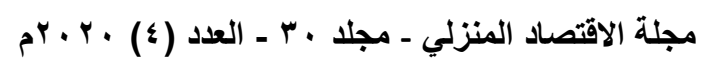

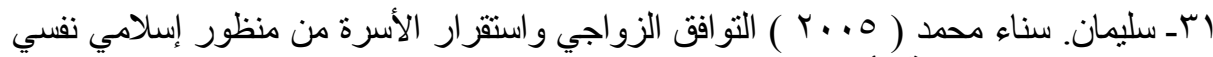

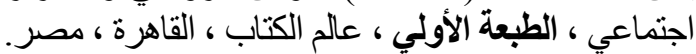

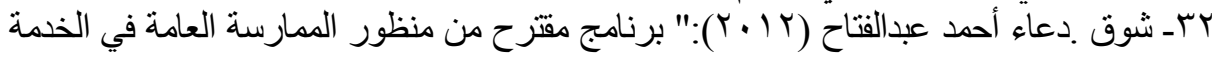

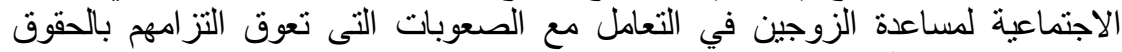

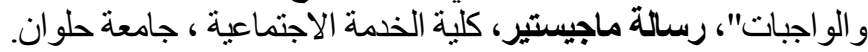

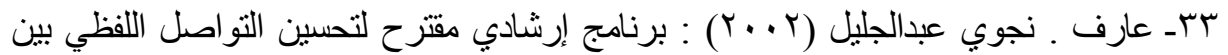

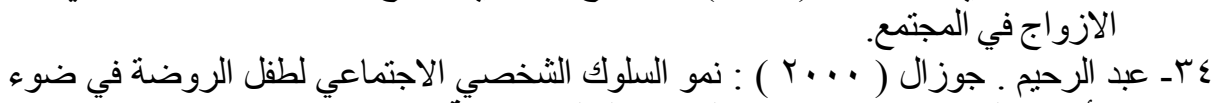

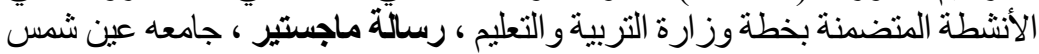

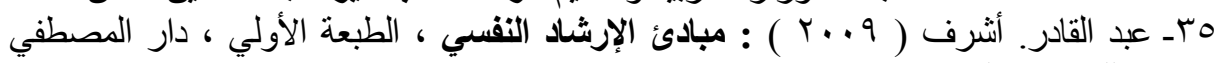

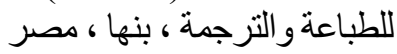

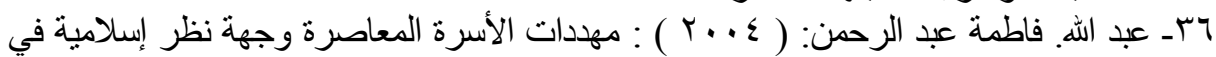
التكوين والعلائق و الآثار التربوية ، مجلة جامعه القرآن الكريم والعلوم الإسلامية ، العدد

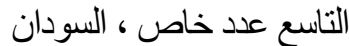

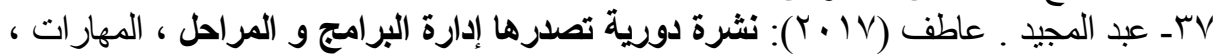

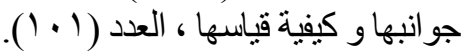

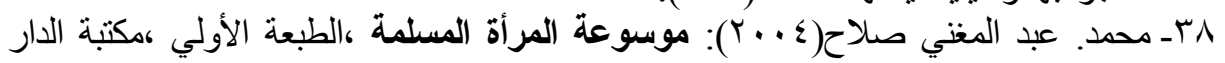
العربية للكتاب.

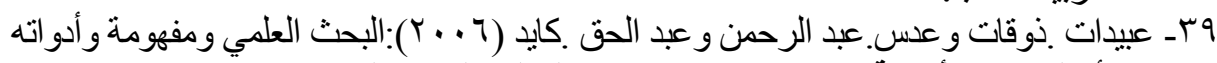

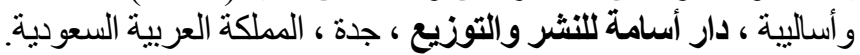

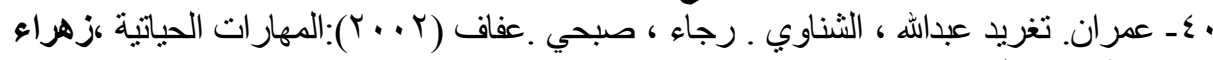

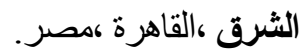

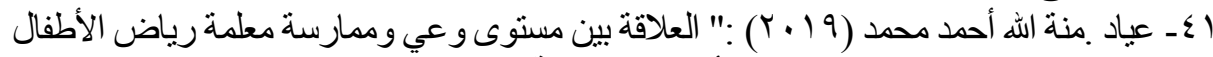

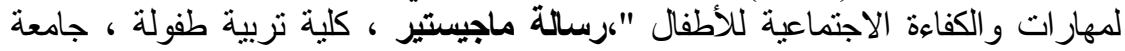

$$
\text { المنوفية. }
$$

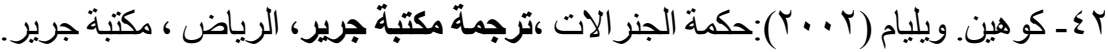

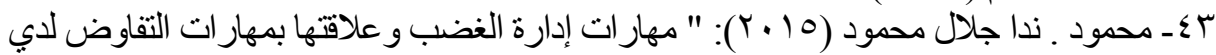

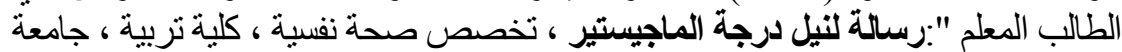

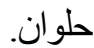
ـ ـ ـ مرسي. كمال ابر اهيم (1991) ) : العلاقة الزوجية و الصحة النفسية في الاسلام و علم النفس -

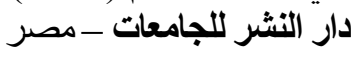

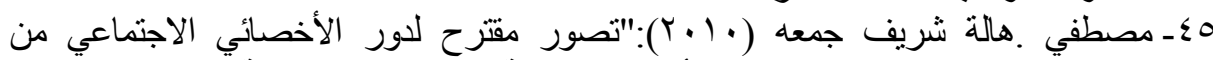
جماعات الثباب لإعدادهم للحياة الأسرية" ،رسالة للحصول علي درجة الماجيستير ، كلية

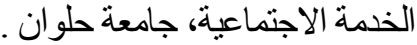

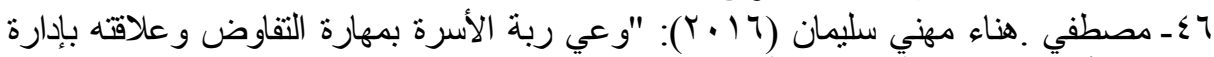

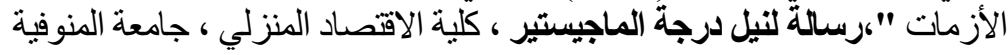

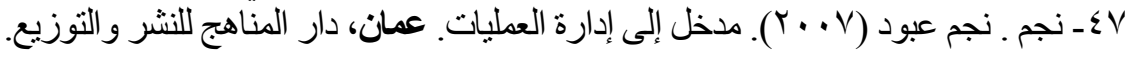




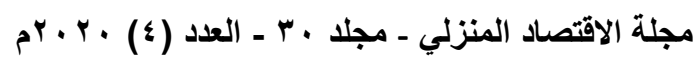

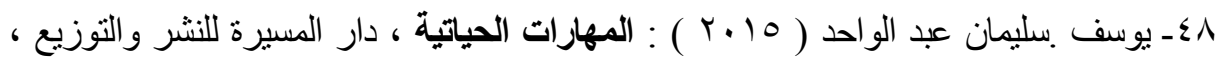

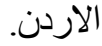

49- Ali,s.,(2013 ): The Art of Negotiation . Aleppo university publication ,

50- Alison Doyle(2019): Skill Set Defineition and Exampies ". www.thebalancecarecareers.com \retieved. 30-1-2019. Edited.

51- Bove C.F : sobal , J .\& Rauschenbach . B . S ( 2003 ) : Food Choices Amongnewly Married Couples : Convergence Conflict, Individualism, and Projects Journal of Appetite . Vol . 40 . no . ( 1 ) . feb

52- Cockburn,Orbie.(1991):Marital adaptation to illness Acomparison of cardiac and back pain patients and their spouses .bh,D,Taxas Woman,s University .p.138

53- Denham , S, A ( 2007 ) : dealing with feelings : how children negotiate

54- Haseley ,KAMAS ( 2007 ) , Marital Satisfaction among Newly Married Couples , ( $381-400)$. International New York Wiley Sons .

55- Judith Lothian (2000) : family Adbbtapility family cohesion , marital communication and the emerging family ( Transitiol,barenthood ) - New,york -Unversity

56- Ogilvie , J , R , \& carsky , M . L . ( 2002 ) : Building emotional intelligence in negotiations . international journal of conflict management

57- Rowland, A . V (2006) : the scale of interpersonal situations : A Measure for theintra - interpersonal model of relationships, Reno , university of Nevada

58- Wilcox , J .E ( 2000 ) : coping with conflicts : participant,s workboo paper in document of guides learner. Utah state university logan : cooperative extension se rvice worlds of emotions and social relationship . cognitive crier comportment journal vol . 11 . No . ( 1 ) March 


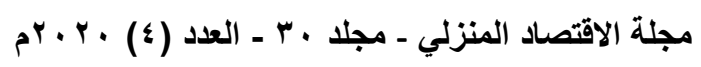

The $7^{\text {th }}$ international- $21^{\text {th }}$ Arabic conference for Home Economics

"Home Economics and sustainable development2030"

\title{
Journal of Home
}

Economics

December -15th, 2020

http://homeEcon.menofia.edu.eg

ISSN 1110-2578

Negotiation Skill and Its Relationship to Predict the Success of Family Life Among a Sample of Girls Appetizers on Marriage

\author{
Rabie Mahmoud Nofal ${ }^{1}$, Maysa Mohamed Al-Habashi ${ }^{23}$, \\ Omnia Mahmoud Abdallah
}

${ }^{1}$ Professor, Department of Home and Institutional Management, Faculty of Home Economics, Menoufia University

${ }^{2}$ Associate Professor, Department of Home and Institutional Management, Faculty of Home Economics, Menoufia University

${ }^{3}$ Researcher in Home and Institution Management Department, Faculty of Home Economics, Menoufia University 


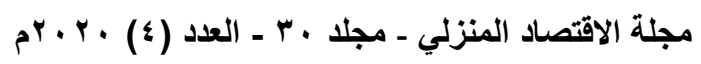

\begin{abstract}
The current study aimed to identify the nature of the relationship between negotiation skill in its four dimensions (Awareness of negotiating skill, solve problems, for the dialogue package, and discussion ) and the prediction of success of family life in its four axes (life partner selection specifications, the ingredients for successful family, duties of wife towards her husband, and rights of wife. I have a sample of girls who are about to get married, and some social and economic variables for the girl and her family (the age of girl, school age group, numbers of family members, level of father's education and level of mother's education and monthly income groups ) studying the difference between students of scientific and theoretical specializations in each of the four dimensional negotiation skill and the prediction of success of family life in its four axes according to monthly income groups for family .

The current study followed Descriptive analytical method, where a questionnaire on negotiation skill was prepared and a questionnaire on predicting the success of family life . I have a sample of girls who are about to get married, and the questionnaire was applied to a sample of girls coming to marriage who are chosen in purely coincidental way consisting of 1250 girls from Menoufia governate from different social and economic levels

.The results indicates that there is a positive correlation statistically significant between each of the four dimensional negotiation skill and the prediction of success of family life in its four axes at the level of significance 0,01 . there is a positive correlation relationship with statistically significant between each of the girl's age and the number of family members and between each of the four dimensional negotiation skill and the prediction of success of family life in its four axes at the level of significance 0,01 . there is a negative relationship statistical significance between categories of monthly income each of the four dimensional negotiation skill and the prediction of success of family life in its four axes at the level of significance 0,01 . The absence of a statistically significant correlation between level of father's education and level of mother's education between each of the four dimensional negotiation skill and the prediction of success of family life in its four axes . The absence of a statistically significant differences between the average scores of female students in scientific and theoretical specializations in each of the four dimensional negotiation skill and the prediction of success of family life in its four axes. There is a statistically significant difference between the girls in the study sample
\end{abstract}




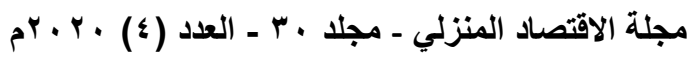

in each of the four dimensional negotiation skill and the prediction of success of family life in its four axes according to the categories of his family's monthly income, at the level of significance 0,01 for the categories of his family's monthly income from 2000 pound even less 3000 .

The study presented a set of recommendations, the most important of which was the preparation of an awareness program in the various media through specialists from family and psychological sociology professors and specialists in home management and family relations for girls who are going to marry to educate them how to build a successful family and resort to constructive dialogue in all affairs of her life to reduce the severity of her negative emotions and help them find alternative negotiating strategies to calm their emotions with others

Key Words : negotiation skill, success of family life, girls who are about to get married. 